NOTE TO USERS

This reproduction is the best copy available.

(B)

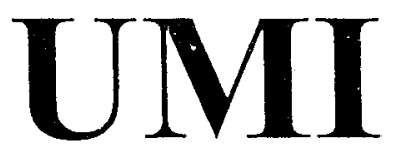



b15667777

\title{
ASSESSMENT OF THE SUBSURFACE PATHOGEN ABATEMENT EFFECTS OF NUTRIENT MANAGEMENT POLICY IN ONTARIO
}

\author{
by \\ Steven Rebellato, B. ìc (Ryerson) \\ A thesis \\ presented to Ryerson University \\ in partial fulfillment of the requirement for the degree of \\ Master of Applied Science \\ in the Program of \\ Environmental Applied Science and Management
}

Toronto, Ontario, Canada, 2004

CSteven Rebellato, 2004 
UMI Number: EC52946

\section{INFORMATION TO USERS}

The quality of this reproduction is dependent upon the quality of the copy submitted. Broken or indistinct print, colored or poor quality illustrations and photographs, print bleed-through, substandard margins, and improper alignment can adversely affect reproduction.

In the unlikely event that the author did not send a complete manuscript and there are missing pages, these will be noted. Also, if unauthorized copyright material had to be removed, a note will indicate the deletion.

(

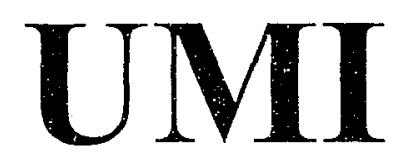

UMI Microform EC52946

Copyright 2008 by ProQuest LLC.

All rights reserved. This microform edition is protected against unauthorized copying under Title 17, United States Code.

ProQuest LLC

789 E. Eisenhower Parkway

PO Box 1346

Ann Arbor, Ml 48106-1346 
I hereby swear that I am the sole author of this thesis.

I authorize Ryerson University to lend this thesis to other institutions or individuals for the purpose of scholarly research.

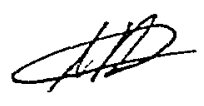

1 further authorize Ryerson University to reproduce this thesis by photocopying or by other means, in total or part in, at the request of other institutions for the purpose of scholarly research.

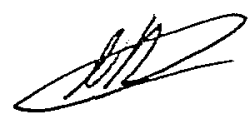


Ryerson University requires the signature of all persons using or photocopying this thesis. Please sign below, and give address and date.

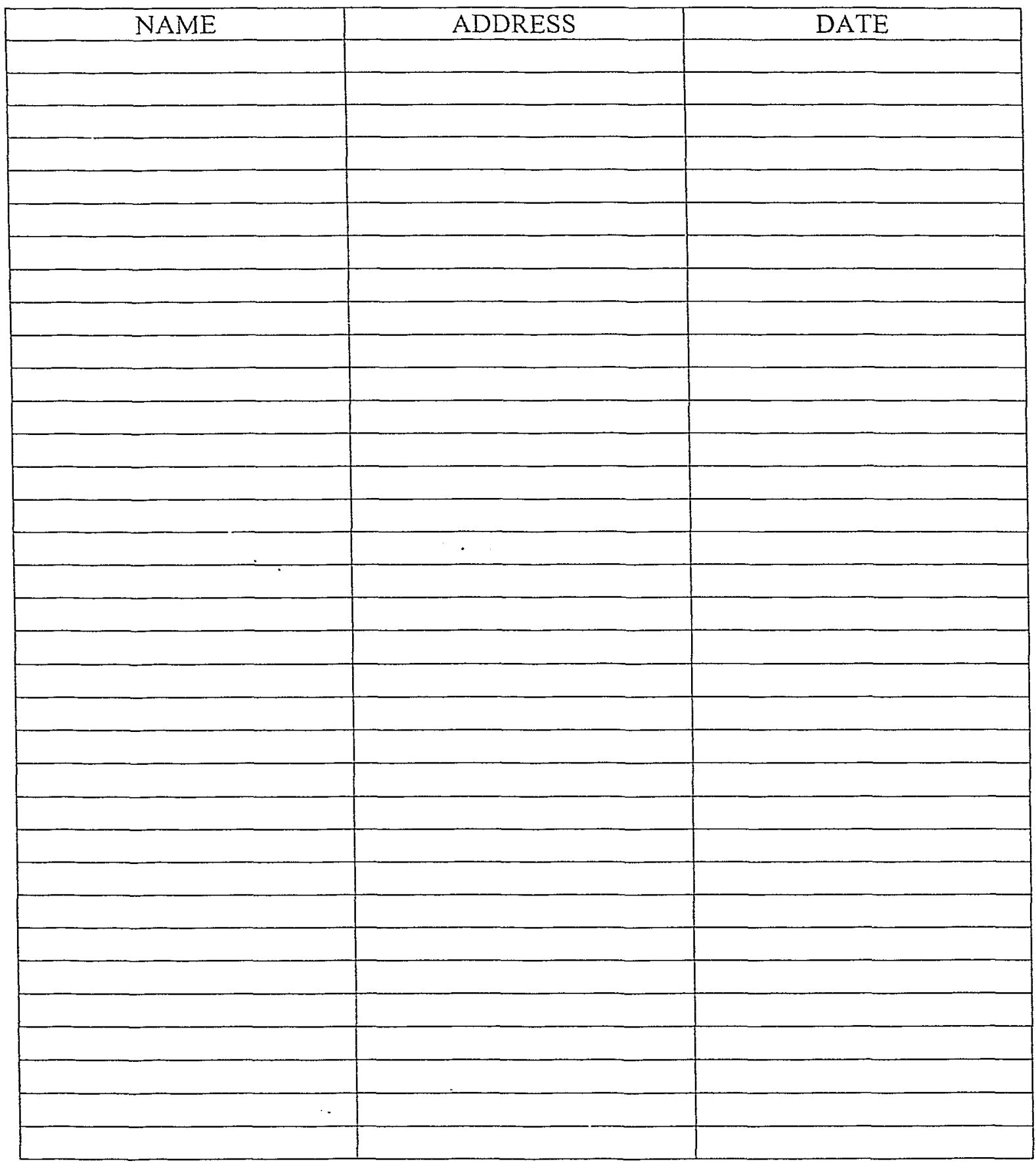




\author{
ABSTRACT \\ Assessment of the Subsurface Pathogen Abatement Effects of Nutrient Management \\ Policy in Ontario. \\ (C)Steven Rebellato, 2004 \\ Master of Applied Science \\ in the Program of \\ Environmental Applied Science and Management
}

The transport mechanisms of pathogens through the subsurface environment are complex. Provincial legislation, such as Ontario's Nutrient Management Act (2002) is designed to control nutrients in agricultural settings and it is assumed that the Act also attempts to control pathogens from reaching source waters. The study examined the progressive restrictions on agricultural practices that are sources of pathogens in water. Furthermore, current research in microbial subsurface transport and modeling was examined to determine if existing legislation is sufficient in controlling pathogens. Analysis showed that research gaps in microbial subsurface transport studies restricts subsurface research and transport models from effectively predicting the fate of pathogens. Furthermore, gaps in research restrict nutrient management legislation from protecting source waters from pathogens. Research showed that a 'critical control point' strategy that acts to decrease pathogen loading to agricultural surfaces is key in reducing the risks that microorganisms pose to ground water sources. 


\section{ACKNOWLEDGEMENTS}

I would like to thank a number of people that made this thesis possible

I would like to thank both Dr. Ron Pushchak and Dr. Steven Liss for their guidance and support over the past two years. Their expertise and professionalism in scholarly research is unsurpassed. Many thanks to you for encouraging me to continue my education; I am forever grateful.

I would like to thank the Ministry of Agriculture and Food for their support and interests in my research. I am thankful that I had an opportunity to work with their organization.

I am appreciative to have met and collaborated in research and studies with my friends at Ryerson University.

Thank you to Sara-Jane Varlese. You are all the encouragement I will ever need to succeed and to strive to be better both in school and in life. I am indebted to you forever.

Special thanks to my parents and family. In particular, thank you to my father who taught me that hard work and determination is the key to success in all aspects in life. 


\section{Table of Contents}

Chapter One: Introduction.....................................................

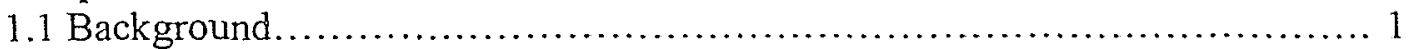

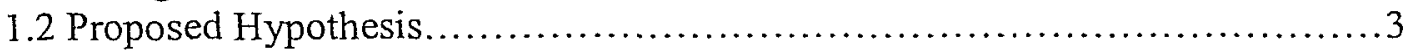

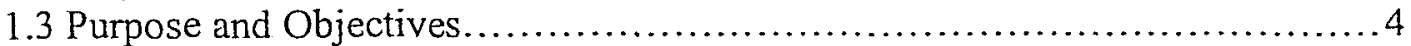

1.4 Outline ................................................................. 5

Chapter Two: Pathogen Abatement and Nutrient Management in Ontario:

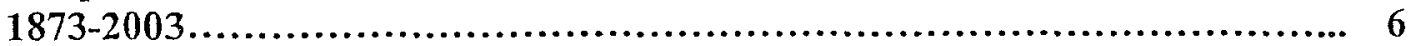

2.1 Previous legislation..................................................... 7

2.1.1 An Act Respecting the Public Health (1873), the Health Protection and Promotion Act (1990), and the Mandatory Health Programs and Services Guidelines (1997)....................................................... 7

2.1.2 Canadian Code for Farm Buildings (1964) ............................ 9

2.1.3 Environmental Protection Act (1971) ..................................... 10

2.1.4 Canada Animal Waste Management Guide (1972) ........................ 12

2.1.5 Agricultural Code of Practice (1973) .................................... 14

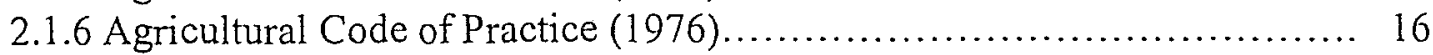

2.1.7 Guidelines for the Utilization of Waste (other than sewage sludge) on Agricultural land (1992) ................................................. 19

2.1.8 The Guidelines for Sewage Sludge Utilization on Agricultural Lands (1992).20 2.1.9 Ontario Environmental Farm Plan (1993) ............................... 21

2.1.10 Guide to Agricultural Land Use (1995) ............................... 21

2.1.11 Minimum Separation Distances (MDS I and II) (1995).................. 24

2.1.12 Best Management Practices for Farmers -Agricultural Canada (1995)........ 25

2.1.13 Guidelines for the Utilization of Biosolids and other wastes on Agricultural

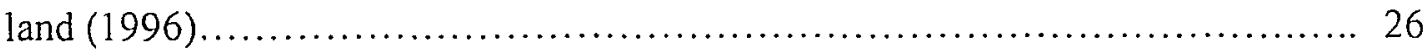

2.1.14 Ontario Building Code Act (1992), The Ontario Building Code (1997).... 27

2.1.15 Farming Food Production Protection Act (1998) ......................... 28

2.1.16 The Nutrient Management Act (2002) ............................... 29

2.2 Discussion - Pathogen Abatement and Nutrient Management in Ontario...... 32

2.2 .1 Odour............................................................... 33

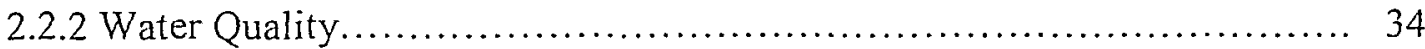

2.2.3 Setback/Separation Distances and MDS I \& II....................... 36

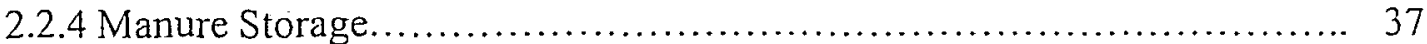

2.3 Nutrient Management Policy and Pathogen Control...................... 37

2.4 Conclusion....................................................... 38

Chapter Three: Abatement and Transport of Microorganisms in the

Subsurface Environment.................................................. 40

3.1 Physical and Chemical Properties of movement........................... 41

3.1.1 Vertical Movement...................................................... 44

3.1.2 Horizontal Movement................................................. 45

3.1.3 Electrostatic, Biological and Chemical processes........................ 45

3.2 Environmental subsurface conditions.................................... 47

3.2.1 Soil Water Content (including precipitation) ........................... 47

3.2.2 Plants and Plant Roots............................................... 50

3.2.3 Soil Composition and Soil Structure ................................... 52 
3.2.4 Research in Soil Structure and Pathogen Abatement and Transport: Intact

Soil Samples vs. Natural Environment Studies............................ 53

3.2.5 Porosity and Macropores.......................................... 54

3.2.6 Shear Stress and Root Growth...................................... 55

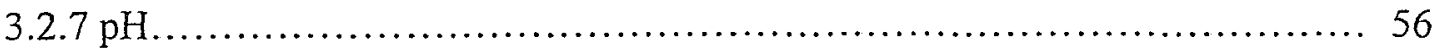

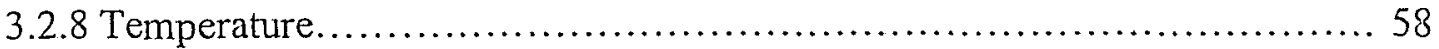

3.2 .9 Tillage Practices ....................................................... 59

3.3 Environmental and Microbiological Factors............................... 60

3.3.1 Types of Waste.................................................. 60

3.3.2 Types of Microorganisms............................................ 63

3.3 .3 Viruses............................................................. 64

3.3 .4 Bacteria......................................................... 67

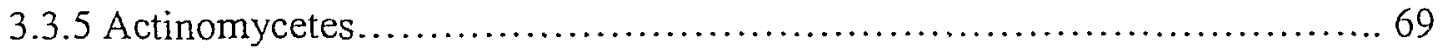

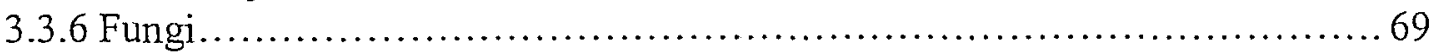

3.3 .7 Protozoa ......................................................... 70

3.3.8 Heterogeneity of soils.............................................. 71

3.4 Discussion - Key findings in Pathogen Abatement and Transport Research 72

3.4.1 Gap Analysis -Pathogen Transport Research.......................... 75

3.4.2 The New Ontario Landscape ...................................... 76

3.5 Conclusion........................................................... 77

Chapter Four: Models of Subsurface Survival and Transport................ 78

4.1 Risk Analysis and Risk Assessment in Microbial Transport Modeling......... 79

4.1.1 Sensitivity Analysis, Uncertainty and Variability....................... 81

4.2 Models............................................................ 83

4.3 Reactive Transport Models......................................... 88

4.3.1 Physiochemical Processes........................................... 90

4.3.2 Biological Processes............................................. 92

4.3.3 Reaction Transport Models - Gap Analysis and Risk Assessment Potential. 92

4.4 Stochastic-Geometric Models........................................ 94

4.4.1 Stochastic-Geometric models - Gap Analysis and Risk Assessment.......... 98

4.5 Mass Balance (Advection-Dispersion) based Transport Models ............. 101

4.6 Model Validation................................................ 102

4.7 Discussion - The Nutrient Management Act, Subsurface Microbial Transport

Modeling, and Risk Assessment and Analysis............................ 104

4.7.1 Challenges in Future Microbial Transport Modeling in the Subsurface

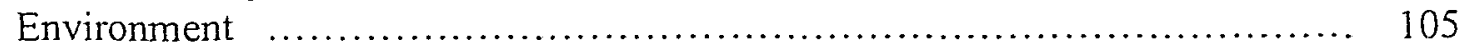

4.7.2 Uncertainty and Nutrient Management............................. 108

4.7.3 HACCP, Risk Analysis, and Subsurface Microbial Transport Technology 109

4.8 Conclusion....................................................... 112

Chapter Five: Alternative Pathogen Management Strategy............... 113

5.1 Critical Factors in a Pathogen Management Strategy........................ 114

5.1.1 Operational and Procedural Objectives................................. 115

5.1 .2 Public Health Objectives......................................... 116

5.1.3 Risk Reduction Strategies......................................... 117

5.2 Management Strategies.............................................. 117

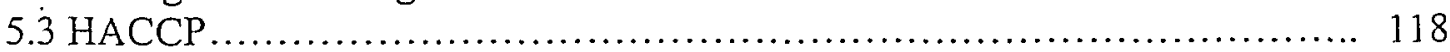


5.3.1 HACCP and Nutrient Management Systems - Advantages................ 120

5.3.2 HACCP and Nutrient Management Systems - Disadvantages.............. 121

5.4 ISO 14001 - Environmental Management.............................. 122

5.4.1 ISO 14001 and Nutrient Management Systems - Advantages.............. 124

5.4.2 ISO 14001 and Nutrient Management Systems - Disadvantages............ 124

5.5 The Alternative Nutrient Management Strategy........................... 125

5.6 Conclusions......................................................... 128

Chapter Six: Conclusions and Recommendations ........................ 130

6.1 Conclusion.......................................................... 130

6.2 Recommendations................................................. 131

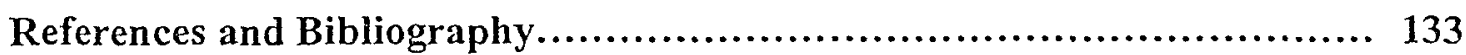

Appendix................................................................... 147

Appendix 2.1: Pathogen Abatement and Nutrient Management in Ontario.

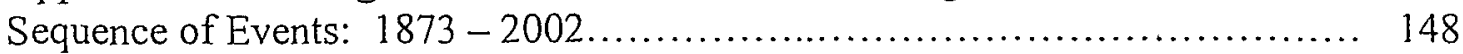

Appendix 2.2: Summary of Previous Legislation........................... 149

Appendix 3.1 Other Microbial Subsurface Transport Models and Approaches... 160

Appendix 3.2 Advection Dispersion Model - General Formula................. 161 


\section{List of Tables}

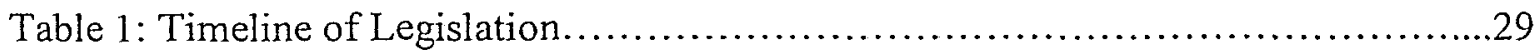

Table 2: Bacteria of epidemiological concern in livestock nutrients..................68

Table 3: Significant Factors Affecting Pathogen Abatement in the Subsurface

Environment............................................................ 73

Table 4: Risk Analysis Processes and Key Elements of the Reaction Transport Model........................................................................94

Table 5: Risk Analysis Processes and Key Elements of the Stochastic-Geometric Model.................................................................. 100 


\section{List of Illustrations}

Figure 4.1: Microbial Subsurface Flow Model..................................85

Figure 4.2: Reaction Transport Model Components and Gap Analysis...............89

Figure 4.3: Stochastic-Geometric Model Components and Gap Analysis............97

Figure 4.4: Transport Models and Gap Analysis............................103

Figure 4.5: Critical controls in a nutrient management perspective...................111 


\section{Chapter One: Introduction}

\subsection{Background}

As part of the government of Ontario's Clean Water Strategy, the Nutrient Management Act_(2002) provides province-wide stanciards to address the efiects of agricultural practices on the environment, especially as they relate to land-applied materials containing nutrients. Nutrients, such as nitrates and phosphates, are substances available in animal wastes and are utilized by plants along with surface and subsurface organisms for growth. However, land-applied nutrients, including animal wastes, not only contain high loads of organic matter, but also contain microorganisms, and specifically human and animal pathogens. Originating from livestock, pathogens of concern include bacteria, viruses and protozoa. Of particular concern to public health officials, bacteria, viruses and protozoa can cause disease and death both in animals and in humans.

The purpose of the Nutrient Management Act (2002) is to provide for the managemeit of materials containing nutrients in ways that will enhance the protection of the natural environment and provide for a sustainable future for the agricultural community (Nutrient Managemert Act Backgrounder, 2002). Key to the legislative framework are Nutrient Management Plans (NMP) and Nutrient Management Strategies (NMS) which are science-based tools that use best management practices to manage nutrients in an environmentally-responsible manner (Nutrient Management Act Backgrounder, 2002). The Act is not designed to control pathogens, but rather, is focused on the management of nutrients in agricultural settings. Indirectly, it is assumed that the Act attempts to control both nutrients and pathogens given that flow patterns of nutrients through the subsurface environment are (in some respects) similar to the flow of pathogens as is observed with viral flow. However, due to the differences in microbial size, behaviour, viability, and surface properties (Mawdsley et al. 1995), the transport and survival mechanisms of microorganisms in the subsurface remain different from nutrients. This does not mean that nutrient flow is, in all respects, different from microorganism flow. However, the disparities noted between the flow characteristics 
must be accounted for in legislation so that source waters are protected both from nutrients and pathogens.

Until the release of the Nutrient Management Act (2002), the province of Ontario had never directly addressed both nutrient management and pathogen control at the agricultural level. Although nutrient management and pathogen control practices were not addressed specifically, they were indirectly attended to by best management practices (voluntary based policy instruments) that were intended to decrease nuisances from daily agricultural practices. The scientific aspect of nutrient management, and more specifically pathogen control, did not begin to receive attention until the early portion of the 1970s. Even during the 1970s, nuisance issues such as odours played a significant role in iegislation than did microbiological control. In fact, "organisms' were not mentioned until the release of the Canada Animal Waste Management Guide in 1972.

Scientific evidence in current microbial transport research must play a critical role in the management of nutrients and microorganisms in agricultural operations. Scientific methods and research demand precision. Research in nutrient management and pathogen transport should dictate source water protection legislation. Understanding the transport pathways of specific pathogens of concern is critical to water protection. Furthermore, comprehension of the subsurface environmental conditions which support abatement (meaning to decrease or put an end to) or transport of pathogens is significant. The requirement for pathogen management initiatives in the province of Ontario is critical to health of its population. Not only are large-scale contamination events an important indicator for change, but it is also significant to recognize private contamination events of wells from pathogenic organisms as a serious public health threat. Furthermore, as largescale agricultural operations become increasingly prevalent on the Ontario landscape, it is essential that pathogen control is an important part of any future source water protection strategy.

Is there sufficient research available to develop a pathogen management strategy which identifies 'critical controls' or hazardous environmental settings which would 
abate microorganisms quickly in the subsurface? Is current research adequate to comprehend the transport pathways of all pathogens? Is enough known of the environmental conditions which support transport or encourage abatement of pathogens? Based on current microbial transport research in the subsurface environment, is the Nutrient Management Act_(2002) sufficient to protect Ontario's ground water sources and preserve public health?

The following thesis is a part of broader nutrient and pathogen management research (Stiefelmeyer, 2003) that examined current international nutrient management legislation and studied surface transport of nutrients and pathogens in the environment. The following study will examine previous legislation in the Province of Ontario and attempt to determine if current research is sufficient at controlling microbial transport through the subsurface environment.

\subsection{Proposed Hypothesis}

Based on current research and knowledge in the field of microbial subsurface pathogen abatement and transport, does current nutrient management legislation in Ontario sufficiently protect ground water sources from pathogens?

Once a microorganism is introduced to the subsurface environment, physochemical, biological, and environmental factors affect its movement. Many variables will determine whether the microorganism is abated or transported vertically or horizontally through the soil. Nutrient management legislation, such as Ontario's Nutrient Management Act (2002) although created to protect source waters from agricultural nutrients, is also assumed to protect source waters from pathogens originating from livestock wastes applied to land. It is also assumed that regulations made under the Act are founded on sound scientific research.

The assessment of microbial survival and transport through the subsurface environment will determine if there is sufficient information pertaining to subsurface 
transport in research. The study will then determine if there is adequate research to support requirements provided by nutrient management legislation.

\subsection{Purpose and Objectives}

The purpose of the study is to examine past and current research in the field of soil microbiology, focusing on pathogen abatement and transport to determine if the Nutrient Management Act (2002) is sufficient at reducing the likelihood that pathogens will reach groundwater sources and cause human illness. The study is a research-focused analysis comparing current knowledge of microbial abatement and transport to the Province of Ontario's current management strategy, the Nutrient Management Act_(2002) which aims to protect groundwater from nutrients applied to land. There are 4 objectives in the study:

1. To establish how previous legislation in Ontario has attempted to control pathogen movement to soil and the subsurface environment.

The purpose of this legislation review is to examine the progressive restrictions on agricultural practices that are common sources of pathogens found in water. The legislative review will examine government documents which address (either directly or indirectly) pathogen control and source water protection initiatives.

2. To evaluate current microbial abatement and transport research investigating the subsurjuce environment.

This objective will review scientific research on subsurface survival and transport of pathogens from agricultural sources to determine the current state of knowledge.

3. To assess the relationship between current subsurface microbial transport and abatement research and microbial transport models. 
The purpose of this objective is to examine microbial transport models to determine if fate and transport mechanisms can be adequately predicted based on the findings of current research.

4. To propose an alternative management strategy to protect water sources from pathogens based on current research.

The purpose of this objective is to investigate existing predictive models of pathogen survival and transport in the subsurface environment and to assess the usefulness of models in predicting microbial water contamination.

\subsection{Outline}

The thesis has been laid out as follows. Chapter Two examines previous nutrient management related legislation in the province of Ontario beginning from An Act Respecting the Public Health (1873) to current legislation such as the Nutrient Management Act (2002). Chapter Three examines current microbial subsurface research focusing on fate, transport and abatement of pathogens including bacteria, viruses and protozoa through the subsurface environment. Chapter Four examines microbial models including stochastic-geometric transport models and reaction-kinetic models which replicate and attempt to predict the rate and mechanisms of transport through the subsurface environment. Chapter Four also identifies gaps in modeling research which limit the predictive capabilities of microbial transport models for pathogen management systems. Chapter Five examines existing environmental management systems pertaining to the management of pathogens in agricultural systems. This chapter also identifies (based on current pathogen abatement research) the necessary components for an alternative pathogen management strategy. Finally, Chapter Six concludes and provides recommendations for future research initiatives in subsurface transport and nutrient management strategies. 


\section{Chapter Two: Pathogen Abatement and Nutrient Management in Ontario: 1873-2003}

Since confederation, the agricultural industry in Canada has proven to be a comerstone of economic strength and stability in the economy. Even today, agriculture plays a large role in the sustainability of the economy and serves as a key benchmark for overall market success and health. When the agricultural industry struggles (as was displayed during the Bovine Spongiform Encephalopathy threat in 2003), so does the economy, and vice versa.

Since the incidence of the Escherichia coli 0157: H7 outbreak in Walkerton, Ontario (2000), there has been increasing concern about the relationship between agricultural practices, water quality, and pathogens in the environment. However, the events of Walkerton are not the only concern for the province of Ontario. Large-scale microbial contamination events of private wells point to the requirement for pathogencontrol centered legislation. For example, a study by Goss et al. (1998) showed that $14.9 \%$ of wells registered in the province of Ontario had positive registered evidence of pollution with Escherichia coli. Legislation and research have taken predominant roles in the relationships between these entities so that agricultural practices are managed, water quality is protected, and pathogen abatement is implemented. With the introduction of the Nutrient Management Act in 2002, large and small-scale agricultural businesees alike in Ontario have been asked to comply with more stringent legislation than the industry has ever been asked to meet in the past.

Since 1885, legislation has been an important part of the everyday processes of the farming community. Earlier in the $20^{\text {th }}$ century, most government publications did not specifically address nutrient management and pathogen abatement directly. This was due in part because research did not dictate a concern in these areas of agricultural process. However, as time passed, issues such as nutrient application to land, nutrient storage, water quality, odour control and setback distances became more prominent in communities. Furthermore, the need for legislation stemmed from the ever-increasing 
collisions between rural settings and urban communities. Nuisance complaints and odour concerns played a large part in the development of several codes and guidelines that helped shape legislation in subsequent years. Chapter Two discusses the documents that shaped nutrient management legislation from as early as 1873 with the introduction of the Public Health Act to the release of the Nutrient Management Act in 2002. The following is a comprehensive look at government documentation in Ontario which focus' (or have focused) on nutrient management, pathogen management and source water protection initiatives.

\subsection{Previous legislation}

Nutrient and pathogen management activities have been addressed either directly or indirectly in several government documents and legislation since 1873 . The following section attempts to indicate the progressive changes/controls on farm manure practices to control pathogens, and to indicate the limitations (if any) in controlling surface and subsurface pathogens from agricultural sources in Ontario. This section identifies significant government documentation pertaining to pathogen centered provincial documents. For further reference to documents with added relevance to this study, see Appendix 2.2.

\subsubsection{An Act Respecting the Public Health (1873), the Health Protection and Promotion Act (1990), and the Mandatory Health Programs and Services Guidelines (1997)}

An Act primarily developed for the control of disease and spread of illness among the residents of the Province of Ontario, An Act Respecting the Public Health (1878) along with its later successor, the Health Protection and Promotion Act (1990) utilized several general duty clauses which indirectly tackled the issues of nutrient management and control of pathogens which may have been a threat to the public's health. Neither Act directly mentions, restricts, or regulates the application or management of nutrients on agricultural land. However, general duty clauses in both Acts allow the Ministry of Health to become involved whenever (in the opinion of the Medical officer of Health), a legitimate "Health Hazard" exists. 
In the Act Respecting the Public Health (1878), a general duty clause pertaining to health hazards was given as follows;

If upon such examination they find that the premises are in a filthy or unclean state, or that any matter or thing is there which, in their opinion, may endanger the public health, they or any two of them, may order the proprietor or occupant of the premises to cleanse the same and to remove what is so found there.

(Act Respecting the Public Health, 1878, s. 2)

Similarly, in the Health Protection and Promotion Act (1990), a clearer definition of what constitutes a 'health hazard' is provided,

A Health hazard means,

(a) a condition of a premise

(b) a substance, thing, plant, animal other than man, or

(c) a solid, liquid, gas, or combination of any of them,

that has or is likely to have an adverse effect on the health of any person.

(Health Protection and Promotion Act, 1990, s. 1(1))

The focus of programs and legislation developed under the umbrella of the Ministry of Health have been for the protection of the public good and environments where people live. Developed under the Health Protection and Promotion Act (1995), the Mandatory Health Programs and Services Guidelines (MHPSG) were created for all Health Units in the province of Ontario to follow. Programs within the Guidelines include, among others, a program for 'Safe Water'. Although water quality is accounted for through Provincial legislation in the Ministry of the Environis. ent and the Ministry of Agriculture and Food, the Ministry of Health still has a role in the protection of water such as testing of potable public domains along with acting as leaders in the interpretation of water results for public consumption. The goal of the Safe Water Program is to reduce the incidence of water-borne illness in the population. In doing so, Provincial Health Units are expected to maintain records of all public drinking water systems, receive 
reports of adverse drinking water test results from the drinking water systems, have a written protocol for dealing with adverse drinking water test results from the drinking water systems listed, and act in accordance with the Ontario Drinking Water Objectives (revised 1994) to protect the health of the public whenever an adverse drinking water test result is received.

\subsubsection{Canadian Code for Farm Buildings (1964)}

Released in 1964, the Canadian Code for Farm Buildings v'as developed as a guide for the design, construction, remodeling and evaluation of a wide variety of farm buildings (other than living quarters) by the Associate Committee on the National Building Code. Like guidelines, codes are information-based voluntary documents available to the public. They do not hold any legislative merit, unless adopted by a regulation or an act. Although the code falls short of prescribing codes for nutrient management, it is clear that the practices consistent within the code are required for effective management of nutrients, especially those practices dealing witn adequate storage capacities and sighting of storage facilities in relation to water courses and other structures.

The recommendations in the Code, unless otherwise stated, "are consistent with good management practices to promote efficient production and storage, economical construction and the protection of environmental quality" (1975). For example, foundations and footings are constructed in relation to water table levels on a farm or agricultural operation.

Like other codes developed and released in the 1970s, the Canadian Code for Farm Buildings was consistent in attempting to reduce the likelihood that neighbouring communities would be nuisanced by farming and other agricultural practices. Any and all existing or proposed animal enterprises and facilities were required to be built at "adequate" distances from neighbouring residences (Canadian Code for Furm Buildings, 1975, s. 1.3.2.1. (5)(a)). Furthermore, location and arrangement of new animal production facilities were based on considerations of dust, odours, prevailing winds and the proximity and direction of neighbours. Additional issues included site surface 
drainage, subsoil conditions, manure storage (type and location), manure pile and feedlot runoff detention, natural surface and subsurface waters, snow cover, space for expansion/renovations, and traffic routes for farm operations (Canadian Code for Farm Buildings, 1975 s. 2.1.1.). The main focus of the section entitled 'environmental protection' pertained to the storage of manure with sufficient storage capacity to avoid the necessity of disposal on snow, frozen ground or sensitive crops (Canadian Code for Farm Buildings, 1975, s. 2.2.6.1 (1)(2)). As will become apparent in future codes and guidelines, nutrient application on snow and frozen ground is not permitted.

Manure storage systems (based on the Code released in 1970) were designed based on the type of manure (solid or liquid) and the number of animals present on the farm (indicated by a numerical table). No information about how numbers were obtained was provided in the Code. Storage facilities were encouraged to be designed to control liquids and to withstand environmental conditions so that runoff was controlled. Wash waters from manure storage facilities were required to be offset into manure tanks or lagoons so as to avoid unnecessary runoff to land.

Much of the detail provided in the 1970, 1975 and 1977 Codes is not included in more recent editions $(1983,1990)$. The 1983 edition of the Canadian Farm Building Code was rewritten to reflect the focus of other building codes in Canada and as a result placed less emphasis on agricultural practices and standards. Codes release after 1983 are concentrated in three areas of building construction including fire safety, health and safety, and structural sufficiency and are more involved with matters of occupational health and safety (safety railing requirements and ladders).

\subsubsection{Environmental Protection Act (1971)}

Released in 1971, the Environmental Protection Act (EPA) (Bill 94) is the crown jewel of environmental legislation governing the protection of the environment in Ontario. The purpose of the Act is to provide for the protection and conservation of the environment. Like the Health Protection and Promotion Act produced by the Ministry of Health (see section 2.1.1), the main role of the EPA is to support for the implementation 
of more specialized regulations (such as the Waste Management Regulation, Regulation $347)$ that focus on a variety of environmental issues raised in the context of the EPA.

Definitions contained within the EPA give the Act its broad powers over several sectors of the environment, including agriculture. Like similar acts of its kind, specific topics such as pathogen abatement are covered explicitly, instead of implicitly. Several definitions cover the role of application of contaminants to land and the environment which broadly brush over several agricultural actions such as the use of biosolids and nutrients. For example, 'contaminant' is defined as;

Any solid, liquid, gas, odour, heat, sound, vibration, radiation, or combination of any of them present in the natural environment as a result, directly or indirectly of the activities of man.

(Environmental Protection Act, 1971, s. 1(c))

Similarly, the definition of 'pollutant' is given as;

Any contaminant or combination of contaminants present in the natural environment or any part thereof in excess of the maximum permissible amount, concentration, or level prescribed by the regulations.

(Environmental Protection Act, 1971, s. 1(1))

Of the more important sections with regards to nutrient containment is Section 15 (1) of the Act, which states that;

Every person who;

(a) deposits in, adds, emits or discharges into part of the natural environment

(b) is the person responsible for a source of contaminants that deposits in, adds to, emit or discharges any part to the natural environment...

shall forthwith notify the Department of the deposit.

Despite the clause, it is stated in the EPA that subsection 1 (above) does not apply to waste disposed of in accordance with normal farm practices (for further information on 'normal farm practices', see the Farming Food Production and Protection Act, section 2.1.15). However, the Act could apply to actions where 'normal farm practices' are not applicable such as during events of severe run-off into estuaries or deliberate well water pollution. 
Of particular importance to the EPA and its accompanying Regulations are Certificates of Approvals. Certificates of Approval are ministry-based contracts issued for specific endeavors requiring approval from the Ministry of the Environment. Examples of certificates pertaining to agriculture include waste disposal and recycling and the application of non-agricultural wastes to lands. For example, under the Guide to Agricultural Land Use (see section 2.1.10), it is stated that the Environmental Protection $A c t$ requires that the prior approval of sludge and septage utilization operations and application sites. This ensures that odour and water pollution are minimized and therefore prevents an excessive buildup of a heavy metals and other contaminants in the soil. Until the implementation of the Ontario Water Resources Act (1990) and the Nutrient Management Act (2002), the EPA was the main source of litigation for cases of malpractice in the agricultural sector.

\subsubsection{Canada Animal Waste Management Guide (1972)}

Produced by the Canada Committee on Agricultural Engineering, the Canada Animal Waste Guide was developed due mostly to growing public concern of environmental pollution, large intensive livestock operations, and the increasing number of residential dwellings on or near farmland. The Guide assumed that the eventual solution to waste management problems would involve a balanced ecological system, meaning that the application of nutrients should be in balance with those removed by crops grown. The purpose of the guide was to bring together the current practices that provided reasonable approaches to handling animal wastes. Reference legislation given in the Guide for the Province of Ontario included the Environmental Protection Act (1971), the Water Resources Commission Act (1956), and the Public Health Act.

The Guide was the most comprehensive of any publication released in reference to agricultural best management practices and implied scientific background and direction. Manure management, utilization of manure in crop production, site selection, zoning and building construction, manure handling systems, and processing of animal wastes were discussed in the Guide. 
The 'Water Pollution' component of the Guide included pollution opportunities created in an agricultural operation. The main water pollution hazards included inadequate storage facilities, winter application on frozen soil, or excessively high rates of manure on land.

The Guide stated that manure and/or its constituents can be carried overland into surface water supplies and would be responsible for;

(a) Nitrate poisoning of animals and humans that drink contaminated water

(b) The transmission of certain diseases if these disease-producing organisms are present in the manure

(c) Nutrient enrichment (eutrophication) and the resultant unsightly growth of algae and

(d) Septic and unsightly conditions due to depletion of the dissolved oxygen caused by the BOD of the organic material in manure.

Odour and other nuisances such as noise continued to play a large role in the management principles listed in the Guide. The principles included;

(a) Access to sufficient land for crop utilization of manure and limiting the rate and time of application to avoid water pollution.

(b) Separation between confined animals and neighbours to avoid nuisance complaints by allowing for the dilution of unavoidable barn and feedlot odours and flies and dissipation of noise.

(c) For household animals, frequent manure removal from the barn into separate and undisturbed storage to minimize odour levels in the barn and avoid animal and human exposure to gas hazards, particularly from stored liquid manure.

(d) Sufficient manure-tight storage capacity to control surface water and groundwater pollution and avoid land application of manure that may reach water.

(e) Rapid soil cover of manure to control odours during land spreading and control manure washing from fields when surface runoff occurs.

(Canada Animal Waste Management Guide, 1972) 
Nitrogen management was a critical part of the Guide. Information on avoidance of runoff waters and nitrogen balance applications was provided. Soil sampling and analyses of manure was encouraged. Methods of soil application included the 'plowdown method', which diverts manure downward into a 4-foot swath while a second tractor follows and pulls a plow slightly larger than the swath and covers the manure in seconds. The second method included soil injection, which, according to the Guide was the more favorable method as it 'reduces odour to neighbouring communities'. Finally, methods of treating the manure were included in the Guide so that farmers would have methods for reducing odours and water pollution. Methods included dehydration, incineration, lagoons, and composting. The Guide proved to be a benchmark for future codes and guides since it is essentially the first piece of legislation which identifies organisms as an important component to animal wastes.

\subsubsection{Agricultural Code of Practice (1973)}

The Agricultural Code of Practice took a significant step towards legitimizing best management practices and bringing them together in a complete code that other codes had failed to do such as the Canadian Code for Farm Buildings. The Code was released as a 'cooperative action between farmers, farm organizations, municipal officials, and a number of ministries of the Ontario Government". Of particular significance is the relationship between the Code and the Environmental Protection Act (1971). The Codes practices were viewed as 'best management practices' of the day and therefore, any certificates of approval granted by the Ministry of the Environment had to have been consistent with the guidelines of the code.

Key measures are detailed in the Code that could "minimize pollution problems" included sufficient land area on which to spread manure, sufficient manure storage capacity to hold the manure until it can be properly spread on the land at appropriate times, sufficient separation distances from livestock and poultry buildings and manure storages to neighbouring dwellings, management guidance in keeping with existing knowledge on the storage, handling and use of animal manures, and guidance for dead animal disposal. 
Unlike the Canada Animal Waste Management Guide, the Code encouraged proactive means of reducing nuisance problems. For example, buffer zones were required to prevent livestock from accessing local surface waters and posing a threat of contamination, to public water sources. The intensity of odour from the building and the manure storage capacity relates closely to separation distances. Manure could not be spread within 600 feet of a neighbouring home. Furthermore, the Code stated that the objectionable effects of odour in a neighbourhood could be reduced if livestock and poultry facilities were located as far as was practically possible from neighbouring facilities.

Unlike future codes and legislation, specific separation distances were provided from residential areas and roadways. Of significance was the absence of distances provided from watercourses and wellheads. The following distances were provided for new livestock and poultry buildings and manure storage facilities;

1. At least 2000 feet from land presently zoned for residential use

2. At least 1000 feet from dwelling on adjacent property

3. At least 300 feet from the center line of any public road

4. At least 200 feet from the lot lines of the site on which the production unit is situated.

Animal units were used in the Code for the first time in any legislation or policy, equating units for particular species and providing specific units for each animal. The origin of Animal Units was not defined in the Code. Furthermore, it is unclear how the number of acres was determined for land application processes. The 'minimum acreages' are those land requirements needed to avoid the risk of groundwater pollution by compounds of nitrogen. According to the Code, it is expected that nutrients used on applicable land will be spread evenly on farm grounds. Soil type is broken down into 2 categories of spread media (based on percolation rates) including 'Loam-to-Clay Soil', and secondly, 'Sandy Soil'. 
According to the $C$. storage of manure piles was expected to be in watertight facilities so as to divert all unsdde drainage away from feedlots by dikes, ditches and drains. Storage facilities were to be built so as to facilitate up to six months of storage capacity. Liquid manure systems were to be used so as to be incorporated into the soil as soon as possible and certainly with a 24-hour period. Methods of nutrient incorporation included plow-down or liquid manure injection. Manure spreading during the spring and winter months was also discussed in the Code. It is stated that the greatest fertility value for manure is realized when manure is stored properly and incorporated into the soil after spreading which will invariably reduces odour problems and guard against runoff. Winier application was discouraged, however not prohibited. The decision of spread was ultimately left up to the farmer to make his or her best judgments.

In summary, the Code leaves much to be desired in terms of microbiological concerns in the agricultural framework o: the day. Management of manure was viewed simply as a means of reducing inconvenience to neighbouring communities.

\subsubsection{Agricultural Code of Practice (1976)}

The second and final release of the Code, the 1976 Agricultural Code of Practice was a significant advance over its 1973 predeccssor. The 1976 code was developed and based on the concert that all livestock manure should be returned to the soil to grow crops. However, it was emphasized that the land can safely accept only a limited amount of manure without increasing the potential for water pollution and reduction in crop yields. While the 1973 Code contained a framework for establishing and expanding livestock expansions, it provided little protection from the encroachment by other users of the land. The Code of 1976 incorporated a number of changes from the 1973 version by providing a "wo-way" approach to the maintenance of a strong livestock industry. A trend towards increasing manure production, especially large production operations and storage increased the demand for a code, which accounied for the significant increase in manure piles, especially in larger operations. Pollution concepts were addressed on several levels in the 1976 edition of the Code. In fact, the goal was to provide guidelines for livestock operations to minimize land, water, and air pollution potential. Water pollution is addressed in the Code where it is noticeably absent in its previous edition. 
There are several similarities between the two codes of practices including the incorporation of buffer zones, manure storage capacity requirements, sufficient land availability, and the use of animal units. However, several differences in the Codes exist including the use of the Minimum Separation Distance Formulae (M.D.S. I, II, and III). The M.D.S. formulae were developed strictly for the separation distances required for the application and storage of untreated manures and to provide a consistent and fair technique to determine separation distances between nori-compatible land uses. Prior separation distances failed to incorporate individual characteristics between farms that might have led one farm with severe slope and permeable soil to have a separation distance twice the length of a farm with no slope and slow-permeation soil characteristics.

M.D.S. Formula I was developed to determine the minimum separation distance between other land uses such as residences establishing or expanding in close proximity to a livestock operation. M.D.S. Formula II was used to determine the setback and separation distances between a new enlarged or remodeled livestock facility and other non-compatible uses. Finally, M.D.S. III was used by agricultural engineers to determine the minimum separation require: ments for existing livestock setups not contemplating change of operational or structural nature where a Certificate of Compliance (Environmental Protection Act, 1971) would have been required. Although it was not explained how the formulae were created, the following factors were incorporated within the formulae in order to determine corresponding distances and calculations including type of livestock, number of livestock, degree of change, manure systems, manure storage, and type of encroachment (in M.D.S. Formulae I).

Other differences between the two Codes included the ability of the farmer to test his manure to be analyzed for nutrient content where nutrients could be analyzed in 1976 and could not have been analyzed in 1973. In turn, recommendations on nutrient use and nutrient application were made available to the farmer based on the inferred analysis of manure, soil type and type of crop grown from the Ministry of Agriculture. Unlike the 1973 Code, animal units are defined in the 1976 edition as 'the number of that lind of 
livestock that would produre 150-170 pounds of nitrogen in their manure'. This amount of manure is sufficient to provide the nitrogen fertilizer requirements for one acre of corn. Animal units and rates of livestock manure application remain consistent in both Codes.

Odour issues were tackled often in the 1976 Code through various avenues including application times, application conditions, proper design of new buildings, moisture content of storage facilities, and taking maximal advantage of topographical and local climatic conditions when spreading occurs. Manure storage facilities were expected to be constructed and maintained based on the following conditions;

1. Protection for ground and surface water

2. Minimum odour levels

3. Six months minimum storage capacity to hold the manure until it can be efficiently used on the land

4. Safety and security

5. Minimum nutrient losses during storage

6. Prevention and control of disease in the building

7. Minimum storage within the building

For the first time, manure treatment methods were discussed. However, the treatment methods pertain more to the treatment of human wastes as opposed to other wastes (animal wastes) on a farm setting. Similar to several other practices contained within the Code, it was stated that usually 'the main objective of manure treatment is odour control'. Methods of treatment include aeration and chemical treatment, along with composting, drying, and manure lagoons.

Coliform bacteria and nitrates from manure are listed as pollutants that can potentially contaminate both surface and ground water supplies. Nitrates are a problem in drinking waters since it can cause illness in humans at high concentrations including laboured breathing, rapid pulse, weakness, diarrhea and even death. Conditions that could contribute to adverse water quality included runoff from manure spread on sloping frozen soil, physical soil erosion, direct runoff from feedlots, and poorly constructed 
manure storages. The following guidelines were provided in the Code as a means of protecting water quality on farms:

1. Spread manure at specified rates (given by the Ministry)

2. Work manure into the ground within 24 hours where possible

3. Practice good land use by reducing stream bank erosion, constructing grassed waterways, and ploughing across slopes where practical

4. Do not spread manure on steeply sloping land, particularly during winter or early spring, when there is essentially no crop cover

5. Prevent runoff from feedlots and manure piles

6. Construct concrete holding tanks and retaining walls

7. Prevent silage juices from reaching water supplies

The 1976 Agricultural Code of Practice utilized new concepts compared to its previous edition in 1973 such as soil testing and the utilization of M.D.S formulae. By including information on site planning, the M.D.S formulae, and making reference to the importance of the impact of agricultural practices on water quality, the Code would serve as an important document for farmers for several years.

\subsubsection{Guidelines for the Utilization of Waste (other than sewage sludge) on Agricultural land (1992)}

Prepared by the Sludge and Waste Utilization Committee under direction of the Ontario Ministry of the Environment, the Guidelines for the Utilization of Waste (other than Sewage Sludge) on Agricultural Lands was produced for agricultural operations and municipalities who intended to apply wastes to their lands. The Guideline, produced under the Environmental Protection Act (1990), was created to define the criteria which must be met before recycling and use of suitable waste on agricultural land could be considered. The Guideline acted as a template for the 1996 Guidelines for the Utilization of Biosolids and other Wastes on Agricultural Lands.

The 1992 Guideline stressed that 'all waste (manures, biosolids) applied to agricultural land must have an acceptable low potential to generate odours and must contain acceptably low concentrations of organisms pathogenic to man or animals". 
Nuisances, especially odour concerns, remained a concern in the guideline where spreading of wastes should be 'no more objectionable than those arising from other normal farm practices' (see section 2.1.15). Other components included in the analyses of wastes included specified organic and inorganic waste concentrations, including metals.

Unlike other Guidelines and Codes of practice (such as the Agricultural Code of Practice), the Guideline provided general separation distances for all wastes. Distances, soil criteria, and waiting periods were evaluated on a 'case-by-case basis' where significant pathogenic loads were found in the waste. Of particular significance to this study is the implementation of separation distances based on soil permeability and slope of land. Despite setback distance, spreading must have been suspended where runoff was suspected and where ground was snow-covered or frozen.

\subsubsection{The Guidelines for Sewage Sludge Utilization on Agricultural Lands (1992)}

A product of the liaison between provincial Ministries and Federal departments making up the Sludge and Waste Utilization Committee, the Guidelines for Sewage Siudge Utilization on Agricultural Lands (1992) were written to address the concerns of the potential environmental and health impacts of sewage sludge utilization. The Guide was supported by research which (was) ongoing from 1971 to 1992. The purpose of the guidelines was to facilitate the recycling and use of sewage sludge on land while protecting the quality of food, the health of consumers, and the quality of the environr 'cwi The Guidelines supplemented Regulation 309 ('Processed Organic Waste Regulation") of the Environmental Protection Act (1990).

Much like the Guideline for the Utilization of Waste (except Sewage Sludge) on Land, the Guideline contained setback distances from surface water tables ( 0.9 meters), bedrock ( 1.5 meters), drilled wells more than 15 meters deep ( 15 meters), all other wells including dug wells (90 meters) and residential areas (450 meters) (section 5.1.1). Setback distances could be increased depending on soil permeability of the subsurface environment. Soil criteria pertaining to spreading sites included reference to organic soils, metal concentrations of soils, soil $\mathrm{pH}$, soil tests and avoidance of sewage 
application to snow or frozen covered ground. According to the Guideline, the maximum depth of fluid sewage which may be spread at any one time was $1.3 \mathrm{~cm}$. Furthermore, no further application of any nutrient could be applied until the first application had dried. As will be shown in section 2.1.7, the Guideline acted as a supplement to the Guidelines for the Utilization of Biosolids and other wastes on Agricultural land which were released 4 years later in 1996.

\subsubsection{Ontario Environmental Farm Plan (1993).}

A program sponsored in part by the Ministry of Agriculture and Food, Environmental Farm Plans (EFP) were documents voluntarily prepared by farming families to increase their awareness of the environment on their farm. Through the EFP process, farmers who enlisted in the program would highlight environmental strengths on their farm, "identify areas of environmental concern, and set realistic goals and time tables to improve environmental conditions: A voluntary program, farmers who wished to participate in the program were encouraged to complete a self-assessment of their farm, develop an action plan depending on their environmental concerns and submit their plans to a peer-review committee and finally, implement the plan.

Issues of environmental concern include water well safety, fertilizer handling and storage, storage of agricultural wastes, soil management, soil use and management, and several other best management practices shared by the agricultural community, including the Ministry of Agriculture and Food. The Farm Plan is quite similar to the concept of the Nutrient Management Plan that is to be created by all agricultural operations under the Nutrient Management Act (2002). However, the Farm Plan was only shared with a peer-review committee and therefore, the municipality or province did not become involved. Environmental farm plans were essentially abolished when municipal by-laws and the Nutrient Management Act required that nutrient management plans become mandatory for every agricultural operation.

\subsubsection{Guide to Agricultural Land Use (1995)}

Released in 1995 by the Ontario Ministry of Agriculture, Food and Rural Affairs, the Guide to Agricultural Land Use and the Minimum Distance Separation (MDS) I and 
II were the successors to the 1976 Agricultural Code of Practice. Taken together, they formed a two-pronged approach to reducing land use conflicts in rural areas. Similar to previous legislation and guides, the Guide to Agricultural Land Use addressed issues that "sometimes arise between agriculture and other land uses in the Ontario countryside". It advised farmers on how to avoid or reduce conflicts with neighbours and environmental impacts through the use of appropriate farm practices and equipment. The booklet set out the guidelines to create a totally inoffensive environment immediately adjacent to some agricultural facilities. Unlike several acts, regulations, codes and guidelines before it, the Guide to Agricultural Land Use made it clear to non-farm residents that "those who make the choice to accept the advantages of country life must be prepared to accept the noise, odour, and dust associated with normal farm practices".

Topics integrated in the Guide included, the use of livestock manure and other organic residuals, manure management, protection of water quality, noise, and dead animal disposal. The Guide contained advice on avoiding the potential for conflict between neighbouring land uses through appropriate approved development and contained information so that farmers could gain insight into the concerns of rural residents about agriculture. The Guide provided recommendations for manure management issues such as storage and application of manure. Much like the 1976 Agriculture Code of Practice, the Guide focused on issues involved in the management and use of manure (and other organic residues), the protection of water quality, dead animal disposal, and noise reduction strategies.

As the Guide was used in conjunction with MDS I and II formulae, the Guide utilized all recommended setback distances calculated in the MDS formulae based on animal units and livestock units. The Guide suggested that all manure should be applied in accordance with a Nutrient Management Plan. According to the Guide, a Nutrient Management Plan is a written plan of action to handle manure in a way that does not harm the environment. Detailed nutrient management plans ircluded manure nutrient testing, safe application rates, crop nutrient needs, area required for application, 
appropriate reductions in commercial fertilizer applications and emergency actions in case of spills or system failures.

The Guide also mentioned that while crops benefit from manure, problems could arise if it is improperly handled and used including crop damage, water pollution, and excessive odour. Furthermore, the Guide stated that when high manure application rates were used, groundwater could be contaminated by bacteria and nitrogen, and surface water could be contaminated by bacteria, nutrients, toxic levels of ammonia, suspended solids and organic materials. As a result, the Guide suggested that water testing take place at least once per year.

Land spreading is governed not only by the setback distances provided by the MDS I and II formulae but also general separation distances. For example, according to the Guide, 'if solid manure is spread closer than 200 meters to an incompatible use, it should be incorporated into the soil within 24 hours'. Recommended application methods (waste spreading systems) were provided with options for agricultural industries. According to the Guide, over-application of liquid manure 'should be avoided to prevent ponding and possible leaching to drainage tiles...regular checking of tile discharge for polluted water is recommended during liquid manure spreading: The Guide recommended that "if a problem is identified, stop spreading manure and prevent the contaminated tile from leaving the farm. Storage requirements were made based on several environmental factors including protection for groundwater and surface water, minimizing odour levels, storage periods of at least 200 days, minimizing nutrient losses during storage and handling, and prevention and control of disease in the building

Terms new to the Guide included the use of suspended and dissolved materials as they relate to water quality and soil erosion. Grassed buffer zones ( 5 meters) were recommended to reduce the amount of suspended and dissolved solids in lakes and nearby streams. It is obvious that some research came to bear on the Guide as its recommendations and best management practices clearly show. 
According to the Guide, environmental effects of improper manure application included crop damage, water pollution, and excessive odour. When high manure application rates were used by farmers, the Guide stated that "groundwater can be contaminated by bacteria and nitrogen, and surface water can be contaminated by bacteria, nutrients, toxic levels of ammonia, suspended solids and organic materials". Farmers applying sewage sludge and septage were referred to the Guidelines for Sewage Sludge Utilization on Agricultural Lands (1996). Despite the Guide's recommendations for setbacks for nuisance purposes, it is the incorporation of the MDS I and II formulae and incorporation of setback distances that made the Guide unique.

\subsubsection{Minimum Separation Distances (MDS I and II) (1995).}

Released in 1995 from the Ministry of Agriculture and Rural Affairs and the Ministry of Environment and Energy, the Minimum Separation Distance (MDS) formula provided distance separation requirements between existing farms and new community developments. In other words, the MDS was a tool to determine the distance between a livestock facility and another land use. MDS I and II replaced the Minimum Separation Formula I in the Agricultural Code of Practice (1976). The objective of MDS was to prevent land use conflicts and minimize nuisance complaints from odour. Minimum separation distances will vary in length according to a number of variables including type of livestock, size of the farm operation, type of manure system, and the form of development (present or proposed).

MDS I provided minimum separation distances from existing facilities for new development, while MDS II provided minimum separation distances from existing or approved development. MDS I calculated a separation distance based on either the actual housing capacity or potential capacity according to tillable hectares (maximum 150 Livestock Units). MDS I was applied in any non-urban designation where agricultural practices along with the housing of livestock is permitted while MDS II was based more on the community setting where nuisances (odour) may be of significance. One of the main purposes of the MDS program was to incorporate them into official plans and local legislation such as municipal by-laws. It was recommended in the MDS I document that 
the formulae were to be used not by themselves, but in conjunction with 'good farm practices'.

Of particular significance to the MDS formulae and this section are the incorporation of Animal Groups and Livestock units. Animals Groups were defined as "livestock and poultry grouped according to their manure production". A livestock unit was defined as "equivalent values for various types of animals and poultry based on manure production and production cycles". Based on values obtained from both the animal grouping and the livestock units which are given to the particular group, a manure setback distance was provided. However, information of the origin of both Animal Groups and for Livestock units is unavailable in the package. Furthermore, lack of studies and research pertaining to the effectiveness of 'unit-based' systems only adds to the uncertainty of the MDS system.

\subsubsection{Best Management Practices for Farmers -Agricultural Canada (1995) \\ Originally produced in 1995 by the Ontario Federation of Agriculture and} Agriculture and Agri-Food Canada, the series of 'best management practices' documents were released to assist farmers in streamlining agricultural practices at the farm level. Of particular importance to this study was the release of Nutrient Management Practices and Livestock and Waste Management Practices. Nutrient additions and removals played an important role in the nutrient management booklet. Examples of factors contributing to nutrient additions to land include heavy rainfall events, feeds and bedding, nitrogen fixation, fertilizer and organic material additions. Nutrient removals include, erosion, livestock, crops, leaching and gaseous emissions.

Application of biosolid material on land is based on the Guidelines for the Utilization of Biosolids and Other Wastes. Factors to consider in site approval provided by the booklet included soil tests for phosphorus, soil pH, slope of field, soil organic matter content, natural soil drainage, soil moisture content, snow cover and frost, and distance to wells, water table, watercourses, bedrock, or homes. 
According to the nutrient management booklet, biosolids 'contain some undesirable components like metals and may contain pathogenic organisms and other inorganic and organic compounds'. A nutrient management program approach is used similarly in nutrient management plans and nutrient management strategies found in the Nutrient Management Act. It is obvious (based on current literature and literature available in the 1990s) that some scientific knowledge has come to bear on the nutrient management section of best management practices since microbial considerations are made in land application methods and planning.

First printed in 1992, the Livestock and Poultry Waste Management best management practices were developed to provide information to producers who were considering changing the way that manure was managed on their farms. The book examined the environmental risks associated with poor waste management along with other practical problems and solutions many farmers may have experienced.

Microbiological components described in the booklet relate to the application of manure products and potential pollution problems that may include coliform bacteria and nitrate nitrogen which can contaminate water supplies (and contribute to eutrophication) and include pathogenic bacteria that can cause disease in humans and livestock. Runoff of liquids remains an important issue in the waste management booklet. Methods of manure treatment were also included to provide alternative solutions to land use such as utilizing manure for energy purposes.

\subsubsection{Guidelines for the Utilization of Biosolids and other wastes on Agricultural land (1996).}

A joint venture between the Ministry of the Environment and the Ministry of Agriculture and Rural Affairs, the Guidelines for the Utilization of Biosolids and other Wastes on Agricultural Land (1996) was developed to protect environmental quality, consumer and animal health, food quality and the productivity of the land. The Guidelines were developed to facilitate Regulation 347 (The Waste Management Regulation) under the Environmental Protection Act which was designed to control the types of wastes applied to agricultural lands. The document outlines criteria which must be met before biosolids, or other waste materials could be considered for use on 
agricultural land. According to the Guide, materials applied to land must benefit and promote the growth of crops and not degrade the natural environment.

The Guideline discusses several items relating to material application, including potentially desirable and undesirable constituents, spreading rates pertaining to sewage biosolids, separation distances, soil criteria, waste material handling and spreading along with responsibilities and rights. Sampling of soil and sewage biosolids is required by the Guideline. Soil sampling incorporates testing for chemical properties along with soil pH and metal, lime and nitrogen requirements for crops. Sewage biosolids are required to be treated and stabilized prior to spread on land. Standard separation distances are provided in the Guideline for both regular circumstances and special circumstances where low soil permeability and sustained slope are a concern. Separation distances are provided for application distances from groundwater tables (0.9 meters), surface water courses (10 meters), bedrock ( 1.5 meters deep), drilled wells more than $15 \mathrm{~m}$ deep (15 meters), all other wells (90 meters), individual residences (90 meters), and residential areas (450 meters). Since the 1992 release of the Guidelines for Sewage Sludge Utilization on Agricultural Lands, the separation distances have not changed. In fact, the two Guidelines are very similar sighting identical setback distances along with similar best management practices for handling, holding and spreading of biosolids.

It is clear that the focus of the Guideline is the threat of overexposure to and abatement of metals in the soil and watercourses since biosolids have traditionally had high metal concentrations depending on their source. Nevertheless, key pathogen abatement strategies are provided by the Guideline which have a significant effect of reducing the introduction of accompanying organisms to the soil.

\subsubsection{Ontario Building Code Act (1992), The Ontario Building Code (1997).}

Supportive legislation for the Ontario Building Code, the Ontario Building Code $A c t$, provides authority for the establishment and enforcement of an Ontario building code (Toombs, 1992). The Act (along with the Canadian Code for Farm Buildings), applies to the construction, alteration or demolition of farm structures, including manure storages (Toombs, 1992). Obviously, a correlation can be made between the 
malfunctioning of faulty septic systems and the contamination of well water on private and public property. Separation distances are given in the code depending on what type of system is installed on the property. No reference is provided to interpret separation distances nor is any explanation given of their origin.

\subsubsection{Farming Food Production Protection Act (1998)}

Released in 1998 by the Ontario Ministry of Agriculture, Food and Rural Affairs, the Farming Food Production Protection Act "provides protection from nuisance complaints of odour, noise, and dust to farmers carrying out normal farm practices" . (Toombs, 1992). The FFPPA provides stronger protection for nuisances and broadens the definition of what constitutes a farming operation. 'Right-to-farm' legislation arose from several key factors including increasing urban sprawl and a rise in large-scale industrial agricultural productions. Although management of nutrients is not mentioned, the Act does refer to an "agricultural operation" to include practices within the operation such as the application of fertilizers and soil conditioners on the land. Under the FFPPA, a normal farm practice is a practice that;

(a) is conducted in a manner consistent with proper and acceptable customs and standards as established and followed by similar agricultural operations under similar circumstances, or

(b) makes use of innovative technology in a manner consistent with proper advanced farm management practices.

(Farming Food Production Protection Act, 1998, s. 1).

The Act has little significance on the environmental impacts of the farm practices performed by the local farmer. It is clear (and stated within the Nutrient Management Act) that Acts such as the Environmental Protection Act and the Nutrient Management Act would take precedence over the FFPPA where a legitimate health hazard or pollution event has occurred, regardless if it is a nuisance or not. 
Table 1. A timeline of Acts, regulations, codes, guidelines and programs which have directly or indirectly dealt with nutrient management strategies and practices in Ontario.

\section{Dates of significance:}

\section{Environmental Policy Development in Ontario (1873 - 2003)}

1873 - An Act Respecting the Public Health (Provincial)

1885 - Act Respecting Infectious or Contagious Diseases affecting Animals (Federal)

1924 - The Well Drillers Act (Provincial)

1927 - Lakes and Rivers Improvement Act (Provincial)

1956 - An Act to Establish the Ontario Water Resources Commission (Provincial)

1970 - Canadian Code for Farm Buildings (Federal)

1970 - The Waste Management Act (Provincial)

1971 - Environmental Protection Act (Provincial)

1972 - Canada Animal Waste Management Guide (Federal)

1973 - Agriculture Code of Practice (Provincial)

1976 - Agricultural Code of Practice (incorporation of MDS formula) (Provincial)

1985 - Fisheries Act (Federal)

1990 - Agricultural Tile Drainage Act (Provincial)

1990 - Conservation Land Act (Provincial)

1990 - Agricultural Tile Drainage Installation Act (Provincial)

1990 - Health Protection and Promotion Act (Provincial)

1990 - Drainage Act (Provincial)

1990 - Planning Act (Provincial)

1990 - Ontario Water Resources Act (Provincial)

1992 - Ontario Building Code Act.

1992 - Guidelines for the Utilization of Waste (other than sewage sludge) on Agricultural land (Provincial)

1992 - Guidelines for Sewage Sludge Utilization on Agricultural Lands (Provincial)

1993 - Ontario Environmental Farm Plan (Provincial)

1995 - Guide to Agricultural Land Use (Provincial)

1995 - Minimum Separation Distances (MDS I and II) - Officis! Guideline (Provincial)

1995 - Best Management Practices for Farmers (Federal)

1996 - Guidelines for the utilization of biosolids and other wastes on Agricultural land (Provincial).

1997 - First Municipal by-law pertaining to nutrient management (Grey Township)

1997 - Ontario Building Code (Provincial)

1997 - Mandatory Health Programs and Services Guidelines (Provincial)

1998 - Farming Food Production Protection Act (Provincial)

2001 - Municipal Act (Provincial)

2002 - Safe Drinking Water Act (Provincial)

2002 - Nutrient Management Act (Provincial)

\subsubsection{The Nutrient Management Act (2002)}

As part of the government of Ontario's Clean Water Strategy, the Nutrient

Management Act (NMA) provides for province-wide standards to address the effects of agricultural practices on the environment, especially as they relate to land applied materials containing nutrients. The purpose of the Ontario Nutrient Management Act is

to provide for the management of materials containing nutrients in ways that will enhance the protection of the natural environment. Nutrient Management Plans (NMPs) and Nutrient Management Strategies (NMSs) are used to attempt to control how nutrients are 
applied to land by individual farm locations. Both NMPs and NMSs are quite similar to the plans and strategies once used in local municipal bylaws. However, the Nutrient Management Act addresses the variability of muricipal NMPs and NMSs and requires that all agricultural operations follow one template for plans and strategies in the Act so that all operations are similar in content versus municipal nutrient plans and strategies which were different depending on the location and requirements of the local government. Nutrient management plans and nutrient management strategies require active participation and involvement from both the nutrient producer and the municipality where the nutrient presides.

A nutrient management plan (NMP) is a document that provides the details regarding the management of materials containing nutrients that may be applied to agricultural lands. The plan is specific to the farm and the nutrients used on the land. A plan is done for an entire farm unit and will contain all fields receiving nutrients. Included in all NMP: $s$ are a written descriptions of the farm, any leases or agreements with other farms, a contingency plan for any emergency's, a site plan of all storage basins and structures, livestock numbers, animal weights, field sketch's, feed additives used, land availability for spreading, manure application rates and methods, and annual manure volume produced (if any) per year. Also include in the plan are soil and manure tests which are required to be performed every 3 years or whenever changes are made to the NMP.

A nutrient management strategy (NMS) is a document that must be completed by all municipalities as well as generators of nutrients. The purpose of the NMS is to provide an overall picture of the destination and characteristics of the mutrients generated to ensure that they are managed appropriately. Components of NMS include a contingency plan, location maps of storage and water-ways, a site plan, minimum distance separation calculations based on upcoming regulations, lists of quantity and types of all nutrients generated or received, analysis of nutrient content and quality, documentation verifying feed additives effects as well as methods of disposal of nutrients 
(other than land applying). The NMS acts as a second set of eyes on the farm so as to ensure that the NMP is being managed effectively.

It is well known that many of the rutrients generated by farmers, including organic materials, manure, septage, and compost, harbour organisms that can be pathogenic to human health. However, although many of the nutrients used on lands are well known for the existence of pathogenic organisms, the Nutrient Management Act never once mentions the term 'pathogen' or 'microorganism'.

The Act is consistent with the Walkerton Inquiry Report which envisioned a nutrient management strategy that would protect soil and water resources while sustaining agricultural industry growth. The Act reaffirms ultimate authority to the Environmental Protection Act (section 2.1.3), the Ontario Water Resources Act (Appendix 2.2) and the Pesticides Act (Appendix 2.2). Key to the legislative framework are Nutrient Management Plans (NMPs) and Nutrient Management Strategies (NMSs) which are 'science based tools' that use best management practices to manage nutrients in an environmentally responsible manner. The Ontario Ministry of Agriculture and Food (OMAF) and the Ontario Ministry of the Environment (OMOE) are jointly responsible for the Act where the Ministry of the Environment is responsible for enforcement and the Ministry of Agriculture for policy development.

The Nutrient Management Act attempts to reduce nutrient inputs to soil and waterways by managing agricultural practices and implementing best management practices and reducing the concentration of nitrogen and phosphorus in nutrients applied to soil. The Nutrient Management Act ministry protocols set out several specific spreading provisions including restriction of winter application of nutrients (Nutrient Management Act, 2002, s. 8(2)) as stated in the regulation. Although the protocol never states so, restricting winter application of nutrients prevents an excess of nutrients from leaching into receiving bodies of water and the soil during spring run-off. However, animal health, grazing, and food source protection are not mentioned in the Act or its protocols. These gaps address pre-application strategies that aid in microbial load 
reductions to soils. For example, restriction of grazing animals on recently treated land (with manure) is an effective means of reducing contamination of younger herds of animals with pathogens.

The Act also tackles "intermediate operations" incluaing composting (s. 1(1)) and anaerobic digestion. The two methods are well known for their ability to reduce bacterial load in nutrients. Pertinent to other Nutrient Management plans across Canada and in other international jurisdictions, the Ontario Nutrient Management Plan includes standards for maximum setback distances, separation from watercourses and minimum depth to groundwater or bedrock. Farmers are expected to take into account landscape water table variations and seasonal fluctuations in water level in order to protect the drinking water source.

The Nutrient Management Act tends to sway on the side of being preventative whereas acts dealing with similar issues pertaining to water quality (Ontario Water Resources $A c t$ ) are reactive statutes. Pathogen management is dealt with indirectly in the Nutrient Management Act as was observed in previous pieces of provincial environmental legislation. The Act differs from previous legislation because it encompasses all aspects of nutrient control where other government documents were not as inclusive in their scope.

\subsection{Discussion - Pathogen Abatement and Nutrient Management in Ontario}

The study of the history of nutrient management and pathogen control legislation in Ontario is a complex task which helps to identify how the Nutrient Management Act was constructed. Landmark periods of nutrient management legislation can clearly be observed in the periods of the 1970s and the 1990s (see Appendix 2.1), where more than 25 provincial documents were developed. The reason for the fury of activity within these two decades is unclear. However, it is assumed that there was an obvious need for legislation and guidance in the agricultural industry during those periods. 
Up until the early 1970 s, the science governing nutrient management issues had little, if any effect on the legislative makeup of the province of Ontario's nutrient management and pathogen abatement initiatives. Without diminishing the significance of earlier Acts such as the Public Health Act (1873) and the Well Drillers Act (1924) (see Appendix 2.2), landmark documents paved the way for the development of future provincial initiatives such as the 1976 Guide to Agricultural Land Use and the 1992 Guidelines for Sewage Sludge Utilization on Agricultural Lands which obviously incorporated some scientific research. A shift in hierarchical legislative significance is observed from voluntary, information based codes and guidelines (which hold no significant legislative weight unless adopted by acts or regulations) during the 1970 's to the acts and regulations of the 1990's and early part of 2000 . Furthermore, as science evolved over the past 30 years, an increasing number of best management practices were observed. However, it is difficult to validate the practices required by much of the legislation since no experimental data supports many of the requirements such as setback distances and application methods. This is not to suggest that setback distances and application rates were not protective (on the other hand, they could be over protective). However, since local contamination events continue to occur across the province and because best management practices have not been supported by science, it is hypothesized that such regulated and recommended units could potentially be based on the "best professional judgments" of legislators who create legislation at the provincial or federal level.

The following sections highlight several key issues in the management of nutrients based on their developments in previous legislation and documents.

\subsubsection{Odour}

Odour is a prominent issue in nutrient management legislation that may have been the primary reason for the development of several pieces of literature developed both by the Province and the Federal government since 1885. Earlier guidelines and recent legislation tackle aspects of odour, and more specifically nuisances related to the practices of farms. Of consequence to farming communities, odour was (and still is) of particular importance to farms which border housing communities. Despite obvious 
strategies to reduce and avoid instances of nuisance, many practices indirectly had positive impacts on reducing health hazards. For example, the 1973 Agricultural Code of Practice advises against the spread of nutrients during the winter and when ground is frozen to reduce odour problems and guard against runoff. It is well established that winter spread (especially when applied on snow) may lead to excessive runoff and possibly leaching into watercourses. Although it is never established clearly in the Code, the practice indirectly guards against nuisances and pathogens.

It is not until the release of the Minimum Distance Separation Guides I and II (see section 2.1.11) that a shift in focus from nuisances to nutrient management is observed. For example, the MDS I Guide states that the primary purpose of the document 'should be for agriculture'. Furthermore, the Guide states that 'non-farm residents who seek the advantages of country life must be aware of the noise, odour, and dust associated with normal farm practices'.

After the release of the FFPPA (see section 2.1.15) in 1998, the trend towards creating legislation pertaining to nuisance management declined and an increase in environmental awareness and protection legislation was observed. Local advisory committees and local by-law enforcement agencies (as opposed to Provincial officials) addressed issues of nuisance (smells, noise, dust) along with other problems relating to 'normal farm practices'.

\subsubsection{Water Quality}

The standardization of private water quality aided in the creation of current source water protection legislation. Acts released by the Ministry of the Environment such as the Safe Drinking Water Act (2002) and the Ontario Water Resources Act (1990) could not have been possible without water testing technology that requirements within these Acts commands. Despite this, several pieces of legislation tackled the issue of water quality long before scientific equipment and technology was available. For example, the Well Drillers Act (1924) (see Appendix 2.2) requires that all abandoned wells should be capped so as to keep all water in its place of origin and to prevent any fresh or salt water or other injurious substances from entering... (Well Drillers Act, 1924, s. 9(1)). Several 
other examples of generalized sections in legislation regulating safe drinking water and protection of source water include the Ontario Water Resources Commission Act (1956) and the Public Health Act (1873). The Ontario Water Resources Commission Act required that the commission 'develop and make available supplies of water and to construct and operate systems for the supply, purification and distribution of water and for the disposal of sewage' (Ontario Water Resources Commission Act, 1956, s. 10(a),(b)). Not until the 1960s and 1970s do specific practices regulating drinking water safety and source protection begin to surface in legislation and other publications. Information leaflets published by the Ontario Department of Agriculture and Food (1966) advise farmers to avoid application of nutrients in areas with a high water table.

The release of the Environmental Protection Act (1971) had significant impacts in source water protection by prohibiting the release of substances to the natural environment that may cause 'adverse effects'. Several publications including the 1973 and 1976 editions of the Agriculture Codes of Practice make reference to the Environmental Protection Act and the Ministry of the Environment as sources of ultimate authority in agriculture and water related issues. Examples of water quality protection contained in the Agriculture Code of Practice $(1973,1976)$ included setback distances regulating nutrient application from well caps and watercourses, control of surface runoff, surface application rates, restriction of animal access to waterways, and building construction standardization.

The 1990 s proved to be a significant decade for the creation and standardization of water quality legislation. Legislation was created not only at the provincial level, but also at the municipal level where local by-laws tackled local water quality and nutrient management issues such as minimum setback distances, implementation of nutrient management plans, establishing wellhead protection areas, and construction requirements for new barns. The release of the Ontario Water Resources Act (1992) combines several factions of water quality and safety resources including issues of water protection, abstraction, treatment and control. 
The 1997 release of the Ontario Building Code addressed homeowner sewage treatment and setback distances from water sources and percolation rates. The Guide was used for several years as a reference for public health departments for setback distance questions and for on-site sewage system approval. Minimum separation distances were addressed in the 1992 Guidelines for the Utilization of Waste (other than sewage sludge) on Agricultural Lands along with the Guidelines for Sewage Sludge Utilization (1992).

\subsubsection{Setback/Separation Distances and MDS I \& II}

First released in 1973 in the Agricultural Code of Practice, setback distances were originally used for the construction of new manure storage facilities to reduce odour complaints to neighbouring communities. Distance requirements were provided for setbacks from residences, public roads and lot lines. Prior to the release of setbacks distances, land use requirements were required to ensure the farm operation had sufficient land for the amount of nutrients they were was producing.

Not until the release of the 1976 Code of Practice (where setback distances and the incorporation of the MDS I and II formulae) did environmental quality issues come to bare on manure management and water quality. According to the Code of Practice, the MDS formulae were developed to provide a consistent and fair technique to determine separation distances between non-compatible uses. Althuugh non-ccmpatible uses included similar structures and landmarks as the 1973 code (nearest neighbour, commercially designated structures), the formulae still incorporated relatively new techniques such as the use of Animal Units to differentiate one farm's operation from another (depending on how many Animal Units were produced on that farm). According to the 1976 Code, 'the Animal Unit System was developed to equate livestock numbers to the nitrogen content of the manure produced while those animals were on the farm . Although it is unclear how the units were created, it was a relatively new concept in the nutrient management that would later be followed in the 1995 Minimum Distance Separation Guide albeit using Livestock Units. 


\subsubsection{Manure Storage}

Storage of nutrients and application frequencies have been included as important topics in several publications pertaining to nutrient management. Earlier publications from the Ontario Department of Agriculture and Food (1966) (ODAF) advised farmers that the number of months that manure must be held (prior to land application) could depend on the field-cropping program associated with the livestock enterprise. However, to conserve and obtain maximum utilization of the plant nutrients in the liquid manure and to avoid possible pollution of surface water supplies due to runoff from manurv-laden melting snow, it was recommended that the planned holding period be six months (ODAF, 1966).

The 1976 Code of Practice also recommended a six-month minimum storage capacity to hold the manure until it can be effectively used on the land. No explanation of why a six-month period to store nutrients is provided. However, the 1995 release of the Guide to Agricultural Land Use requires a storage period of 200 days (roughly 5.5 to 6 months) with 250 days recommended for optimum flexibility so as to ensure that the manure can be effectively stored and used on the land. According to the Guide, the choice of the most appropriate system is based on moisture content of the manure and the location of the storages in relation to streams, watercourses, wells, neighbours and roads. After the release of the Guide to Agricultural Land Use in 1995, no publications were released mandating minimum manure storage times for optimum application rates. However, nutrient management plans and by-laws in Ontario after 1997 referenced the Guide along with the MDS system for storage requirements until the release of the Nutrient Management Act in 2002.

\subsection{Nutrient Management Policy and Pathogen Control}

The relationship between nutrient management policy and pathogen and nutrient control was examined by Stiefelmeyer (2003). It was shown that nutrient management policies, including the Nutrient Management Act cannot adequately control pathogens in agricultural environments because pathogens (with the exception of some viruses) are transported differently than sediments and nutrients and therefore, legislation designed to 
control pathogens and in particular, bacteria would be ineffective. Specifically, vegetated buffer zones, tillage practices and land application requirements were found to be insufficient at controlling pathogen transport in the subsurface environment based on research from Atwill et al. (2002), Entry et al. (2000), Coyne et al. (1995), Fenlon et al. (2000), and Ogden et al. (2001) among others. Analysis of research focusing specifically on E. coli 0157:H7, Salmonella, Giardia, and Cryptosporidium showed that these pathogens could remain viable when applied to agricultural surfaces. The survivability of pathogenic organisms further enhances their ability to be transported in the subsurface environment. As research has progressed, it has become clearer that pathogens can remain viable under stressed environmental conditions and therefore, legislation designed specifically for pathogen control is required. Furthermore, a pathogen control strategy is required which accounts for differences in environmental conditions and physicalchemical differences of microbiological make-up.

Further analysis of international nutrient management policy showed that the majority of policies, like the Ontario Nutrient Management Act do not address critical pathogen control issues such as herd health, biosecurity issues and treatments used during storage that could aid in pathogen load reduction. Such gaps in policy point to the need for further microbial transport studies so that legislation is supported by sound research.

\subsection{Conclusion}

Scientific research should influence the requirement and implementation for effective legislation in all areas of scientific research including nutrient management so that agricultural practices are managed, water quality is protected, and pathogen abatement through soil to watercourses is controlled.

The history of the Province of Ontario's nutrient management legislation has deep roots in several Ministry s including the Ministry of Agriculture and Food, the Ministry of the Environment, the Ministry of Housing, the Ministry of Mines, the Ministry of Health, the Ministry of Natural Resources, and the Ministry of Energy and Resource Management. Combined, since 1873, the province has developed over 34 documents 
pertaining to nutrient management, water quality, and the protection of the environment from pathogens and various other substances. Many of the nutrient management initiatives reviewed in this chapter have inadvertently acted to protect source waters by controlling for nuisances stemming from agricultural practices and operations. The development of the Nutrient Management Act was clearly supported from the maturity of legislation beginning from the enactment of the Waste Management Act in 1970. For example, the development of nutrient management plans stemmed from the progression of local municipal by-laws in municipalities throughout the province. Furthermore, the incorporation of best management practices and nutrient storage requirements provides evidence of the development of the NMA from other legislative documents.

Despite the development of legislation in the province of Ontario, it is unclear if science has substantiated the requirements made under legislation. Chapter Three will address the current research of subsurface microbial transport and abatement. The research will aid in determining if studies support the modeling of microorganisms through the subsurface and if nutrient management legislation has utilized this research to protect source waters from pathogens. 


\section{Chapter Three: Abatement and Transport of Microorganisms in the Subsurface Environment}

Movement of matter through the soil matrix, including transport through air pockets, water deposits and soil particles presents different challenges for researchers who study movement through the subsurface environment. Transport of pathogens through the subsurface environment has become especially important to the agricultural community and to populations who surround agricultural operations. Depending on soil structure and nutrients used on agricultural lands, source waters may be threatened by biological agents contained within animal nutrients. It is only through research and experimental studies that one begins to understand the relationship between soil and the biological and chemical components contained within it.

The introduction of pollutants to the subsurface environment is well established and researched by the scientific community, ranging from soil and plant nutrients (from agricultural operations) to the microorganisms and organic matter that accompany them in the soil (Mawdsley et al. 1995., Ogden et al. 2001., Blanc and Nasser, 1996., Dighton et al. 1997). The challenge for researchers is to identify those factors that inhibit or encourage chemical and microbial movement. In doing so, researchers can identify situations within environments where source waters may be threatened by nutrients and agricultural practices.

The heterogeneity of the subsurface environment is perhaps the largest governing factor affecting the vertical and horizontal movement of a particle or liquid. Not only must we consider the physical and chemical properties of the foreign particle, we must also consider local environment conditions which can affect how the particle will be transported, if at all, in the subsurface. We cannot simply examine a single environmental factor and analyze its effect on the entire system. Rather, we must look at the subsurface matrix as a myriad of factors that interact with one another which may impede, suspend or encourage movement of a particle in several possible directions. The governing factors of particle movement through the subsurface include physical and 
chemical properties of movement, environmental and microbiological factors, and existing environmental subsurface conditions.

\subsection{Physical and Chemical Properties of Movement}

The laws of biophysics and biochemistry govern microbial movements in the subsurface environment. In order for models to be developed, an understanding of particle movement is essential. It is the interaction between environmental and microbial factors which will determine the fate of the microorganism.

According to a study performed by Loehr (1984), the objective of land treatment with animal wastes is to use the chemical, physical, and biological properties of the soil/plant environment to assimilate waste components without adversely affecting soil quality or causing contaminants to be released into water or the atmosphere. It is important to understand the biophysical and chemical properties of microbial movement in order to protect source waters and the natural environment. Gerba et al. (1991) reported that five key factors determine the physical transport of microorganisms through soil. They include:

1. Advection - the process of transport in bulk motion of flowing water with carriage at a rate equal to the average velocity of the water flow.

2. Dispersion - spreading of the organism as they pass through the subsurface medium.

3. Adsorption - adhesion to soil particles

4. Filtration - removal of organisms from the pore water by size exclusion

5. Decay or die off - inactivation by environmental stress, such as temperature, or lack of nutrients

The retention of organisms in the subsurface is a complex set of reactions that occur at the surface of the sand particle. Angers and Caron (1998) found that most chemical, biological and physical reactions and processes occur at the interface between the solid, liquid, and gas states. For example, Jewett et al. (1999) showed in sand column experiments that as bacteria accumulated in the gas-liquid interface, total cell removal 
was inversely proportional to water content in the system. In other words, total bacterial retention $(\mathrm{Rt})$ was lowest for water-saturated experiments. Decreasing the water content to $84 \%$ water saturation resulted in a $22 \%$ increase in Rt. A further decrease in water content to $46 \%$ saturation produced a $90 \%$ increase in total bacterial retention compared to saturated conditions. Therefore, $51 \%$ of the cells were transported through the column under saturated conditions, while only $5 \%$ of the cells passed through the column in the $46 \%$ water content experiments. The results suggest that increased bacterial removal is observed under gas-liquid interfaces in the subsurface. The increased retention of bacteria at the gas-liquid interface indicates that the interface is an important factor in limiting pathogen migration, for evaluating biocolloid-facilitated transprert of pollutants, and developing bioremediation strategies for unsaturated porous media.

The surface chemistry of soil particles and soil water chemistry influence surface charges on soil particles and adherence of microorganisms to them (Dighton et al. 1997). Organic matter and clay particles both possess large, negatively charged, surface areas, which increase microbial adsorption (Marshall, 1971). This is one of the main reasons why little dissemination of particles through subsurface environments with clay particulates is observed. As a result, the percentage of clay matter within the soil matrix will help determine the overall adhesion and abatement potential of the soil matrix.

Sedimentation is a physical process that requires consideration in analyzing the migration of microbes. Sedimentation is filtration due to gravity and depends on particle buoyancy (Ginn et al., 2002). Many natural bacteria and viruses are neutrally buoyant, thus sedimentation is negligible (Ginn et al., 2002). However, cultured microorganisms are typically larger and sometimes more dense than their native counterparts and may involve sizeable buoyancy-driven filtration (Ginn et al., 2002). Overall, sedimentation is observed as having a negligible effect on the overall movement of microbes and particulates through the soil matrix.

An additional physical process that occurs within the soil matrix is straining. Straining occurs within soil pores smaller than the limiting dimension of the cell, and 
adsorption onto particles controls the movement of bacteria through soils (Catteneo et al. 1997). Straining of microbes and various other particulate in the subsurface is a natural process which accounts for the removal of matter, especially in finer soils such as clays. For example, straining would play a role in clay-based soils where larger microorganisms, such as fungi are added to the soil matrix. The rate of passage of a microorganism through the soil may be affected either by Brownian movement or its own motility (Griffen \& Quail, 1968). Straining and physical filtration represent the removal of microbes from a solution by physical (geometric and intermolecular/surface) forces (Ginn et al. (2002). However, like sedimentation, straining plays a limited role in the overall transport of significant public health microorganisms such as bacteria, viruses, and protozoa through the subsurface environment.

Several researchers have modeled attachment of bacteria to soil particles via sorption mechanisms using the colloid filtration theory. According to Cameron et al. (1997), sorption refers to the processes by which an organic chemical in the soil sorbs onto solid surfaces (soil) or penetrates into the solid matrices. Similarly, colloid filtration theory explains the processes of attachment of matter, and in particular, the attachment between bacteria and sediment. Colloid filtration theory assumes that attachment (of bacteria and sediment) is a 2 -step process. First, the bacterium must be transported to the porous media grain (the "collector") (Ginn et al., 2002). Second, the physochemical interactions that occur upon contact between the two surfaces determine how the bacterium attaches to the surface of the collector (Ginn et al., 2002). Once a bacterium is transported within a separation distance on the order of fractions of its own radius away from a collector, a complex set of interactions occurs that dictates the outcome of the attachment possibility (Ginn et al., 2002).

The Derjaguin-Landau-Verwey-Overbeek (DVLO) theory of colloid stability has been widely employed as a model for describing the interaction forces between a microbe and a solid surface (Ginn et al., 2002). The DVLO force is the sum of the London-van der Waals force and the electrostatic force (the double layer force which may be repulsive or attractive depending on the charges of the two interacting surfaces) (Ginn et 
al., 2002). Flux of microorganisms through soil is, however, reduced if the effects of adsorption and retardation are taken into account (Gerba et al., 1991).

\subsubsection{Vertical Movement}

Vertical and horizontal movement of pathogens through the subsurface are governed by many of the same factors as other non-viable substances. Unless land is saturated (or of an impermeable nature), vertical movement of microorganisms through the soil will occur (Mawdsley et al. 1995) when wastes (or nutrients) are applied to land. Mawdsley et al. (1995) summarized the factors that affect the vertical movement of particles through the subsurface. They include:

- Soil type

- Soil water content

- Rainfall/intensity of rainfall

- Temperature

- $\mathrm{pH}$

- Mesofaunal activity

- Surface properties of microorganismi, and

- Presence of plant roots.

Soil type influences microbial transport by its physical structure (relative proportion of sand, silt, clay, and organic matter) and the variation in adsorptive capacity of its colloidal material (Dighton et al. 1997). The adsorptive properties are thought to be important for viral retention, whereas for bacteria, physical properties are also significant (Goyal and Gerba, 1979) (See section 3.3.4).

Once nutrients have been applied to the soil, it acts as a diffuse source. Crops may take up nutrients, or the nutrients may be available for transport (Goss et al. 2001). In a study performed by Dighton et al. (1997), it was shown that where a new population of bacteria is added to soil, it is likely that indigenous bacteria will occupy most of the adsorption sites. There may be some exchange between the new and the added 
population, but it is likely that the new population will be more readily redistributed by water fluxes (Dighton et al. 1997).

\subsubsection{Horizontal Movement}

Unlike vertical abatement and transport, horizontal movement of particles and microbes is affected to a greater capacity by the topographical features of the land. Mawdlsey et al. (1995) summarized the factors that most affect horizontal movement (and surface runoff) of particles through the soil. They include rainfall/intensity of rainfall, topography of the land and proximity to the pollutant source, agricultural practices, and weather/season at time of application.

Once percolating drainage water reaches zones of groundwater movement, the organisms it is carrying may be moved large horizontal distances (Dighton et al. 1997). However, that depth may be below the zone where soil fauna are found, except perhaps for some of the deeper burrowing lumbricoids (Dighton et al. 1997). Horizontal dispersal in the upper layers is more likely to be brought about by the soil fauna rather than water flux, except in areas of sloping ground. This lateral movement (such as the movement of particulates via surface run-off of material) is a particular problem in soils with impermeable substrata or in waterlogged conditions (Mawdsley et al. 1995), especially as it relates to well water safety.

\subsubsection{Electrostatic, Biological and Chemical processes}

As organisms are introduced into the subsurface environment, they may be altered not only by environmental factors, but also by their own growth and replication methods. The microbial methods affecting abatement or transport are expressed through growth and decay processes and include active adhesion/detachment, survival and chemotaxis mechanisms (Ginn et al. 2002). Typical growth phases of microbial populations (in laboratory settings) include the lag, exponential, stationary and death phases (Madigan et al. 1997). Several factors will determine how successful a microbial population is when introduced into an environment. According to research performed by Ginn et al. (2002), the biological nature of these (growth) processes presents a challenge for transport 
modeling in that one biological mechanism is often dependent on and/or influenced by another.

Several studies have reported that microorganisms exhibit active adhesion/detachment processes that may be responsive to local nutrient availability, survival mechanisms, and/or growth mechanismıs (Ginn et al., 2002). It is possible that the evidently dynamic attachment/detachment processes are in fact ramifications of extracellular polymeric substance (EPS) mechanics or other cell-driven factors under transient metabolic states (Ginn et al., 2002). Smets et al (1997) reported experimental results indicating the adhesion of a pseudomonad to glass was significantly more favorable in the experimental growth phase than in the stationary or decay phase. This was due in most part to the cell surface structure, cell physiochemistry or the hydrodynamic behaviour of the cells at the time of growth (Ginn et al., 2002).

Chemotaxis occurs when an organism moves to or away from a point along a chemical gradient. Taking this chemical process into account, chemotaxis mechanisms may play a role in the transmission or organisms through an environment, especially where chemical gradients exist. Microorganisms that have the capability to move in response to a chemical gradient are termed 'chemotactic" (Ginn et al., 2002). Both random motion (taxis in the absence of a chemical gradient) and chemotaxis have been cited as potential means of transport for subsurface organisms (Ginn et al., 2002). Quantitatively, random motility is an effective diffusing flux for microorganisms that depend on the local spatial gradient in aqueous microorganisms concentration, and chemotaxis is a flux of microorganisms associated with the gradient in nutrient supply (Ginn et al., 2002). According to Ginn et al. (2002), chemotaxis processes require energy (ATP) and are therefore highly dependent on the environment and available nutrients to determine the movement potential of the microbe. Although chemotaxis processes play some role in the transport of microbes, it is unlikely that gradient differences will result in significant microbial transport. However, chemotactic movement may play a significant role in disseminating microbes large distances when small movements cause the microbe to travel through macropores. 


\subsection{Environmental subsurface conditions}

Conditions of an environment will dictate how substances, specifically microorganisms, live and move, either horizontally or vertically (or both) through the subsurface. Factors dictating movement or abatement include differences in degrees of $\mathrm{pH}$, temperature, soil water content (including precipitation), the presence of plants, presence of macropores, soil aggregation practices, and soil composition and structure.

\subsubsection{Soil Water Content (including precipitation)}

Several substances contribute to the complexity of the subsurface environment, including water. Sources of water in the subsurface originate from precipitation events, along with naturally occurring water deposits from ground water sources or from the vertical and horizontal transport of water systems. Saturation of the subsurface environment (particularly the severity of environmental saturation), presents several different scenarios for microbial transport to occur. For example, a heavy rainfall event could cause quick saturation of the subsurface (depending on the composition of the subsurface), and even quicker dissemination of microbes present both within the subsurface and at the top of the soil matrix. A study by Ogden et al. (2001) reported that the risks of Escherichia coli contamination are greatest immediately after an application of slurry, and that the first increments of drain flow (from rainfall events) carry significant bacterial concentrations.

Conversely, the risk of contamination appears to diminish after the first rainfall event (following a dry period). For example, a study by Ogden et al. (2001) found that if weather conditions are dry after application on well-drained sandy soils, it is unlikely that any significant losses of bacteria (to drains) will occur. Under dry conditions, microorganisms may remain on the soil/grass where their numbers will decline due to desiccation and exposure to natural UV radiation (Ogden et al., 2001). Therefore, not only is the environment after saturation events important to microbial abatement or transport, but the condition of the environment prior to saturation seems to determine (among other factors) the degree of microbial transport within the soil either in a vertical or horizontal direction. 
While saturation certainly has some effect on subsurface transport of pathogens, saturation has also been shown to affect existing soil structural form. For example, consider a soil rich in clay matter. Depending on the percentage of clay content, soils show variable potential to shrink and swell. The loss of volume after drying leads to the development of cracks which can be as large as $5 \mathrm{~cm}$ and can extend to considerable depths, up to $80 \mathrm{~cm}$ or more depending on the soil and climatic conditions as well as the presence of vegetation (Ravina, 1983; Angers and Caron, 1998). These 'cracks' can significantly aid in deep microbial transport, especially when liquid manure (or slurry) is added or when dry matter is added to the soil surface only to be followed by precipitation.

The presence of vegetation has also been shown to affect vertical transport of microbes by means of macropore transport (see section 3.2.5). Grevers and De Long (1990) proved that as vegetation biomass increased, the greater the area and length of the macropores (due in most part to water uptake). These pores cause relatively large gaps in the soil matrix allowing for quick dissemination and travel, (within the subsurface) which may lead to water contamination events. As vegetation and root systems die and decay, formation of macropores occurs, causing rapid dissemination of particulates through the subsurface.

Despite internal environmental factors such as micro and macro pores created by vegetative root systems, it seems that the flow intensity of precipitation events and periods of drying are critical to fluid and particulate transport and abatement. For example, according to Dighton et al. (1997), the most important factor in the abiotic dispersal of microorganisms is the flow of percolating soil water. Cycles of intense moisture and drying influence the soil structure causing several changes that affect movement of particles within the soil matrix. Intense rainfall periods disturb soil systems causing particles to flow vertically. Conversely, drying produces cracks and induces soil fractures, while rapid wetting can induce micro-cracks, which can make the soil more friable (Dexter, 1991; Angers and Caron, 1998). 
In general, lack of movement (abatement) and limited survival of pathogens in soil is associated with unsaturated conditions. Inputs of water into a dry subsurface environment can cause an increase in particle dissemination for several reasons including altering the ionic strength of the subsurface. Moisture lowers the ionic strength of the pore fluid and preferential flow paths created by plant roots and soil invertebrates and promotes microbial transport (Zyman \& Sorber 1988; Duboise et al, 1976; Trevors 1990; Madsen \& Alexander 1982). Furthermore, moisture has also been shown to play a. predominant role in the ecosystem by having a large effect on viability of organisms within the soil content. Griffen (1981) showed that moisture plays a selective role in determining whether bacteria or fungi are the dominant organisms in soil respiration (Griffen 1981). With the exception of fungi (see section 3.3.6), which can grow in airfilled pores, the microbial population of soil is restricted to the aqueous phase and the solid-liquid interface (Mawdsley et al. 1995). Therefore, soil water content will not only affect microbial movement, but also survival of microorganisms in soil, with different species exhibiting considerable variation in their ability to withstand hoth high and low water content (Mawdsley et al. 1995). The internal and external characteristics of microorganisms distributed in the soil add to the complexity of modeling subsurface transport. An ability to withstand environmental stresses, along with the surface and behavioral characteristics of the microbe, will affect how it is distributed, if at all.

Pore capacity plays a significant role in determining the amount of water permitted in the pore space along with the aerobic conditions within it. As soil pores become increasingly water-filled, bacteria may find themselves in an anoxic environment (Griffen, 1981). For obligate aerobes, this will probably result in decreased viability and survival (Mawdsley et al. 1995). Conversely, anaerobic microorganisms may thrive in such an anoxic environment. Therefore, the levels of saturation in the subsurface will not only affect the transport of the microorganisms, but the viability of the organisms during and after horizontal and vertical transport. For consistently waterlogged conditions (high ground water tables), anaerobic conditions will prevail, influencing the types of organisms (anaerobic microorganisms) present within the soil matrix. 
Of particular concern to public health agencies are deep subsurface transport and abatement of microbes, specifically pathogens, which can be harmful to humans and cause illness by infiltrating drinking water sources. So-called 'foreign' bacteria may be introduced by the addition of animal wastes to land via human and/or animal actions. However, horizontal transport of microbes is also a concern, especially where land slope and surface waters are concerned. Where nutrients are applied prior to significant rainfall events, horizontal transport (or ponding) is highly probable because soils can't retain and transport waters vertically quickly enough. Horizontal movement and surface runoff becomes a greater concern particularly in agricultural areas where high ground water tables prevail and where well-water potability is essential as a drinking water source. Abu-Ashour and Lee (1999) reported that surface runoff carries bacteria significant distances downstream causing serious threats to groundwater and surface waters. For example, $E$. coli has been shown to survive in semi-arid areas for long periods of time on the surface. This survival increases potential of contamination where runoff potential is high. A later study by Abu-Ashour and Lee (2000) showed that runoff events more than likely cause detachment of cells at the surface of soil particles in heavy rainfall events, which contributes to heavy loads of organisms downstream from where the nutrient (manure) was applied. This horizontal movement can cause contamination where surface water sources are near and where pooling and flooding may occur which can subsequently re-contaminate animal pasture.

\subsubsection{Plants and Plant Roots}

Microorganisms use vegetative root systems as a means of obtaining organic matter. However, the root systems also act as transport mechanisms to which fluid, along with microorganisms may be transported through the soil. Angers and Caron (1998) noted that vegetation affects an organism's structural form and stability at different scales through various direct and indirect mechanisms. By penetrating the soil, roots form macropores which favour fluid transport (Angers and Caron, 1998). The pores create 'zones of failure', which fragment or form soil aggregates (Angers and Caron, 1988). The fluid, which is transported through these 'zones of failure' may carry microbes and other substituents (which are permitted to move vertically) vertically through the soil. 
The distance of rooting systems provides the opportunity for microbes to move down into the subsurface environment through other environmental mechanisms (as will be discussed in further sections). Increased flow of water and other particles along the living roots has been attributed to the presence of a saturated film of water on the surface of the roots (Angers and Caron, 1998). The water acts as a natural 'lubricant' which, among other functions aids in the transport of matter vertically down the root system.

The viability of the root system is irrelevant to microbial and particulate transport. Research performed by Angers and Caron (1998) noted that the whole plant, dead or alive, could be an important source of carbon. The plant systems provide microbes and fauna with a substrate for the production of stabilizing material as well as providing physical protection of the soil surface against structural processes like rainfall or compaction (Angers and Caron, 1998). The by-products released by the metabolic processes of the root system can affect soil structure. Plant roots can promote soil aggregation by releasing material that can directly stabilize soil particles, or, by favoring microbial activity in the rhizosphere, affect soil structure (Angers and Caron, 1998). The 'rhizosphere' presents a very diverse area for microbial activity, largely induced by root exudation and mucilage, root sloughing and favorable aeration and water conditions in the root vicinity (Bowen and Rovina, 1991; Angers and Caron, 1998).

Root systems contribute to the overall chemical structure of the soil environment by contributing substances which can change the chemistry of the local environment. Reid et al. (1982) found that plant roots affect the chemical and ionic environment in the soil, causing the release of minerals and organic matter, which act to increase aggregate stability. Plant roots act as food for several microorganisms. As a result of their growth, microorganisms are dispensed deeper into the subsurface. Dispersal may be further increased as root depth creates new macropores. The length and activities of root systems not only affects structural stability of the subsurface system, but can also threaten local source water reservoirs where ground water tables are low. 


\subsubsection{Soil Composition and Soil Structure}

Soil structure is as much a product of its environment as the microbes that belong to it. Soil structure is central to subsurface functions as it controls water, gas fluxes, nutrient fluxes and storage. According to a study performed by Kay (1990), soil structure can conceptually be characterized by its form, stability, and resilience. Structural form refers to the arrangement of solids and voids that exist at a given time. Stability is the ability of the soil to retain this arrangement when exposed to different stresses (Angers and Caron, 1998). It is the overall stability of the subsurface system which will determine the predominant organisms in it. Along with other factors (moisture inputs), soil composition plays a significant role in transport of microorganisms. For example, Patni et al. (1984) showed that the percentage of annual rainfall that percolated to depths below the drains was greater in coarse as opposed to fine textured soil, suggesting the potential for dissemination of pathogens is greater in soils of the former type.

The ratio between clays, sands and loam will determine the composition of the subsurface enviromment, along with the abatement potential for organisms in the soil. This ratio of particles will help to determine, among other factors, the porosity of the soil structure, the soil-water content, the predominant type of vegetation growing on the surface of the soil, elements present in the soil (relationship between metals and clay particles) and the indigenous microbial population predominant in the soil. For example, a study by Catteneo et al. (1997) demonstrated that microbial transport depended on the clay content of the soil, where higher clay contents were responsible for higher filtration coefficients.

For nutrient applicators, the soil type is critical in predicting potential transport of microbes and nutrients in the soil. For example, it is reasonable to predict that soils high in sand (and therefore high in porosity) will move liquids further vertically by means of gravitational action, decreased compaction, and increased pore spacing. Conversely, it is reasonable to expect that soils high in clay matter (which generally remain wellcompacted), will act to discourage vertical dispersion as porosity is usually low and compaction of pore spaces high. Despite the overall lack of vertical movement, the 
survival of microbes in clay soils is usually greater versus soils high in sand or loam. For example, Mawdsley et al. (1995) showed that soil type is a major factor influencing microbial transport in the subsurface, owing partly to differences in adsorptive properties of its colloidal material. Conversely, the type of dominant species present in the soil matrix may have some effect on soil composition such as soil aggregation.

\subsubsection{Research in Soil Structure and Pathogen Abatement and Transport: Intact Soil Samples vs. Natural Environment Studies}

Studies in the field of nutrient and microbial transport normally take place in one of three methodological settings including a field setting, in a laboratory using intact soil samples, and in a laboratory using re-distributed soil samples

There is a debate about the merits of using intact soil samples as opposed to reconstituted samples for study purposes. Several studies have shown that reconstituted/reconstructed soil sieves are less effective in experiments because they lack the heterogeneity of intact structures found in field studies. For example, Smith et al. (1985) compared movement of a tracer fluid in an intact soil sieve compared with a corresponding disturbed soil sieve. It was shown that at least $93 \%$ of the inoculated $E$. coli cells were retained in disturbed soil from which the majority of channels and macropores had been removed by mixing (Mawdsley et al. 1995). In contrast, in the intact cores, only $21-73 \%$ of inoculated cells were retained, indicating that the role of macropores in bacterial transport had a significant effect on overall transport (Mawdsley et al. 1995) (see section 3.2.5).

It is well established that subsurface transport studies conducted under true environmental conditions are ideal for research purposes. It is also well understood that the characteristics of land receiving manure will influence the fate of nutrient constituents through factors such as soil texture (percent sand, silt, clay), slope, depth to water table, proximity to water resources, and tillage. Weather conditions (wind speed during application, and rainfall intensity, frequency and duration before and after manure application) determine whether potential contaminants move off-site in surface runoff, tile drainage flow, ground water, and air or remain in the root zone where nutrients can be 
taken up by crops. (Goss et al. 2001) In other words, variable environmental conditions will affect overall outcome. As a result, it is impossible to predict what will happen to manure under a given set of conditions (Goss et al. 2001).

Despite the lack of evidence supporting the use of intact core samples in all research initiatives, reconstituted soil columns still play a role in experiments on physical and chemical transport characteristics of organisms in the soil. Intact soil samples will continue to serve as valuable tools because they allow environmental variables to be controlled and they exclude inconsistencies produced by external sources.

\subsubsection{Porosity and Macropores}

Porosity of a soil system is determined by several factors, including environmental stressors and soil composition. Soil porosity provides an assessment of the total volume of soil available for storage, but gives no indication of pore organization. Visual and micromorphological methods, as well as water desorption characteristics and water and gas flow measurements, are used to investigate soil pore space organization (Angers and Caron, 1998). Pore space organization plays a large role in microbial transport, as it helps dictate where organisms will end up in a defined soil environment.

Porosity will determine availability of pore spaces, which may enhance rapid transport of matter, especially in dryer climates where saturation is decreased. When moisture events occur, liquids fill pore spaces and may inadvertently transfer microorganisms vertically and/or horizontally. The structural form of pore environments is governed by inherent soil properties (clay content and type), as well as by human and biological activity such as tillage practices (see section 3.2.9), root decay, and microflora/fauna activity. Soil structure and form will thus evolve in time response to the temporal variation of these factors (Angers and Caron, 1998) as environmental factors change over time.

Macropores play a significant role in subsurface microbial transport, especially in agricultural systems where overall precipitation rates are stable and nutrient application rates are high. Macropores play a role in the preferential flow phenomenon, by which 
taken up by crops. (Goss et al. 2001) In other words, variable environmental conditions will affect overall outcome. As a result, it is impossible to predict what will happen to manure under a given set of conditions (Goss et al. 200î).

Despite the lack of evidence supporting the use of intact core samples in all research initiatives, reconstituted soil columns still play a role in experiments on physical and chemical transport characteristics of organisms in the soil. Intact soil samples will continue to serve as valuable tools because they allow environmental variables to be controlled and they exclude inconsistencies produced by external sources.

\subsubsection{Porosity and Macropores}

Porosity of a soil system is determined by several factors, including environmental stressors and soil composition. Soil porosity provides an assessment of the total volume of soil available for storage, but gives no indication of pore organization. Visual and micromorphological methods, as well as water desorption characteristics and water and gas flow measurements, are used to investigate soil pore space organization (Angers and Caron, 1998). Pore space organization plays a large role in microbial transport, as it helps dictate where organisms will end up in a defined soil environment.

Porosity will determine availability of pore spaces, which may enhance rapid transport of matter, especially in dryer climates where saturation is decreased. When moisture events occur, liquids fill pore spaces and may inadvertently transfer microorganisms vertically and/or horizontally. The structural form of pore environments is governed by inherent soil properties (clay content and type), as well as by human and biological activity such as tillage practices (see section 3.2.9), root decay, and microflora/fauna activity. Soil structure and form will thus evolve in time response to the temporal variation of these factors (Angers and Caron, 1998) as environmental factors change over time.

Macropores play a significant role in subsurface microbial transport, especially in agricultural systems where overall precipitation rates are stable and nutrient application rates are high. Macropores play a role in the preferential flow phenomenon, by which 
creation of new ones which vary in size but are in the macropore range ( $>30 \mathrm{um}$ ) (Angers and Caron, 1998). As discussed in section 3.2.5, pores may be responsible for transport of matter long distances through the subsurface. However, when pores begin to decrease in size (due to an increase in root mass), transport opportunities are reduced.

Barley (1954) showed that infiltration rates could actually be reduced by actively growing roots that compact the soil matrix (more so in the upper layers of the soil). This compaction increases overall shear stress of the soil. In cases where soil structure is already rigid (clay soils), retention qualities of the subsurface increase, while transport may be reduced. However, when plants die and root systems remain (and decay occurs), tissue remnants and the associated microflora linger as a pore coating on channel walls enhancing water transport efficiency (Barley, 1954). As decay continues, pore spaces and transport probability increase. Therefore, in a temporal system where cooler temperatures prevail (in the winter or in the fall), it can be expected that dead or decaying root systems st as a means for rapid transport of matter (especially fluids) as pore spaces increase and overall shear stress decreases during the winter season.

The process of pore formation by roots is believed to be particularly important in undisturbed or no-till soils as tillage tends to disrupt the continuity of the pore system. Tillage is the physical act of altering the top layer of soil (see section 3.2.9). In tilled soils, plant roots contribute indirectly to macropore formation by serving as food for fauna and in particular to earthworms which have a well-documented impact on channel formation (Edwards et al. 1989; Angers and Caron, 1998).

\section{$3.2 .7 \mathrm{pH}$}

The viability of microorganisms in the soil solution depends on several factors including its $\mathrm{pH}$. The $\mathrm{pH}$ of the soil affects the overall stability of the subsurface system, along with the ability of microbes to be retained or transported. Bitton et al. (1974) demonstrated that twice as many bacteria were retained in microcosms of the same soil adjusted to $\mathrm{pH} 3.3$, instead of $\mathrm{pH} 6.6$ (Dighton et al. 1997) due to the surface charges of both the soil particles in the environment and the bacteria surface charge. Similarly, Kemp et al. (1995) showed that significantly fewer genetically-modified Pseudomonas 
fluorescens cells were found in the leachate from soil at $\mathrm{pH} 4.5$ rather than $\mathrm{pH} 7.5$ (Dighton et al. 1997). The $\mathrm{pH}$ of the matrix solution within a porous medium does not seem to have a large effect on bacterial transport because of the heterogeneous structure of the cell surface.

Viral transport can vary greatly depending on the $\mathrm{pH}$ of the porous medium solution (Maier et al. 2000) and depends to a great degree on the type of virus strain. It is shown by several researchers (Goyal and Gerba, 1979., Maier et al. 2000) that as $\mathrm{pH}$ levels drop below 7.0, there is an increase in retention of viral cells, and a decrease in transport potential due in most part because viral surfaces are in most cases homogeneous and therefore, are more prone to surface charges of soil particles. Viruses are amphoterically (either positive or negative) charged, but are negative th most $\mathrm{pH}$ values (Burge and Enkiri, 1978). Adsorption and movement of viruses and bacteria (Kemp et al. 1992) appear to be strongly correlated with increases in soil pH (Dubiose et al., 1976; Burge and Enkiri, 1978; Goyal and Gerba, 1979). For example, Goyal and Gerba (1979) found that soil $\mathrm{pH}$ was the major variable affecting adsorption of viruses to soil where adsorption increased and $\mathrm{pH}$ decreased. It would appear that the effects of soil $\mathrm{pH}$ on virus survival are mediated through a chemical equilibrium, where the charge states are relative concentrations of aluminum and phosphorus (Hurst. et al. 1980).

Despite greater overall microbial retention, both high and low $\mathrm{pH}$ values are known to decrease the survival of most bacterial and viral pathogens (Hurst et al., 1980; Reddy et al., 1981). However, certain organisms are able to withstand extreme levels including protozoal cysts (see section 3.3.7), which are generally considered more resistant to extremes in $\mathrm{pH}$ (Williams, 1979; Mawdsley et al. 1995). Both the biological and physio-chemical properties of soil and the subsurface are affected by $\mathrm{pH}$. In turn, this will affect survival and transport of microorganisms (Mawdsley et al. 1995). pH measurements of soil reflect only its bulk $\mathrm{pH}$, and not those individual pockets or microenvironments which may exist (Mawdsley et al. 1995). In cases where biofilms are present, properties of the entire system may not be indicative of the microenvironment, 
such as is the case with biofilms where $\mathrm{pH}$ and other variables may be completely different from the surface environment.

\subsubsection{Temperature}

The effect that temperature has on bacterial and viral transport is as much a factor of viability and survivability of the microorganism as it is movement. According to Gerba and Bitton (1984), the survival and migration of microorganisms in soil and groundwater are controlled by the specific microorganism type, the nature of the soil, and the climate of the environment. The overall ambient temperature of the subsurface system has different effects on different species of organisms. It is this diversity amongst different subsets of organisms that prevents researchers from generalizing concepts and relationships between subsurface temperature, abatement opportunities, transport pathways and viability of microorganisms.

Ambient temperatures seem to have little effect on the viability or transport of microorganisms. However, where temperatures are extreme (hot or cold), a significant difference in transport may be observed. For example, Nasser et al. (1996) found that the most important factor for viral persistence in the environment is temperature. Results that focused on virus movement and viability in colder climates point to similar findings by Reneau et al. (1989). Like bacteria, Blanc and Nasser (1996) found that viruses survive for long periods of time in soil at ambient and cooler temperatures. The observations indicated further that viruses persist for long periods of time in soil and groundwater under low temperatures. Furthermore, Reneau et al. (1989) found that bacterial survival times are longest in moist, cold soils and shortest in dry, warm soils.

Soil tempersture may influence the transport of microorganisms through the soil by its effect on dispersal, survival or adsorption (Kemp et al., 1992). In general, low temperatures favour survival of both viruses (Yeager and O'Brian, 1979; Hurst et al., 1980) and bacteria (Kibbey et al., 1978; Zibilske and Weaver, 1978; (Mawdsley et al., 1995) (see section 3.2.8). However, it must be stressed that viability does not necessarily lead to abatement or transport. For example, although certain protozoa 
(Giardia lamblia) are able to withstand extreme environmental conditions ( $\mathrm{pH}$, temperature), transport may not necessarily occur.

\subsubsection{Tillage Practices}

According to Elliot and Coleman (1988), manipulation of soil structure is one of the principal means by which microbial dynamics can be controlled both at the laboratory and field scales. This control arises through alterations in habitat space, water and substrate distribution, and the spatial arrangement of pore pathways. Tilling the soil is an effective means of redistributing the top layers of soil, typically in the topsoil section of the subsurface. In doing so, soils become more fertile as nutrients are redistributed in the layers where root growth and saturation are likely to occlir.

Disturbance of maciopores by cultivation prior to liquid manure injection in fields can (further) reduce the levels of contamination in surface runoff and tile drain waters compared to surface applied and conventional injection methods (King et al. 2000). King et al. (2000) showed that the modified injection method is effective in reducing surface contamination levels both immediately after manure application and following irrigation. However, the conventional injection method appears to result in the highest levels of bacterial contamination vertically following manure application and is comparable to the surface application method following a simulated heavy rainfall (King et al. 2000). King also indicated that while conventional injection methods are effective in reducing surface runoff losses, they contribute equal or greater manure contaminants to the tile drains as surface application techniques (King et al. 2000).

While King et al. (2000) suggests macropore flow is a likely pathway of manure to tile drains, additional research is required to determine the pathways and processes of nutrient and bacterial transport. In some cases, as the soil is redistributed, microbes may be exposed at the top of the soil, leaving them vulnerable to the effects of UV from the sun. However, where microbes are not destroyed by environmental effects (UV light, temperature changes), they may be re-dispersed into the soil matrix by precipitation events. Depending on several factors included in the distribution and make-up of the subsurface, microorganisms may be redistributed even further prior to tillage. 
Low rate sprinkler irrigation of nutrients, in addition to pathogen dispersal through soil.results in the possibility of aerosol dispersal. Undoubtedly, bacteria, protozoa and viruses will all be present in aerosols, but the time they remain viable largely depends on environmental conditions (Mawdsley et al. 1995). King et al (2000) found that the lack of disturbance or disruption by tillage (associated with no-till systems) has been shown to increase earthworm activity that can significantly contribute to macropore formation. As noted in section 3.2.5, the phenomenon of preferential flow by macropores acts to conduct water and solutes quickly to significant depths without the soil matrix being saturated (King et al. 2000). It is generally considered that to decrease the possible risk of air contamination, wastes should be dispersed where there is a low wind speed, warm bright sunlight and a relative humidity of between 40-60\% (Elliot and Ellis, 1997; MAFF, 1992b; Mawdsley et al. 1995). In general, it has been shown that an accompanying disturbance in the soil from direct agricultural aggregation leads to increased bacterial activity except where compaction is caused by heavy agricultural machinery (Dighton et al. 1997).

\subsection{Environmental and Microbiological Factors}

The interaction between viable organisms and the physical and chemical characteristics of the subsurface environment creates a complex environment. Environmental and microbiological variables are constantly changing to adapt to atmospheric pressures and the chemical and physical stressors in the subsurface.

\subsubsection{Types of Waste}

Products used in agricultural settings such as manure carry significant pathogen loads because of their origin. It is well reported that the disposal of waste (of fecal origin) entails a major risk in the spread of specific bacterial pathogens, as animals are reservoirs of pathogens that can enter the food chain and cause human infection (Ogden et al. 2001). Biochemical wastes pose a contamination threat due to their high biochemical demand and their ability to release phosphates and nitrates into the environment (Mawdsley et al. 1995) where nitrates pose a threat to human health and phosphates cause eutrophication of water bodies. However, chemical wastes should not 
be confused with viable microorganisms such as bacteria. A study by Goss et al. (2001) showed that bacteria and other pathogenic microorganisms are much larger than nitrate ions and their movement is more likely to be affected by the flow associated with the size of pores in which they are transported. They have variable source charges which allows stronger adsorption of the bacteria to soil particles.

An important feature of microorganisms is that their populations are dynamic. They are alive and are influenced by factors that affect their survival and motility in the subsurface (Goss et al. 2001). Mawdsley reported that the major source of contamination on most farms is likely from slurry or farmyard manure (Mawdsley et al. 1995). Traditionally, farmers and agricultural operations composted farmyard manure. An aerobic process, composting occurs where wastes are stored in bulk where microbial activity causes temperatures to rise as high as $70^{\circ} \mathrm{C}$. At such high temperatures, a majority of pathogens present in manure are destroyed (Jones, 1980; Mawdsley et al. 1995). However, in modern intensive systems, slurry is collected and stored under conditions which rapidly become anaerobic. High temperatures and the concurrent destruction of pathogens, seen in composting, does not occur (Mawdsley et al. 1995).

A common practice linking all the types of agricultural waste is their application on grass or arable land. Agricultural operations must consider how and where nutrients are applied, especially on land where animal grazing is a common practice. Another factor for the nutrient applicator to consider is the type of animal waste applied to the land. For example, Strauch (1991) showed that survival (of microbes in the environment) is longest in cattle slurry, shorter in pig slurry, and shortest in manure from poultry and calf slurry.

Long periods where wastes are permitted to stay on land without animal interaction or harvesting exercises are required to encourage die-off of microorganisms (Fenlon et al. 2000). Die-off is encouraged by submitting organisms to environmental conditions such as ultraviolet light, periods of drying and periods of intense heat and cold. Furthermore, preventing animals from grazing on lands recently treated with 
nutrients reduces the infection of animals. Die off during the pre-harvesting and pregrazing periods discourages infection and subsequent re-infection of grazing animals so that nutrient loads are not as concentrated with pathogenic organisms once manure is collected for land application and storage.

Along with animal wastes, human wastes have been used as a source of nutrients for many years and are referred to as biosolids. Wastes may be applied directly to land either as an untreated waste or after the wastes are treated or permitted to settle (in municipal treatment plants). Municipalities who process wastes in a wastewater treatment plant sometimes make this treated waste available for use. Microbial and chemical composition, together with the rate and extent of movement of the microbiological component following application to land will vary with waste type (Mawdsley et al. 1995).

Biosolids present several challenges for the agricultural community as they bring threats of not only microorganisms, but also heavy metals and other chemicals which if not properly treated, may present problems for vegetation (through absorption via root channels) along with wildlife and water sources. Metals have very high binding capacities for clay soils and organic matter that may interfere competitively with microbes for available binoing sites. Similar to microorganisms, the flow of metals in the subsurface environment is affected by speciation, $\mathrm{pH}, \mathrm{E}_{\mathrm{h}}$, ionic strength, composition of the soil solution and the clay and organic matter content of the soil (Gove et al. 2001). For example, in sand and in soils low in organic matter, metal adsorption can be expected to be low, and therefore leaching is likely to be relatively high (Gove et al. 2001). Gove et al. (2001) found that sandy soils with low organic content are representative of worstcase scenarios where leaching of metals is likely to be a problem.

The composition and type of waste (nutrients) applied to land will play a major role in the dissemination of microbes to the subsurface environment. Three main agricultural wastes predominantly used as soil nutrients include manure, biosolids and slurry (liquid and solid mixture). According to Strauch (1991), farmyard manure refers 
to a mixture of excreta together with substantial quantities of bedding materials (straw, wood shavings, sawdust, peat) dense enough to be handled as a solid. 'Slurry' on the other hand, is a mixture of faeces and urine, which can also contain cleaning water, rain water, small quantities of bedding material and spoiled feed particles. Strauch (1991) added that as stored slurry is usually anaerobic, no spontaneous generation of heat that could entail the destruction of pathogens would occur in that medium either in summer or winter. Therefore, slurries containing pathogens always pose a microbial hazard to animals and water.

Several studies have examined the survivability of selected organisms such as enteroviruses in slurry media. Research by Goss et al. (2001) found that bacteria tend to be more evenly distributed in liquid than solid manure due in part to their mobility. Strauch (1991) found that enteroviruses are relatively 'tenacious' in slurry. Furthermore, the tenacity of pathogens (such as bacteria) is affected not only by environmental conditions, but also by conditions prior to application such as storage conditions and type of nutrient media (manure or slurry).

Overall, bacterial survival in nutrient media is enhanced by reduction of temperature and an increase in solids content (Strauch, 1991). Quantitative investigations in slurry samples with direct isolation of viruses showed a virus titre of about $10^{6} \mathrm{TC}_{\text {IDso }}$ per litre, whereas in samples which yielded enterovirus only after concentration, about 50-100 $\mathrm{TC}_{\mathrm{ID} 50}$ per litre were found (Strauch, 1991). Differences in the chemical and biological composition of both media (manure and slurry) depend on several factors including animal health along with storage and treatment methods. Animal health, especially with regard to animal feed, is an important issue in agricultural and water safety management that should receive further attention in future research endeavors.

\subsubsection{Types of Microorganisms}

The study of microbial transport in the subsurface depends on the technology available to identify the biological and chemical characteristics that affect the organism. Recent genetic detection technology has permitted researchers to discover genetic material deep in subsurface environments, showing that microbes are well suited for deep 
subsurface travel. For example, PCR technology allows researchers to identify DNA from microscopic organisms, such as Escherichia coli. However, the technology does not disclose whether the genetic material came from a viable organism. Pathogenic microorganisms may be inactivated in the subsurface (or surface) environment over time such that, even if physically detected in groundwater, they are incapable of causing infection. The rate of this inactivation is organism-specific and highly influenced by subsurface physical and chemical conditions as discussed previously (Macler \& Merkle, 1999; Hurst et al. 1980; Hurts and Goyle 1986; Kutz and Gerba 1988; Hurst et al. 1989).

Along with their pathogenicity, flexibility and survival strategies of microorganisms have become equally important factors when transport mechanisms are ; '-dicted. However, Egli et al. (2002) noted that two additional aspects nave become qually important biological mechanisms. First is the microorganism's ability to easily acquire resistance to one or more antimicrobial drugs. Second is their capability to transfer ge: etic material related to pathogenicity and resistance-carrying DNA segments horizontally to other organisms. Different species and families of organisms possess different surfaces and survival characteristics that allow them to either flourish in the environment or cease to exist. Interest in the subsurface transport of microorganisms stems from their ability to cause illness and death in both humans and in animals. Thus, the focus of most research is customized to public health pathogens (see table 74) including bacteria, viruses and protozoa.

\subsubsection{Viruses}

The unique characteristics of viral particles make them difficult both to track and investigate. As opposed to bacteria, virus are much smaller and thus, their transport is in most cases, synonymous with particle transport. According to Maxwell et al. (2003), mathematical models of virus transport in saturated porous media typically assume that viruses represent a class of submicron particles $(<1 \mathrm{um})$. As such, factors affecting their

migration include advection with liquid phase flow, hydrodynamic dispersion, physical or chemical attachment onto the solid phase of a porous medium, detachment in the liquid phase, as well as inactivation or 'die-off' in either the liquid or solid phase (Maxwell et al., 2003). 'Physical attachmen'' refers to the transfer of free virus particles in the pore 
liquids to the solid phase minerals by their direct physical interception, as well as their subsequent retention on these surfaces by van der Waals forces. The rate of this transfer depends on the virus size, density, grain diameter, local flow velocity and other properties of the liquid and porous medium. 'Chemical attachment' on the other hand, refers to the adsorption of free virus particles in the solid phase as a result of electrostatic attraction or other chemical attractants (Maxwell et al., 2003).

Viruses can originate from many sources. The most frequently reported sources include sewage from septic tanks, land application of sewage and sewage sludges, domestic landfills, oxidation ponds and deep-well sewage injection (Nasser et al. 2002). Viral transport in groundwater is difficult to study because the principal waterborne human viruses - the rotaviruses, adenoviruses, Norwalk viruses and the Hepatitis $A$ virus (HAV) - are more difficult to assay and therefore more difficult to detect (Sinton et al. 1996). According to research from Strauch (1991), only in recent years have improvements in isolation techniques for viruses from heavily contaminated material led to remarkable successes in identifying viruses in faecal matter (Strauch, 1991). Recent techniques that allow for gene expression, such as DNA microarrays and Polymerase Chain Reaction (PCR) techniques will no doubt improve interest in the topic of virus transport. For example, virus detection techniques are showing many groundwater sources to test positive for viruses where they previously did not show contamination (Maxwell et al., 2003).

Studies that have examined viral transport in the subsurface environment have utilized few virus strains, opting for easily cultured viruses that are readily detectable. For example, Sinton et al. (1996) found that although there have been some studies of viruses in groundwater (for example Sobsey et al., 1986), most investigators have used enteroviruses (which are the most easily cultured human viruses) or bacteriophages in their research. Although virus sources, pathways, and receptor links are certainly more numerous than previously documented, methods are still lacking to predict virus transport pathways in realistic geologic settings and to evaluate the sensitivity of virus transport given geologic heterogeneity (Maxwell et al., 2003). 
Viral survival and transport through the subsurface environment, like bacteria, are influenced by several environmental and microbial factors. Sinton et al. (1996) found that the effects of filtration and sedimentation are generally negligible and that the principal factors affecting viral transport are the level of soil saturation, virus type, adsorption rate, and inactivation potential.

Like bacteria, there is generally less movement of viral particles in unsaturated conditions (Sinton et al. 1996). Furthermore, adsorption and abatement rates tend to be higher at low $\mathrm{pH}$, low flow rates, in fine textured soils (particularly those with high clay content), and in the presence of high cation concentrations (Sinton et al. 1996) due to surface charges of subsurface particles. Adsorption is lower in the presence of dissolved organics, and desorption may occur in the presence of percolating rainwater.

Genetic exchange amongst viral particles is common. According to Dighton et al (1997), provided that viral particles can withstand the physical constraints of the soil environment, they will remain unaltered (Dighton et al. 1997). However, genetic modification of viruses in the subsurface environment appears to reduce their ability to withstand harsher physical constraints and environmental stresses (Dighton et al. 1997).

Virus adsorption to soil particles is influenced by soil texture, presence and concentration of cations, soluble organics, $\mathrm{pH}$, and virus type (Gerba et al., 1975; Nasser et al., 1993; Blanc and Nasser, 1996). Hurst et al (1980) noted that adsorption of viruses to soil significantly affects virus survival. Cameron et al. (1997) stated that viral adsorption by soil constituents is the primary mechanism of retention (Cameron et. al, 1997). However, overall soil retention is reduced as saturation (via rainfall) is increased.

Factors found to most influence virus survival in the subsurface environment include;

- temperature

- soil moisture content

- presence of aerobic microorganisms 
- degree of virus adsorption to the soil

- soil levels of resin-extractable phosphorus

- exchangeable aluminum

- soil pH.

According to Hurst et al. (1980), temperature and virus adsorption to soil appeared to be the most important factors affecting virus survival. Hurst et al. (1980) added that temperature was a significant predictor of virus survival under all sets of conditions as inactivation rates increased when temperatures increased. Blanc and Nasser (1996) determined that subsurface type (loamy soil) and virus type were key factors in overall adsorption and transport of viruses. The effect of water quality on virus adsorption to soil was virus type-dependent. In general, virus adsorption to sandy soil was greater than loamy soil. Blanc and Nasser (1996) explained this relationship b identifying that lower adsorption of viruses to loamy soil can be attributed to the high content of organic material in the soil. In the study, no virus die-off was observed at low temperatures $\left(10^{\circ} \mathrm{C}\right)$ under any one of the study conditions. These results indicate that viruses can persist for long periods of time in soil and groundwater under low temperatures.

\subsubsection{Bacteria}

Research focused on contamination of public and private drinking water supplies is primarily concentrated on bacterial transport to source water reservoirs. Bacterial movement through the subsurface environment has captured the attention of public health agencies and is recognized as a threat to water quality and human health. Although the focus of research in the past few years has been on a small number of bacteria (Escherichia coli and Salmonella), several other types are of genuine concern to public health (see Table 2). The study of organisms such as Escherichia coli has allowed researchers to focus on specific traits of bacterial behaviour. For example, Willshaw et al. (1994) showed that low numbers of Escherichia coli 0157:H7 entering drinking water can still be hazardous due to a low infective dose. Because Escherichia coli is often used as an indicator for soil and well water quality, this research is significant in identifying the conditions that abate bacteria in nutrient application (Willshaw et al. 1994) 
According to Strauch (1991), the type of bacteria isolated will vary with the geographical location of the agricultural operation and the animal species. As discussed in section 3.3.1, the physical and chemical composition of manure used as a nutrient may determine the type of pathogen present (Strauch, 1991). It is the composition and concentration of bacteria contained within the waste material, along with several other environmental factors which will determine the ultimate fate of the organism.

Sinton et al. (1996) revealed that the principal attenuating factors of bacterial abatement and transport are filtration, adsorption, and inactivation. Inactivation rates differ between species and appear to decrease for adsorbed cells, but increase with high levels of antimicrobial activity or low soil water levels (Sinton et al. 1996). As discussed in section 3.3.4, bacterial movement is restricted by soil pore size. In fact, Griffen and Quail (1968) found that soil pore size is so important to overall abatement that there is little bacterial dispersal below a pore neck radius of $1.5 \mathrm{um}$ for bacterial cells of $0.5 \mathrm{um}$ in diameter (which may be seen in soils which are rich in clay particles).

Table 2

Bacteria of epidemiological concern in livestock nutricuts

Salmonella spp.

Escherichia coli

Brucella spp.

Leprospira spp.

Bacillus anthracis

Treponema hyodysenteriae

Mycobacterium spp

Chlamydia spp.

Rickettsia spp.

Although most bacteria have some type of self-propulsion mechanism (flagella, pili), bacteria dispersal by their own motility in soil water films is generally very restricted in distance traveled (Dighton et al. 1997). In fact, Dighton et al. (1997) showed that the largest recorded distance moved by self-propulsion was $60 \mathrm{~mm}$ per day while the average distance is more likely below $10 \mathrm{~mm}$ per day as reported by Wong and Griffen (1976). Obviously, the motility of bacteria will likely hinge on the saturation content of the subsurface as mobile mechanisms require fluid environments in order to be transported. In dryer enviromments, motility mechanisms such as use of flagella will have little, if any impact on transport. 


\subsubsection{Actinomycetes}

Actinomycetes exist predominantly in soil as spores, which are tolerant of prolonged starvation and desiccation (Wellington et al., 1990). It is as spores that dispersal is most likely to occur under the same conditions and constraints as bacteria (Dighton et al.; 1997). Wang et al. (1989) showed that modified strains of Streptomyces lividans could survive in non-sterile soil for 30 days as both spore and mycelia inoculants, but some inoculated spores were able to survive at least 10 months (Dighton et al., 1997). According to research performed by Ruddick and Williams (1972), surface characteristics and structure of Actinomycetes will be the determining factors in how far the spore may be dispersed in the subsurface environment (Dighton et al., 1997). For example, a single smooth spore of Micromonospora sp. is much more likely to be moved downwards by percolating water than the spiny-sheathed spore chains of S. viridochromogenes as the surface characteristics of S.viridochromogenes would likely prevent movement through tight pore spaces. Actinomycetes are not considered a significant public health concern. Their distribution through the environment is varied and research focusing on their survival and transport in the subsurface is sparse.

\subsubsection{Fungi}

The transport and survival of fungi in the environment can only be modeled as spores, which will behave similarly to bacteria. Fungal spores are larger than bacteria (2200 um diameter) and are therefore more easily retained by soils with small pore spaces (Dighton et al., 1997). In undisturbed (non-tilled) soils, the vertical movement of fungal spores is normally limited $(\mathrm{cm})$, but may increase where tillage of topsoil takes place and small vertical $(20-30 \mathrm{~cm})$ and larger horizontal movements occur or where large macropores are prevalent (Dighton et al., 1997). However, deep spore transport does not normally take place as the size of the spore usually inhibits vertical movement.

The soil environment and conditions within it play a major role in the composition and microbial makeup of the subsurface, including those soils that contain fungus. For example, as soils become more acidic and less disturbed, organic residues accumulate favoring fungal growth over bacteria (Dighton et al., 1997). In general, tillage redistributes fungal propagates vertically in the ploughed layer (Dighton et al., 
1997). Tilling and other agricultural practices add to the horizontal dispersal of fungal spores via displacement of soil particles. Overall, fungal species play a small role in threatening water sources, as deep subsurface transport is unlikely due to their large size.

\subsubsection{Protozoa}

Unlike Actinomycetes and fungal spores, protozoa play a significant role in water potability and public health. The activity of protozoa, like other microorganisms is closely related to soil moisture conditions (Bamforth, 1988). Like bacteria, increased moisture levels in the subsurface lead to increased transport of protozoan species. Soil pore size will also affect their distribution as flagellates and small amoebae can occupy pore spaces down to 8 um in diameter and thus could be more important vectors in compacted soils (Dighton et al., 1997).

From a public health perspective, protozoa play a significant role in disease transmission, especially where the dissemination of Cryptosporidium parrum in the environment is a possibility. Oocysts of Cryptosporidium pavrum are of particular concern in climates where environmental conditions are unstable and temperatures are colder because oocysts are hardy and can withstand a variety of stresses. Fleming et al. (1997) reported that once applied on the soil, oocysts are capable of surviving for long periods of time (in excess of 100 days). Furthermore, Fleming et al. (1997) showed that oocysts could survive for long periods of time (up to several months) in tap water, river water, and in liquid cattle manure (slurry). It was also found that composting was effective at rendering oocysts non-viable where temperatures typically reach from 30 to 50 degrees Celsius (Fleming et al. 1997). However, in temperate conditions, average temperatures rarely reach the extreme conditions found in composting. Fleming et al. (1997) showed that desiccation (drying) was 100\% effective at killing the oocysts in less than 4 hours.

In the aqueous stage (slurries), oocysts are more easily transported over the soil surface and not subjected to filtering effects in passing through the soil profile. The breaking of macropores in soil helps to slow water transport through the profile of the soil and hence transport of any organism in the water. This increases the soil's 
opportunity to absorb organisms (Fleming et al. 1999). Grazing of animals (particularly cattle) on recently treated pasture adds additional concern, especially where animal infection and shedding rates are high. According to Strauch (1991), many parasitic infections of farm animals are transmitted by ingestion of infective materials, including pasture contaminated with faeces. Disseminated faeces are a concern not only as potential threats to subsurface transport, but in particular for horizontal transport in surface runoff. As reported by Fleming et al. (1997), an assumed source of Cryptosporidium is agricultural runoff, including overland runoff from manure storages and feedlots, runoff from fields receiving livestock manure and livestock manure entering streams as a result of defecation in or near streams.

Overall, it is the hardiness and stability of the oocysts in the environment which is its most favorable attribute to prolonged viability. Little research has shown the potential for the organism's vertical transport capability. Rather, most studies of Cryptosporidium pavrum have focused on the fate of and capability of the oocysts to be transported horizontally in run-off events.

\subsubsection{Heterogeneity of soils}

Research on the transport of particles through soil is not simply the study of a single element, variable, or factor that acts to contribute to or restrict particle movement. Rather, it is the heterogeneity of soil environments where several variables and factors contribute to soil structure, function and aid in the dispersion or restriction of microbes. Several models of particle flow (in particular microorganisms) have been developed to predict the transport of a particle as it enters the subsurface environment. Models in abatement and transport theory have been developed and tested using field setting plots or reconstituted soil structures in laboratories. Much of the heterogeneity of the original soil samples, including macropores, native soil microorganisms and plant root channels (Dighton et al, 1997) has been removed in past and present studies. However, it is likely that these variables will be key in explaining the extent of the dispersal or restriction (Dighton et al, 1997). Rather, more recent studies have used 'in-tact' soil samples which mimic subsurface settings more efficiently. 
Despite the fact that colloids and microbes are subject to the same physochemical phenomena as are colloids, there are a number of strictly biological processes that affect the transport of microorganisms differently than colloids (temporal changes in surface properties due to changes in metabolic state; predation by other substrate organisms) (Ginn et al. 2002). In most dispersal and abatement models, the importance of heterogeneity in natural soils (vertical stratification, root channels, soil fauna burrows) is usually excluded (Dighton et al., 1997). It is the heterogeneity that dictates the fate and disposition of microbes after they are introduced to the subsurface environment. Therefore, is the heterogeneity of the subsurface environment a limiting factor in predicting microbial transport? Recent research focusing on stochastic models of particle distribution and microbial movement (see section 4.4) has examined this relationship. However, modeling stochastic-geometric microbial processes is still in its infancy stages and has yet to be proven reliable at the field level (see section 4.4).

\subsection{Discussion - Key findings in Pat̂hogen Abatement and Transport Research}

Due in most part to public health concerns and water safety initiatives, most subsurface abatement and transport research has focused on bacteria, viruses and protozoan microorganisms as they are known threats to groundwater sources and public health. Despite significant transport research, the diversity of the subsurface environment, along with the interactions between the subsurface and various environmental factors has raised questions among : usearchers who look to a single variable which will have the 'greatest observed effect' on transport. This diversity and environmental interaction has proven to be especially difficult for those wishing to develop generalized transport mechanisms for a specific organism or group of organisms. Rather than focus on several environmental and microbial factors (variables), most studies isolate individual variables $(\mathrm{pH}$, temperature) to observe their affect on a controlled environment. The majority of the experiments are performed in laboratory settings to control for factors that might limit results in actual settings. However, it is the uncertainty in the natural environment that adds to the complexity and diversity of the system. 
Several researchers have identified general principles that help the research community to draw conclusions based on factors that either aid or impede transport, especially where bacteria, viruses and protozoa are concerned (see Table 3).

Table 3. Significant Factors Affecting Pathogen Abatement in the Subsurface Environment.

\begin{tabular}{|c|c|c|c|c|c|c|}
\hline $\begin{array}{l}\uparrow=\text { increase }(\mathrm{s}) \\
=\text { decrease }(\mathrm{s})\end{array}$ & $\begin{array}{l}\text { Surface and } \\
\text { subsurface } \\
\text { temperature }\end{array}$ & $\begin{array}{l}\text { Soil } \\
\text { moisture } \\
\text { content } \\
\text { and } \\
\text { rainfall } \\
\text { intensity }\end{array}$ & $\begin{array}{c}\text { Presence of } \\
\text { indigenous } \\
\text { organisms }\end{array}$ & $\begin{array}{c}\text { Soil } \\
\text { composition, } \\
\text { structure, } \\
\text { and } \\
\text { agricultural } \\
\text { Practices }\end{array}$ & Soil pH. & $\begin{array}{c}\text { Porosity } \\
\text { and } \\
\text { presence of } \\
\text { plants and } \\
\text { macropores }\end{array}$ \\
\hline $\begin{array}{l}\text { Bacterial, } \\
\text { Viral, and } \\
\text { protozoan } \\
\text { transport } \\
\text { and } \\
\text { abatement } \\
\text { potential. }\end{array}$ & $\begin{array}{l}\text { A } \downarrow \text { in } \\
\text { temperature } \\
\text { favours survival } \\
\text { of both viruses } \\
\text { and bacteria. }\end{array}$ & $\begin{array}{l}\uparrow \text { in } \\
\text { moisture } \\
\text { inputs } \\
\text { produces an } \\
\uparrow \text { in } \\
\text { microbial } \\
\text { transport. } \\
\text { Unsaturate } \\
\text { d conditions } \\
\text { produce } \\
\text { a } \downarrow \text { in } \\
\text { microbial } \\
\text { abatement. }\end{array}$ & $\begin{array}{l}\text { Presence of } \\
\text { indigenous } \\
\text { organisms in } \\
\text { soil } \uparrow \\
\text { transport } \\
\text { opportunities } \\
\text { as adsorption } \\
\text { sites to soil } \\
\text { particles } \downarrow \\
\text { thus leading } \\
\text { to increased } \\
\text { movement } \\
\text { opportunity. }\end{array}$ & $\begin{array}{l}\text { An } \uparrow \text { in } \\
\text { microbial } \\
\text { transport } \\
\text { occurs in coarse } \\
\text { soils with larger } \\
\text { pore spaces } \\
\text { than in finer } \\
\text { textured soils } \\
\text { where pore sizes } \\
\text { are significantly } \\
\text { smaller. } \\
\text { Tillage } \\
\text { practices tend } \\
\text { to disrupt pore } \\
\text { systems and } \\
\text { therefore } \downarrow \\
\text { abatement } \\
\text { potential. }\end{array}$ & $\begin{array}{l}\text { A } \downarrow \text { in } \mathrm{pH} \\
\text { below } 7.0 \uparrow \\
\text { abatement } \\
\text { of } \\
\text { organisms. } \\
\text { Neutral pH } \\
\text { levels are } \\
\text { favorable } \\
\text { for } \\
\text { microbial } \\
\text { and virus } \\
\text { abatement } \\
\text { in all soils. }\end{array}$ & $\begin{array}{l}\text { An } \uparrow \text { in } \\
\text { porosity due } \\
\text { to } \\
\text { macropores } \\
\text { produces an } \\
\uparrow \text { in } \\
\text { microbial } \\
\text { transport } \\
\text { potential. } \\
\text { An } \uparrow \text { in } \\
\text { vegetation } \\
\text { yields } \uparrow \\
\text { abatement } \\
\text { opportunities } \\
\text { when roots } \\
\text { decay. }\end{array}$ \\
\hline $\begin{array}{l}\text { Supporting } \\
\text { Author(s) }\end{array}$ & $\begin{array}{l}\text { Mawdsley et al. } \\
\text { (1995), Wang et } \\
\text { al.(1996). Olsen } \\
\text { et al.(1996), } \\
\text { Blanc and } \\
\text { Nasser (1996). }\end{array}$ & $\begin{array}{l}\text { Ogden et al. } \\
\text { (2001), } \\
\text { Grevers } \\
\text { and De } \\
\text { Long } \\
(1990), \\
\text { Angers and } \\
\text { Caron } \\
\text { (1998), } \\
\text { Mawdsley } \\
\text { et al. } \\
\text { (1996). }\end{array}$ & $\begin{array}{l}\text { Dighton at al. } \\
(1997), \\
\text { Strauch, } \\
\text { (1991), Yates } \\
\text { et al. (1990). }\end{array}$ & $\begin{array}{l}\text { Patni et al. } \\
(1984) \text {, Catteneo } \\
(1997), \\
\text { Mawdsley et al. } \\
\text { (1995), } \\
\text { Tan et al. } \\
\text { (1991). }\end{array}$ & $\begin{array}{l}\text { Dighton et } \\
\text { al (1997), } \\
\text { Mawdsley } \\
\text { et al. } \\
\text { (1995), } \\
\text { Kemp et al. } \\
\text { (1992). }\end{array}$ & $\begin{array}{l}\text { Angers and } \\
\text { Caron (1998), } \\
\text { Cameron et } \\
\text { al. (1997), } \\
\text { King et al. } \\
(2000) \text {. }\end{array}$ \\
\hline
\end{tabular}

The factors found to most influence microbial abatement and transport in the subsurface environment include surface and subsurface temperatures, soil moisture content and rainfall intensity, presence of indigenous bacteria, soil composition and soil structure, soil 
$\mathrm{pH}$, porosity and presence of plants and macropores, and topography of the land (horizontal movement).

Although these factors are important in understanding subsurface transport, it is essential to consider the concept of microbial viability in order to estimate the fate of microorganisms. As viability of the organisms in the subsurface increases, the potential for transport too increases. For example, where cyst formation is an available component of physiological structure (Giardia lamblia), transport opportunities are increased, especially where environmental stresses (extreme temperatures) are part of the ecosystem. While other organisms may become inactivated, protected organisms may persist and be transported.

The subsurface environment is extremely diverse. The importance of environmental diversity and the multiplicity of interacting variables is key to the understanding of microbial abatement and transport. Ultimately, the heterogeneity of the subsurface environment is the governing factor in microbial transport. Understanding and quantifying the influence of heterogeneity on the process of virus transport is important since soil heterogeneity controls transport processes (velocity, filtration) by the natural existence of pores, cracks, and preferred channels as well as barriers to (microbial) movement (Maxwell et al., 2003).

Nutrients (especially nutrients of animal origin) differ in chemical and biological composition and are extremely diverse. Issues such as animal health, nutrient storage methods, environmental application conditions (and frequency) add to the complexity of predicting microbial subsurface transport. For example, research from Goss et al. (2001) looked at transport of E.coli 0157:H7 through soil. It was found that continued research on manure management in relation to pathogens is clearly required. There are clearly gaps in knowledge surrounding the shedding of E.coli $0157: \mathrm{H} 7$, particularly on the basis of seasonality alnng with the influence of diet and dietary changes of agricultural animals. Goss concluded that the development of vaccines to prevent the colonization of cattle by E.coli 0157:H7 needs to be completed (Goss et al. 2001). Besides animai 
interactions, other environmental contributions such as weather conditions and human interactions (the use of pesticides and other agricultural practices) will add to either impede or encourage transport capacities.

\subsubsection{Gap Analysis -Pathogen Transport Research}

Despite the number of studies, several gaps in research have been identified that would likely help in pathogen abatement and nutrient management. For example, adhesion and detachment processes of microbes to particulates, the metabolic effects of microbial transport, the role biofilms in subsurface transport and the role of surface properties (bacteria and viruses) on transport are rarely examined in current research.

By minimizing the number of variables in the studies, researchers are able to isolate changes in environments and hypothesize how such variables will affect the entire system. However, in the natural environment, single variables or sudden changes are not likely to affect the system to a great degree. Rather, it is the relationship between all subsurface particles (along with buffering capacities of ecosystems) that will determine the microorganism's ultimate fate.

The general lack of predictability of factors has led several authors to question how current research is performed. As authors such as Mawdsley (1995), Dighton et al. (1997), and Ginn et al. (2002) have shown in their research, factors affecting subsurface transport do not act alone. In fact, microbial and environmental factors are influenced by one another. For example, an ecosystem with increased moisture and sandy soils will likely have a relatively stable $\mathrm{pH}$, and as a result, increased particulate and microbial flow. However, if the $\mathrm{pH}$ level of the system were to change (due to environmental conditions or other factors), there would still be little change in overall particle catchment due to total soil porosity and moisture events.

In order for effective transport models to be developed, models must account not only for environmental and microbial diversity, but the relationships between variables, which may change depending on environmental and subsurface characteristics. Transport models must account for how microorganisms enter the environment. 
Transport models that study the transport characteristic of a single organism are unrealistic as microorganisms usually enter the subsurface attached to some other matter (soil particles). Realistically, microorganisms are transported in colloids and films (or clumps), rather than as single entities, which act alone. Models should account for this phenomenon by accounting for films and clumps of matter which enter a subsurface environment.

\subsubsection{The New Ontario Landscape}

The gap bc:ween rural and urban interfaces in Ontario is closing. As large-scale community development and urban sprawl continue, dense populations are increasingly surrounding agricultural operations and incurring associated problems. For example, odour concerns and potability of drinking water continue to dominate community concerns, especially where agricultural operations are surrounded by dense housing developments. Shared well-water systems and aquifers are stressed, not only by intensive agricultural operations, but also by constraints from growing communities. In addition, the number of anthropogenic sources of viruses such as septic systems, leaking sewers, animal farming operations, riverbank filtration, and the practice of artificial recharge of treated wastewater has grown due to population increases (Maxwell et al., 2003). In tum, these activities have led to increased virus loading to several aquifers used as drinking water sources. Related to this effect of urban sprawl and the human perturbations that accompany it are physical changes in 'sensitive' aquifers that makes them more conductive to virus transport (Maxwell et al., 2003).

Control of pathogenic organisms begins with source-water protection activities to prevent faecal contamination of aquifers and wells. According to Macler and Merkle (1999), these include assessment of wellhead vulnerability to faecal contamination of aquifers and correction of identified deficiencies (Macler \& Merkle, 1999). As detection methods improve, the list of identified pathogens in the subsurface environment, including drinking water sources will increase. Hundreds of pathogens in the subsurface, including bacteria, viruses, and protozoa are known threats to human public health and will continue to be in the future. 


\subsection{Conclusion}

There are several studies in subsurface pathogen transport research which point to the diversity and complexity of soil matrices. Complexity poses a problem for researchers wishing to create general transport models. Since the behaviour of all microorganisms cannot be accurately predicted and since gaps in microbial transport have been identified, it is difficult to develop microbial policy which is capable of abating all pathogens until gaps have been addressed.

Several environmental and microbial variables garner more attention in abatement and transport research because of their ability to influence microbial movement. They include the effects of surface and subsurface temperatures, soil moisture content and rainfall intensity, presence of indigenous microorganisms in the environment, soil composition and soil structure, agricultural practices, soil $\mathrm{pH}$, porosity and presence if plants and macropores and the topography of the land. Similarly, as it is unlikely single organisms will be transported through the environment, it is important to look at particle movements through the subsurface as microorganisms will likely attach to other matter. The governing factors of particle movement through the subsurface include the physical and chemical properties of the particle, physical and chemical properties of movement, environmental and microbiological factors, and existing subsurface conditions.

Though it is poorly understood how factors affecting microbial transport inieract, it is clear in existing research that the interaction between organism type and soil particles is key to determining the fate of the organism. The diversity of subsurface environments is also significant for management purposes as are nutrient and soil analyses. 


\section{Chapter Four: Models of Subsurface Survival and Transport}

The laws of biophysics and biochemistry govern the conceptualizations of microbial movement in the subsurface environment. In order for models and studies to realistically simulate the transport of microorganisms, an understanding of the laws of particle movement in the subsurface environment is essential. Viable organisms introduce additional variables to predictive exercises, including subsurface transport modeling. Not only must the researcher conceptualize the transport pathway the organism will take, but must also determine if environmental cenditions favour viability of the species. It is this interaction between environmental conditions and microbial factors which will determine a microorganism's ultimate fate in the subsurface environment.

Modeling pathogen transport is a sophisticated process involving knowledge in several scientific and mathematicai disciplines. Risk analysis and risk assessment skills are essential to modeling transport mechanisms. Quantitative risk assessment addresses the translation of pathogen concentrations to certain effects (health effects) which are observed (Teunis \& Havelaar, 2002). The estimation of risks involved in the transport (or abatement) of microorganisms and various other particulates in the environment is complex and involves an extensive set of factors. Environmental, physical, chemical, and biological factors are all relevant aspects which must be included in transport models. If a single factor is ignored, models may be found to be inconclusive and low in predictive ability. In general, the more parameters considered in a model, the greater potential the model would have for producing relevant transport predictions (Maier et al. 1999).

It is imperative that model developers gauge potential risks and either incorporate or dismiss potential factors of having relevance to transport and flow. The process of determining the relevance of such risks is an arduous process involving extensive research in pathogen movement and interaction in the subsurface via experimentation. Ultimately, it is the risk of human harm caused by pathogenic orgarisms that enter source drinking waters that policy makers attempt to prevent. However, only through the abatement of pathogens through the subsurface environment can the risk be mitigated and 
controlled for. By utilizing microbial transport models in specific environments where contaminants (microorganisms via animal nutrients) are distributed into the subsurface environment, one can theoretically estimate the risk to source waters and protect against the threat accordingly. If not, protection measures must be taken in order so that pathogen loads are decreased and risks to source waters are mitigated.

All subsurface microbial transport models take different approaches in risk analysis and assessment but have many similarities in modeling and mechanistic approaches. The predictive nature of the models, although prognostic, is essential in nutrient management planning. Despite difficulties associated with monitoring the subsurface environment, several researchers have attempted to tackle the task of creating models of microbial transport (Murphy \& Ginn, 2000; Zysset et al., 1994; Hornberger et al., 1992; Murphy et al., 1997; Li et al., 1996; Zhang, 1997; Wu et al., 2003; Aguirre \& Haghighi, 2003; Dillon \& Fauci, 2000; Sun et al., 1999). These models are predominantly reactive transport and stochastic-geometric models. Reactive transport models are no more than a collection of process representations (physical, chemical, and biological) of varying accuracy and sophistication that are used to describe the transport of a microorganism in a coupled dynamic system. Stochastic-geometric models bring forward the complexities of the subsurface environment and model the transport of microbes through heterogeneous settings. Both reaction-transport and stochasticgeometric models are examined further in sections 4.3 and 4.4 .

\subsection{Risk Analysis and Risk Assessment in Microbial Transport Modeling}

The concept of risk is critical to nutrient management and microbial transport modeling. As environmental, microbial, and physical factors vary to some degree in each environment, risks, which threaten source waters, vary significantly. The estimation of such risks in the subsurface environment allows for variation in management technicuss that aid in or impede microbial movement. Management fractices are intended to discourage rapid microbial transport and encourage abatement. According to Crane \& Moore (1985), in order to protect surface and groundwater sources from enteric bacterial pollution, management practices must be based on sound knowledge of the fate of these 
organisms in the enviromment. However, unless risks are estimated and projected adequately, threats to source waters remain high where microorganisms enter the subsurface environment.

There is considerable research on the factors affecting microbial transport in the subsurface environment. However in many cases, the research has been found to be inconsistent. For example, if all factors affecting microbial transport were easily quantifiable (and available), the creation of a 'pathogen index' would be a manageable task. The trouble with many of the studies to date is that only single factors have been tested experimentally to measure their effect on the system. However, single factors rarely have an effect on the entire subsurface system and hence, microbial transport. Rather, it is the complex interaction between environmental, physochemical and biological processes that determines the ultimate fate of the organism.

Other difficulties in research stem from technological factors that prevent researchers from readily identifying organisms and their interactions in the subsurface environment. According to White et al. (1998), the assessment of microbes and their insitu interactions in various environments (including subsurface environments) is a major problem that requires the application of non-traditional methods. For example, it has been repeatedly documented in literature that viable, or direct counts of the number of bacteria attached to sediment grains are difficult to establish and measurement may grossly underestimate the extent of the existing community in a sample (White et al. 1998). Pathogenic microorganisms may be inactivated in the subsurface (or surface) over time such that, even if physically detected in groundwater, they are incapable of causing infection. The rate of this inactivation is organism-specific and highly influenced by subsurface physical and chemical conditions (Macler \& Merkle (1999).

Variability in envirommental conditions must be accounted for in experiments and transport studies, as the subsurface is not a closed entity. Rather, conditions change and effectively, so do the transport characteristics of organisms. As a result, models must be extensive enough that fluctuating values may be computed within the model to provide a single value of risk. Such values of risk would be invaluable in agricultural settings 
where estimation of risk to sensitive sources (aquifers) is crucial to human and animal health.

According to Zwietering \& Gerwen (2000), risk analysis is a process which scientifically evaluates the probability of occurrence and severity of known or potential adverse effect(s). According to Zwietering \& Gerwen (2000), the risk analysis process consists of four steps, which include;

(i) hazard identification

(ii) exposure assessment

(iii) hazard characterization

(iv) risk characterization

Hazard identification is the identification of (those factors) which are capable of causing adverse effects, or in the case of pathogen management, those organisms which are capable of being transported through the subsurface environment. Exposure assessment is the qualitative and/or quantitative evaluation of the likelihood that the biological agent will reach a selected distance or objective location. Hazard characterization is the qualitative and/or quantitative evaluation of the nature of the adverse effects associated with the cause. In health risk assessment, this step estimates the dose-response relationship. In pathogen management, hazard characterization would vary depending on the type of microorganism being studied and the virulence of that microbe. Risk characterization is the qualitative and/or quantitative estimation of the probability of occurrence of a biological agent reaching a location and an estimate of the consequences (Zwietering \& Gerwen, 2000). Risk characterization is determined by estimating the likelihood of an event occurring and of people being exposed. In microbial subsurface transport studies, risks are more easily determined where models are used. Together, these four steps complete the risk assessment process.

\subsubsection{Sensitivity Analysis, Uncertainty and Variability}

Although unavoidable, uncertainty must be accounted for and may ultimately alter risk assessment calculations in modeling. The issue in risk assessment models is accounting for uncertainty and variability as sources of variation in model parameters 
(Nauta, 2000). Second-order modeling, involving the separation of uncertainty and variability of model parameters, is important in several fields of risk analysis (Nauta, 2000). According to Nauta (2000), 'uncertainty' represents the lack of perfect knowledge of a parameter value which may be reduced by further measurements. Variability, on the other hand represents a true heterogeneity in the population that is a consequence of the physical system and irreducible by additional measurements. It is expected that any model of microbial transport, due to limitations in experimental research, will have a high level of uncertainty and variability entrenched in its calculations and mechanistic makeup. In other words, when the nature of the probability distribution of a model parameter is not clear, it may be better to imprecisely assign a parameter as uncertain than to not separate them at all (Nauta, 2000).

According to Zwietering \& Gerwen (2000), it is impossible to determine risks with high accuracy due to many inaccurate and unknown aspects. Such variability, especially in the subsurface environment, is expected. However, with sensitivity analysis tools, such uncertainty can be better managed. Sensitivity analysis is used as an effective tool which determines the relevance of variations of factors (Zwietering \& Gerwen, 2000). The three stages of sensitivity analysis include;

(i) "Deterministic analysis" - which selects the most relevant determinants of risk

(ii) "Worst Case Analysis" - which finds relevant process steps in worst-case situations, and shows relevance of variations of risk.

(iii) "Stochastic Analysis" - which studies the effects of variations of factors for the variability of risk estimates.

(Zwietering \& Gerwen, 2000).

Often, the trend in research is to utilize a "worst case analysis" so that all risks are accounted for. However, it is this 'overprotection of values', which often overestimates risk of a particular variable within the model. According to Coleman (2003), most predictive microbiological models represent worst-case situations that may introduce systematic biases and result in an overestimation of risk. Such overprotection of values undermines the purpose of microbial transport modeling where the goal for risk assessors 
should be developing reliable models. The goal of a nutrient management strategy would be to incorporate a system where worst-case scenarios along with average conditions are accounted for.

Wherever possible, all uncertainty should be removed so as to remove any identifiable bias. Where uncertainty becomes a necessary part of the model concept, it must be accounted for when calculating overall instability of the system. Several methods are used to decrease and discourage uncertainty. For example, when one knows the mean and stochastic distribution of all factors (after repeated experimentation), it is possible to perform a Monte-Carlo simulation in order to determine overall uncertainty. In a Monte-Carlo simulation, a large number of simulations are carried out where, for each simulation and for every input factor, a sample is drawn from its distribution. The distribution in the outcome of the risk calculation then gives a realistic probability distribution of the risk. A Monte-Carlo analysis can be used as a type of sensitivity analysis so as to find the most relevant effects, but cannot be used to determine a realistic uncertainty (Zwietering \& Gerwen, 2000).

According to Lammerding \& Fazil (2000) the modeling of complex systems (such as the modeling of subsurface microbial transport) requires some simplification and the use of assumptions as all information in many cases is unavailable or not possible to produce. Every effort should be made to validate the results produced by a model, preferably against independent observed data if such data are available in other studies.

\subsection{Models}

One of the main objectives of predictive subsurface microbiological research is to develop models, including microbial subsurface transport models which are reasonably predictive, without bias or uncertainty, and governed by the laws of science. Transport models are sinuplified representations of reality, taking into account the main effects, and even for these main effects, the models are not exact (Zwietering \& Gerwen, 2000). Accordingly, there is more or less inaccuracy in the prediction. However, transport models are useful tools to quantify the kinetic processes and to determine the order of 
magnitude of the outcomes (Zwietering \& Gerwen, 2000). According to Walls \& Scott (1997), microbiological transport models are used to predict the growth, survival and inactivation responses of microorganisms to different envirommental conditions. Microbial transport models can be used to predict the movement of both incorporated and in situ microorganisms in the subsurface environment, along with the fate of the organism. More often than not, the processes of transport and the process of microbial fate go hand-in-hand.

Developing a transport model which attempts to replicate (or predict) the path of an organism as it enters the subsurface environment involves several disciplines in science, including biology, chemistry, and physics. Coupled together, the interactions between the disciplines involve physical-chemical and biological processes. However, according to Ginn et al. (2002), there is not necessarily a clear distinction between processes that are physical-chemical and biological. In fact, many processes important to microbial transport are termed 'physio-chemical-biological' phenomena (the effects of cell-surface macromolecules on bacterial partitioning and adhesion) (Ginn et al., 2002). These effects, along with their interaction with environmental conditions combine to either aid in or abate the transport of organisms in the environment.

The amount subsurface microbial transport information available in studies and experiments is extensive. Modeling of microbial transport through the subsurface environment is complex. However, the flow of microbes is simplistic in terms of predicting the basic processes of movement and microbial fate (see Figure 4.1). Crane and Moore (1985) showed using their own transport models that the use of predictive models is helpful in organizing large quantities of data from diverse sources io forecast enteric organism populations in soil and water systems. Developing transport models is just as important as testing the ineffectiveness and experimental performance is a necessary component of the modeling process. After all, without proper experimentation to test theories or predictions, the model may be considered inconclusive and without credible and necessary justification. Despite the fact that experiments are necessary for 
model justification, several authors note that the cost of performing experiments is high and therefore in many cases, experiments are not carricd out.

Figure 4.1 - Microbial Subsurface Flow Model

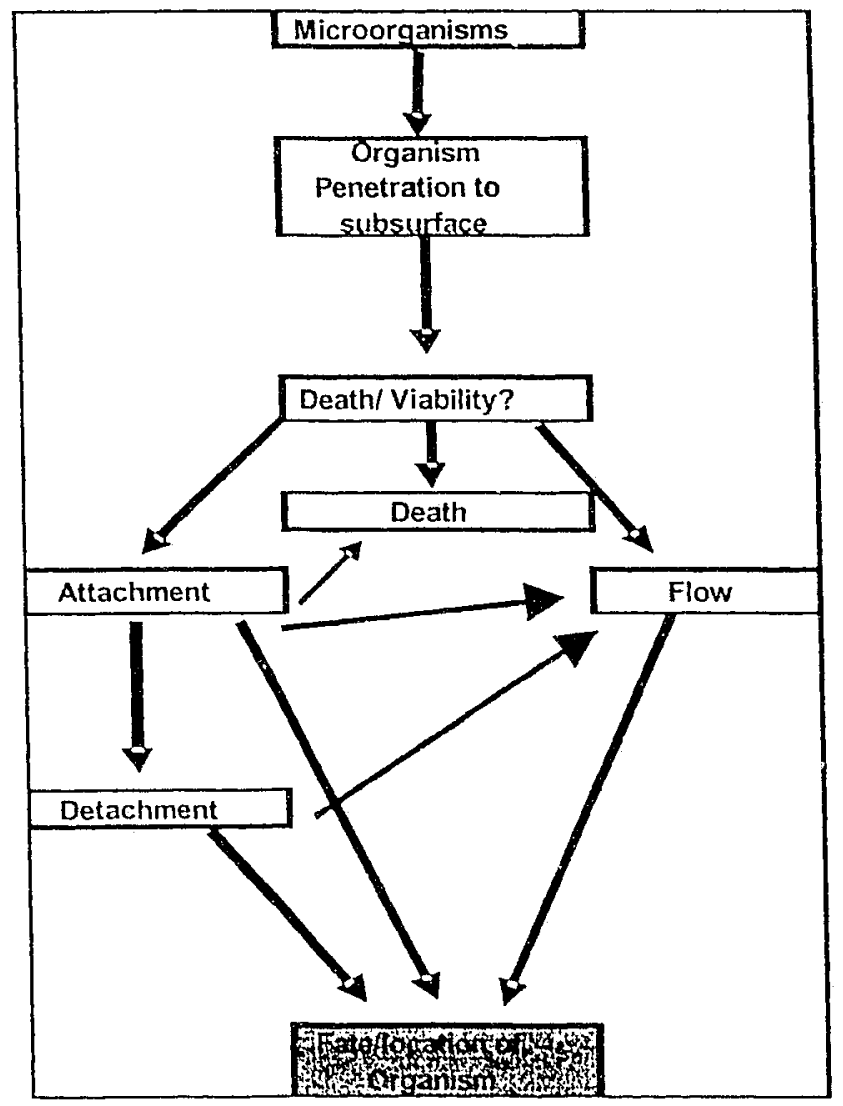

Not only must we consider the lactors that contribute to transport (as discussed in

Chapter 3). we must also consider the factors that affect microbial viability. Aceording to ('rane \& Moore (1985), if models can be dereloped to accurately' predict bacterial die-olf following defecation of manure by animals in agricultural operations. the number of bacteria that are available to contaminate the soil. groundwater and surface water can be estimated. Clearly. factors allecting microbial viability prior to land treatment (animal health. Waste pre-treatment) must be considered in transport models since microorganism loading to the soil may be affected by such beginning of the pipe processes. Nomally. the die-off rate of organisms in the subsurface enviromment is represented using firstorder model dic-off kinetics. The first-order model appears to accurately describe the die off of bacteria under all conditions. However. the die-off coefficient is a highly variable parameter spanning several orders of magnitude for any given bacterial type (Crane \& Moore. 1985). Although not the most accurate estimate. first-order kinctic models are 
used regularly by researchers as they are easily accounted for and implemented into transport models.

Most reactive transport models (see section 4.3) incorporate a variety of physical processes, such as advection, dispersion, straining and physical filtration (Ginn et al., 2002). According to McGechan \& Lewis (2002), smaller microorganisms (viruses and bacteria) are transported (like chemical constituents) by adsorption onto otherwise harmless mobile colloidal clay particles or soil organic matter.

Unlin a the biological processes, physical processes affecting microbial transport have beer the focus of numerous experiments and numerical modeling studies (Ginn et al., 2002). Potential impediments to movement of colloids through soil can be divided into straining and filtration, depending on whether a particle has a dimension greater than pores /le ting to physical trapping) or much smaller. The task is further complicated becai:, transport models must account for several simultaneous interactions and phases occurring tetween the organism and subsurface particulates. The rate of such processes is further mitigated by the structure of the organism along with environmental conditions (temperature, $\mathrm{pH}$, moisture content) which vary in time and location. Although several studies have been performed which focus on the attachment prosesses of microorganisms, significant research has yet to be determined such as the role of extracellular polymeric substances (EPS) in attachment. According to Ginn et al. (2002), no generally accepted quantitative treatment of dynamic, biologically-mediated adhesion/detachment processes exists to date. The kinetics and mechanisms of such attachment process are significant in modeling methods, as the availability of 'free', or unattached microorganisms is considerable.

Biological processes, such as growth/decay procedures along with survival and chemotactic mechanisms are not fully understood or agreed upon in all scientific circles. According to Ginn et al. (2002), the biological nature of these processes presents a challenge for transport modeling in that one biological mechanism is often dependent on and/or influenced by another biological mechanism. For example, chemotaxis, the 
process by which an organism moves in response to a chemical gradient, is a factor in environments with higher nutrient levels (Ginn et al., 2002). Chemotactic processes would be significant in environments where animal nutrients are applied to land. According to Brockman \& Murray (1997), soils and subsurface environments can differ dramatically in their rates of nutrient flux. Soils which receive a large input of nutrients by plants and animals are very dynamic as a result of seasonal changes and where temperature and moisture levels fluctuate. In contrast, soils that are nutrient poor, exhibit a 2 to 6 order of magnitude decrease in available biomass (Brockman \& Murray, 1997). This is likely to result in significant differences in variability and scale of microbial heterogeneity between soils and subsurface sediments (Brockman \& Murray, 1997).

Much of the emphasis in subsurface research to date has been on quantitative representations of either the kinetics of containment degradation of the physical (or physochemical processes) that affect the transport of bacteria in porous media, primarily because these issues are more tractable to the microbiological and hydraulic transport fields (Murphy \& Ginn, 2000). Although the majority of transport models to date have focused on subsurface transport, several models exist which address surface transport. One such example is the United States Environmental Protection Agency's Model for Protecting Surface Water Resenvirs. Ground water discharge and surface runoff models may be used to assess the potential impact of individual contaminant sources, and to identify watershed areas with the greatest potential impact on source water quality. Modeling can be used in conjunction with source water assessments to enhance source water quality protection efforts.

A number of models have been developed to assess the impact of changing land use on water quality. Simpler models require less detailed, site-specific hydrologic information and provide more generalized and descriptive output. More complex models require more extensive input data and provide output with greater predictive capability and site specificity. Site-specific output can provide locations of contamination sources and yield relatively accurate predictions of variable flows and water quality at any point in a watershed (USEPA, 1997). Although not within the scope of this study, surface 
water runoff models may provide valuable information about the origin of microorganisms, as surface runoff may deviate from animal nutrient sources.

Based on consistencies in microbial subsurface processes and mechanisms, the following approaches in modeling microbial subsurface transport have been identified as effective tools in predicting transport pathways in the subsurface environment. They include, reactive transport models, stochastic-geometric approach models and advectiondispersion models.

\subsection{Reactive Transport Models}

Research over the past decade has indicated that there is a close link between microbiological processes and environmental conditions (Mawdsley et al. 1995., Wang et al. 1996., Ogden et al. 2001., Dighton et al. 1997., Cameron et al. 1997). Environmental conditions play a role in encouraging transport or promoting abatement of microbes. As conditions change, so do microbial physochemical and biological processes. Progress in modeling microbial processes in porous media is essential to improving our understanding of how physical, chemical, and biological processes are coupled in groundwater, and their effect on groundwater chemistry evolution, bioremediation, and the reactive transport of contaminants and microorganisms (Murphy \& Ginn, 2000). The processes between the microorganism and the subsurface matrix make transport of each microbe unique and difficult to predict.

Reactive transport models are no more than a collection of process representations (physical, chemical, and biological) of varying accuracy and sophistication that are used to describe a coupled dynamic system (see Figure 4.2). Ti.iugh a single, allencompassing reactive transport model has yet to be accepted, the concepts supporting existing models satisfy many of the criteria thought by most researchers to be responsible for the transport of micruorganisms through the subsurface environment. In order to model the migration of a dissolved contaminant in the subsurface, an appropriate governing equation should include the effects of the transport processes of advection and dispersion and the effects of reactive processes such as adsorption and biodegradation 
mechanisms (Tebes-Stevens et al. 1998). Reactive transport models focus mainly on two key processes in microbial and particulate movement including (i) physochemical (see section 4.3.1) and (ii) biological processes (see section 4.3.2).

Figure 4.2 - Reaction Transport Model Components and Gap Analysis

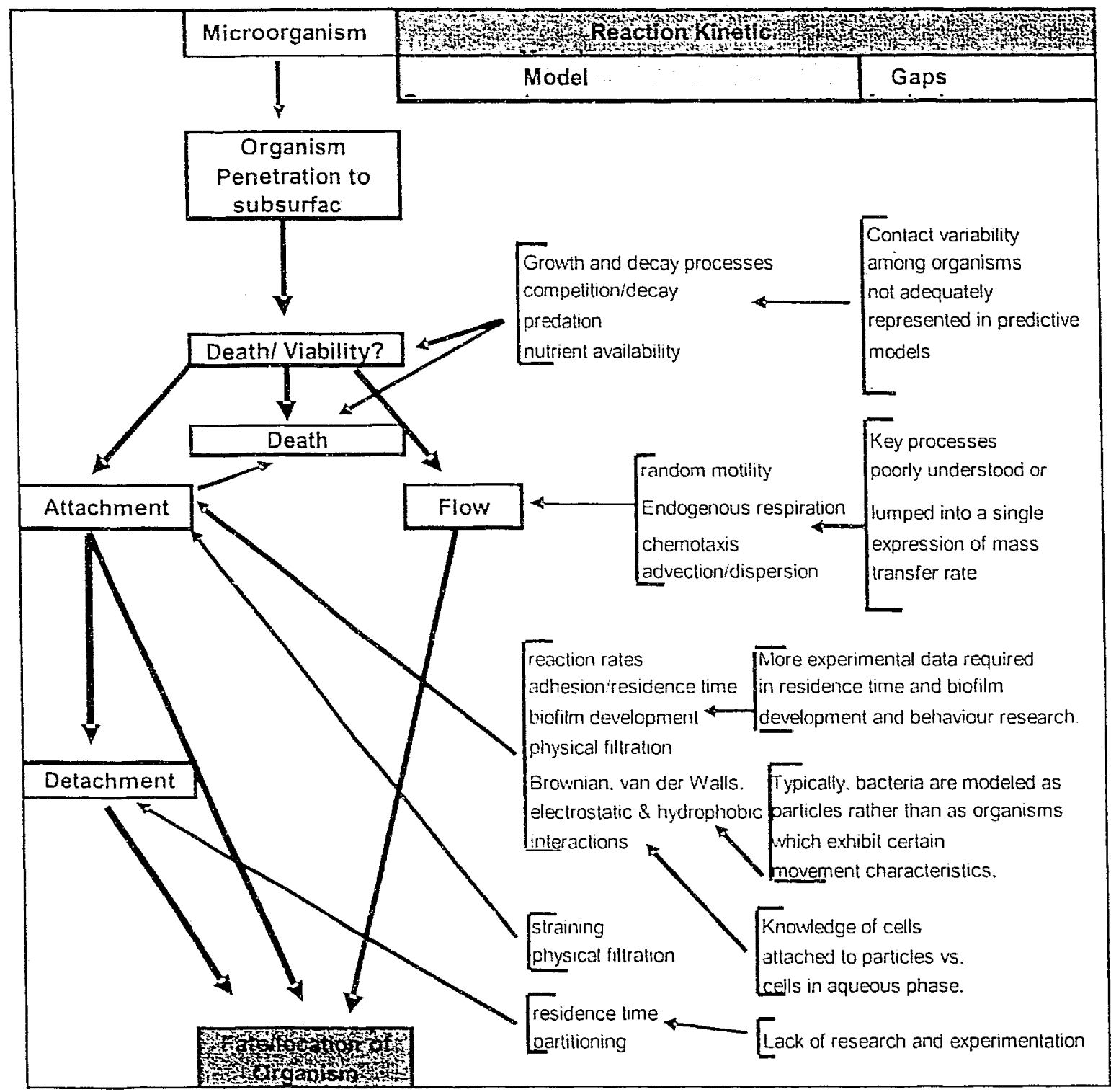

The process of physical attachment by bacteria and viral particles alike is intricate in its procedure and mechanisms. Both the microbial strain and en: ionmental conditions play significant roles in attachment and detachment between the microorganism and particle. As such. several variables must be aceounted for such changes in subsurface structure and climate. For example. in growth-limited environments (oligotrophic. or 
carbon limiting environments), physical processes likely dominate transport of the biomass in the system (Murphy \& Ginn, 2000). In contrast, in nutient-rich environments such as in contaminated aquifers, field observations consistently indicate a higher level of biomass in the aqueous phase indicating different methods of microbial transport (or abatement) (Murphy and Ginn, 2000).

Physical, chemical, and biological processes are coupled in groundwater and their effect on groundwater-chemistry evolution, bioremediation, and the ractive transport of contaminants and bacteria is significant (Murphy \& Ginn, 2000). However, in many cases, key variables may be misrepresented or remain static in value to mimic laboratory settings and not the settings of a true subsurface environment. More often than not, key processes in reaction transport models are either poorly understood or lumped into a single expression of mass-transfer rate (Murphy and Ginn (2000).

Reaction rates of microbial interaction with subsurface matter are often taken for granted as a given, static value in many microbial transport models. According to Murphy and Ginn (2000), one of the aspects most important to modeling fate and transport in porous media is the rate of the reaction rates. Reacting mixtures can involve a variety of individual reactions, each with a particular rate and the set of rates can range from the very slow to the very fast to the instantaneous (Murphy \& Ginn, 2000). The rate of this reaction is important to overall transport pathways as microorganisms may be slowed or be transported easier through the subsurface.

\subsubsection{Physochemical Processes}

Most reactive transport models that consider microbial processes incorporate physochemical processes such as advection, dispersion, straining, and physical filtration (Murphy \& Ginn, 2000). The physochemical processes are primarily based on the structure and properties of the groundwater flow system and porous media.

Consequently, most reactive transport models incorporate some major physical processes. These physical processes have been the focus of numerous experimental and numerical modeling studies on colloid and biocolloid research. As outlined in Chapter 3, the main pliysical processes responsible for the transport of microbes through the subsurface 
environment include advection, dispersion, straining and physical filtration. More complex mechanisms of movement (chemotaxis) that require energy via intracellular mechanisms are biological mechanisms. Though important in their own right, most physical processes, specifically the process of attachment, are influenced by the following factors;

(1) Solution ionic strength through the effect on electrostatic forces (Tan et al. 1994),

(2) $\mathrm{pH}$ (Mawdsley et al. 1995), and

(3) Mineralogy (Fletcher and Loeb, 1979; Scholl et al., 1990; Mills et al., 1994).

Physochemical processes are primarily based on the structure and properties of the groundwater flow system and porous media (Murphy \& Ginn, 2000). Unlike the biological processes, physochemical processes affecting microbial transport have been the focus of numerous experimental and numerical modeling studies. These important processes provide the framework for bacterial transport and reaction in porous media (Murphy \& Ginn, 2000). Quantitative representations of physochemical processes are distributed into three categories including, flow processes, transport processes and physical microbial attachment/detachment processes. Physical forces resulting in attachment (Brownian, electrostatic, van der Waals forces) are the dominant mechanisms for partitioning of biocolloids to solid media and have received substantial attention, partly because of their quantitative tractability (Murphy \& Ginn, 2000).

Several physochemical processes are incorporated within reactive transport models quantitatively. Quantitative representations are grouped (according to Murphy \& Ginn, 2000) into three categories including flow, transport, physical microbial attachment/detachment processes. The laws of fluid transport that govern flow processes include Darcy's Law, along with the water mass conservation law, where assumed constants include fluid density and viscosity. Processes governing microbial transport processes include solutes and microbes undergoing convective and mass fluxes whereas Stokes law (for descent of a sphere) is used to represent the pathway (vertical movement) of an organism (or particle). Physical microbial attachment/detachment processes 
incorporate several quantitative representations including (among others) physical partitioning between solid and aqueous phases that are governed by kinetic models of reaction (first or second rate reaction kinetics) (Murphy \& Ginn, 2000).

\subsubsection{Biological Processes}

Biological processes are inherently linked through growth-based mechanisms. Growth kinetics (Monod kinetics) along with biodegradation mechanisms plays a significant role in the transport process. Biological processes include competitive inhibition processes, co-metabolism, random motility and chemotaxis, metabolic lag, microbial growth and biodegradation processes (Murphy \& Ginn, 2000). Additional biological processes affecting microbial transport are expressed through the growth/decay process and include active adhesion/detachment, survival, and chemotaxis (Murphy \& Ginn, 2000).

The biological processes of growth/decay, chemotaxis, predation, physiological adaptation (survival), and adhesion or active detachment are characteristics of the bacterial population and by comparison, have received little attention in field-scale hydrogeologic transport models (Murphy \& Ginn, 2000). For example, Murphy \& Ginn (2000) note that few studies have considered the presence of cells at various phases, but they have also assumed microbial reaction kinetics to be independent of the phase in which the cell resides. This assumption may not be adequate because cells attached to the solid phase may behave differently from the cells suspended in the aqueous phase. More research is required in this realm of reactive modeling (specifically biological processes) as it relates to biological processes for microorganisms other than bacteria such as viruses and protozoa.

\subsubsection{Reaction Transport Models - Gap Analysis and Risk Assessment Potential}

Reaction transport models may be effective tools in predicting the transport of microbes in the subsurface environment. They incorporate several existing physical, chemical and biological mechanisms that are required for detailed pathway expression. However, reaction transport models have significant limitations (see Figure 4.2). Murphy and Ginn (2000) note that several advances in science will improve overall efficiency of 
reactive models. For example, the complexity of the biological process requires advances in numerical and theoretical modeling in order that specific representations may be made. Further advancements in the field of microbial subsurface transport would allow researchers to better understand the processes of residence time (the time an organism spends attached to a particle) and how larger groups of incorporated microbial mass, such as biofilms interact with the subsurface and how the transport of organisms is affected accordingly.

No single reaction transport model has been developed which takes into account all critical reactions. True, the reaction transport model developed by Murphy and Ginn (2000) does incorporate many of the key factors involved in the transport and abatement of microorganisms in the subsurface. However, many of the processes in the model have been proven to have limitations when biological and physochemical processes were incorporated. For example, the process of biodegradation is modeled using Monod equation factors. However, as noted by Murphy and Ginn (2000), it is difficult to distinguish the kinetic rates for attached and unattached microorganisms. Furthermore, flow processes, such as groundwater velocity are represented through Darcy's Law and the water mass conservation law. However, limitations in modeling groundwater velocity include unknown multiscale variability of permeability in the subsurface which make modeling flow processes particularly difficult.

Based on risk analysis criteria (see section 4.1), the reaction transport model could potentially be an efficient model for predicting the fate of a microorganism in the subsurface environment (see Table 4). However, until further experimental research takes place and gaps are addressed, it is difficult to establish if the model could predict the fate of an organism reliably. Table 4 identifies the key elements in the risk analysis process and compares them to the key elements incorporated in the reaction transport model. 
Table 4: Risk Analysis Processes and Key Elements of the Reaction Transport Model

\begin{tabular}{|c|c|}
\hline $\begin{array}{l}\text { Risk Analysis } \\
\text { Process }\end{array}$ & Reaction Transport Model - Key elements \\
\hline $\begin{array}{c}\text { Hazard } \\
\text { Identification }\end{array}$ & $\begin{array}{l}\text { - Identifies important elements to subsurface transport } \\
\text { including biological and physochemical processes. } \\
\text { Key processes accounted for including flow \& transport } \\
\text { processes, microbial attachment/detachment processes, } \\
\text { biodegradation, microbial growth \& respiration activities, } \\
\text { random motility and chemotaxis, competitive inhibition \& } \\
\text { cometabolism progressions. }\end{array}$ \\
\hline $\begin{array}{c}\text { Exposure } \\
\text { Assessment }\end{array}$ & $\begin{array}{l}\text { Experimentation and extensive study would strengthen } \\
\text { validity of model components in order to determine fate of } \\
\text { microorganism. } \\
\text { - Parameter fitting is often invoked to fit, sometimes non- } \\
\text { uniquely, a set of simplified process representations to } \\
\text { describe a particular situation }\end{array}$ \\
\hline $\begin{array}{c}\text { Hazard } \\
\text { Characterization }\end{array}$ & $\begin{array}{l}\text { - Heterogeneity and variability of environmental conditions } \\
\text { would likely change probability of biological and } \\
\text { physochemical processes. Variability must be accounted for } \\
\text { in model components. }\end{array}$ \\
\hline $\begin{array}{c}\text { Risk } \\
\text { Characterization }\end{array}$ & $\begin{array}{l}\text { - Formulations and model make-up not tested experimentally. } \\
\text { - Some model assumptions may modify predictive capacity of } \\
\text { model. }\end{array}$ \\
\hline
\end{tabular}

\subsection{Stochastic-Geometric Models}

The subsurface environment is anything but a uniform and homogenous setting. Mixtures of sands, loams and clays, inconsistent voids and cracks, air pockets and developments of small microbial communities add to the diversity and complexity of different subsurface ecosystems. In laboratory settings, experiments are created so that repeated testing can be performed to ensure consistency of results. Through consistency in research, models may be created to reflect findings observed during experimentation. However, in the subsurface environment, modeling has proven to be more difficult as the heterogeneity of the subsurface matrix along with the variability of environmental conditions adds complexity to the overall modeling process. Variability is the common denominator of all natural phenomena. Variability in a property or process of interest is the observed result of a spatially heterogeneous pattern (Brockman \& Murray, 1997). Variability does not exit in isolation. Rather, it is affected by the patterns of numerous interacting abiotic and biotic properties in the ecosystem (Brockman \& Murray, 1997). 
Stochastic geometric transport models attempt to reproduce the effect of diverse spatial structures and heterogeneous difficulties. Most stochastic theories (e.g. Dagan, 1989; Cushman, 1997) for groundwater flow and solute transport in porous formations are developed under the following assumptions:

(1) A steady-state flow with no boundaries (or infinite boundaries)

(2) A stationary hydraulic conductivity field

(3) A uniform mean velocity and

(4) Simple initial conditions for solute plume, such as point source or rectangular box with instant or step release

(Wu et al, 2003)

According to $\mathrm{Li}$ et al. (1996), stochastic-geometric modeling techniques incorporate to varying degrees random walk, fractal and percolation approaches which act as alternatives to mathematical and numeric models that describe subsurface transport (see figure 4.3). Conceptually, key concepts in random walk, fractal and percolation theories are intuitively associated with geometric features of the subsurface geophysics and microbial growth transport, such as straining flow in porous media (see section 3.2.3), pore size (see section 3.2.5), streamlines, fractal networks (see section 3.2.6), microbial clusters (biofilms), microbial sizes and microbial aggregation (Li et al, 1996).

Random walks, or Brownian motion of microbial processes are the simplest natural example of a random diffusion process. The random walk method comes from statistical physics and has long been used in the analysis of diffusion and dispersion process in porous media. Spatial structures play an important role in stochasticgeometric modeling where spacing affects microbial transport and even microbial populations ( $\mathrm{Li}$ et al, 1996). The stochastic approach used for derivation of the largescale transport model consists of four basic steps;

1. The local governing transport equation is averaged over the ensemble of soil property realizations. 
2. Cross-correlations between concentration and specific discharge fluctuations are evaluated analytically and then, the expressions for the effective transport parameters are developed.

3. Simplified linearized equations relating concentration fluctuations to soil property fluctuations are derived.

4. The large-scale transport model and the effective macrodispersion parameters are developed.

(Aguiree \& Haghighi, 2003).

Survival of subsurface microorganisms can involve a number of factors including the microbial species involved, temperature, the presence of microbial competitors, predators and parasites (bacteriophages) and geochemical and hydrogeologic conditions (Knox et al., 1993; Abu-Ashour et al., 1994). Over the past decade, several studies have addressed the complexity of subsurface heterogeneity and modeling difficulties. According to Brockman \& Murray (1997), there is the potential for a high degree of microbiological heterogeneity in the subsurface. Models to date have attempted to use strict mathematical and numerical techniques to address such factors. So-called 'realistic' numerical or mathematical simulations are frequently used in subsurface modeling. However, they have been found to be extremely complicated, and in some cases, difficult to apply because of severe non-linearity in soil composition. In most cases, these mathematical models cannot reflect the non-homogeneous nature of subsurface microbial systems ( $\mathrm{Li}$ et al, 1996).

According to Li et al. (1996) advances in microbial transport in heterogeneous subsurface media have proven to be important in studies of the spatial heterogeneity of subsurface chemical, physical and microbial processes. Heterogeneity at different scales is a basic factor that needs to be considered in models of microbial macrodispension (Harvey, 1991; Harvey et al, 1993). The difficulty lies in how such diversity can be placed into a model with precision, while having flexibility in order to accommodate different environments. Natural environments are complex, and the distribution of microbiological properties results from overlapping spatially non-homogeneous 
distributions of numerous physical, chemical and microbiological properties (and their interactions) that yield patches of optimal and non-optimal conditions for microorganisms must be accounted for (Brockman \& Murray, 1997).

Figure 4.3 - Stochastic-Geometric Model Components and Gap Analysis

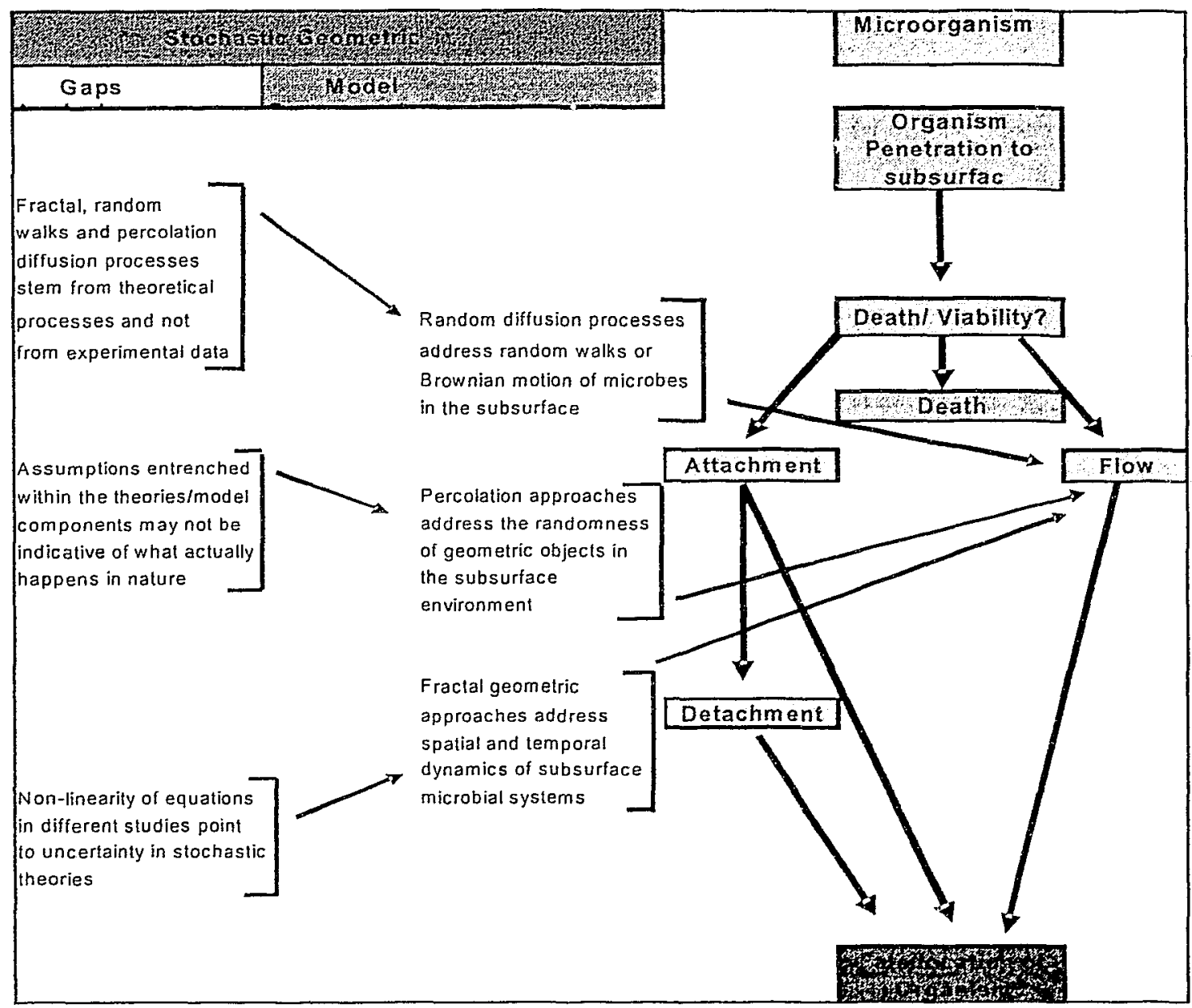

In general, natural porous media are disordered. Representing porous media by something that is intrinsically ordered (as is the case in several mathematical and numeric models) seems inadequate. Statistical homogeneity may not be sufficient in general cases of microbial transport through porous media. Thus, alternative approaches such as those provided by stochastic geographic models have been sought. In the case of highly heterogeneous and/or fractured geologic media, the selection of an adequate conceptual model is by no means obvious. The difficulty in modeling heterogeneous processes is complicated by the non-linearity of the governing equations ( $\mathrm{Li}$ et al, 1996). 
Many researchers have used tracers to track the mobility of fluids and particles in the subsurface. Because the subsurface contains all 5 major groups of microorganisms (bacteria, actinomycetes, fungi, algae and protozoa) as well as viruses, and because microbes exhibit behaviour like death, reproductive predation, species-specific methods of detachment to and detachment from surfaces and particles, growth as aggregates or biofilms, production of spores with distinctly different physical properties and behaviours than active cells and motility, the transport of microbes over long time and space scales is different from that of innate particles or tracers (Li et al,. 1996).

To understand the process of subsurface microbial transport, the important role of spatial structures in heterogeneous porous media must be understood. Spatial structures in heterogeneous porous media affect microbial movement and population dynamics (Li et al, 1996). Transport in random heterogeneous media is controlled by the underlying velocity field which in turn is determined by the hydraulic conductivity, hydraulic head, kinematic porosity, saturation and other factors (Zhang, 1997). Flow properties such as conductivity, head, and saturation levels are usually treated as random functions. Stochastic theories have been developed rapidly during the last two decades to explain single flow-phase transport in saturated media (Zhang, 1997). The subsurface environment often exhibits a pronounced spatial heterogeneity in physical properties as a result of the stratified nature of many subsurface deposits and the actions of hydrologic and geochemical processes over time (Brockman \& Murray, 1997). Perhaps the most significant element of stochastic-geometric model is that it addresses" variability in microbial and geophysical processes and attempts to simplify them into normalized equations.

\subsubsection{Stochastic-Geometric models - Gap Analysis and Risk Assessment}

One of the purposes of the stochastic-geometric model is to bring forward the complexities of the subsurface environment. Otherwise, models such as the advectiondispersion model (see section 4.5) would be effective as advection-dispersion hinges upon the homogenization of the environment. The effectiveness of the stochasticgeometric model hinges upon the availability of research in spatial representation of pore 
structures which makes the model more suitable than other models which attempt to predict transport (advection dispersion models) In the case of highly heterogeneous and/or fractured geologic media, the selection of an adequate conceptual model is by no means obvious ( $\mathrm{Li}$ et al. 1996). According to Li et al (1996), the stochastic-geometric model may be more suitable than other methods because data are not available for models that depend on explicit spatial representation of pore structures. Despite the model's strength in geometric structuring and transport flow, the stochastic-geometric model would likely serve as an additional support in an all-encompassing microbial subsurface transport model, which incorporates biological and physochemical processes as demonstrated in the reaction-transport model concept (see section 4.3).

Clearly, as with any microbial transport model, there are certain gaps (see Figure 4.3 ) in information that allow for criticism in the modeling approach. According to Wu et al. (2003), calculations used in stochastic models are quite simplistic. For example, adoption of a unified flow velocity for a fluid or microorganism is clearly not indicative of what actually occurs in nature. According to Wu et al. 2003, the assumption of mean velocity is generally not valid and is only suitable for some specific regions (or zones) of the subsurface environment.

According to Wu et al. (2003), the predictions of classical theories and models may significantly deviate from actual field findings. Recently, some of these assumptions have been relaxed and stochastic models are gradually extended to more complicated cases (Wu et al, 2003). Ultimately, it is the predictive capacity of stochastic models that falls victim to the uncertainty of the subsurface environment. Despite the fact that numerical techniques have been improved drastically, they cannot yield accurate results since effective large-scale (or field-scale) parameters cannot be accurately determined (Aguiree \& Haghighi, 2003). This limitation of the standard deterministic modeling approaches, especially in the vadose zone of the soil horizon, emphasizes the use of statistical techniques that can incorporate the effects of natural variability of soil parameters (Aguiree \& Haghighi, 2003). 
Table 5 - Risk Analysis Processes and Key Elements of the Stochastic-Geometric Model

\begin{tabular}{|c|c|}
\hline $\begin{array}{c}\text { Risk Analysis } \\
\text { Process }\end{array}$ & \multicolumn{1}{c|}{ Stochastic-Geometric Model - Key elements } \\
\hline $\begin{array}{c}\text { Hazard } \\
\text { Identification }\end{array}$ & $\begin{array}{l}\text { Complexity and heterogeneity of the subsurface environment } \\
\text { accounted for unlike many other transport models. }\end{array}$ \\
\hline $\begin{array}{c}\text { Exposure } \\
\text { Assessment }\end{array}$ & $\begin{array}{l}\text { Spatial representation of pore structures key quantitative } \\
\text { variable identified in stochastic methods. }\end{array}$ \\
\hline $\begin{array}{c}\text { Hazard } \\
\text { Characterization }\end{array}$ & $\begin{array}{l}\text { Intricate modeling techniques allow for incorporation of } \\
\text { spatial heterogeneity, which has been identified by several } \\
\text { authors as the key determinant in microbial transport } \\
\text { modeling. }\end{array}$ \\
\hline $\begin{array}{l}\text { Risk } \\
\text { Characterization }\end{array}$ & $\begin{array}{l}\text { Predictive ability of the model is unknown. } \\
\text { - } \begin{array}{l}\text { More experimentation and studies are required to test the } \\
\text { validity of the model. }\end{array} \\
\text { Stochastic-Geometric model would likely serve as an } \\
\text { additional support in an all-encompassing microbial } \\
\text { subsurface transport model, which incorporates, biological } \\
\text { and physochemical processes as demonstrated in the reaction- } \\
\text { transport model concept }\end{array}$ \\
\hline
\end{tabular}

A common approach in reaction-kinetic, stochastic, and advection dispersion (see section 4.5) models is to simplify values used to describe microbial behaviour observed in the subsurface environment. For example, the die-off rate of organisms in the subsurface environment is normally represented using first-order model die-off kinetics. The first-order model appears to accurately describe the die off of bacteria under all conditions. However, the die-off coefficient is a highly variable parameter spanning several orders of magnitude for any given bacterial type (Crane \& Moore, 1985). Although not the most accurate estimate, first-order kinetic models are used regularly by researchers as they are easily accounted for and implemented into transport models. Notwithstanding, streamlining values using generalized formulas is an acceptable and widely used practice in microbiological research. Nevertheless, as the practice of generalizing such formulations is anything but accurate, such inefficiencies should be accounted for.

The stochastic-geometric model incorporates a key factor which must be accounted for in all microbial transport models: heterogeneity. Although the predictive capacity of the entire model is unknown due to a lack of testing of the model at the field 
level, it would appear that the model accounts for spatial particle variability, which is a key determinant in modeling subsurface microbial movement and determining risk. Coupled with a transport model that describes key biological, physochemical and environmental variables, the predictive capacity of the stochastic model would be improved with experimentation and laboratory research.

\subsection{Mass Balance (Advection-Dispersion) Based Transport Models}

Contaminant transport models, specifically advection-dispersion models and filtration models (see appendix 3.1) are often modified for application to microbial transport. Factors that influence microbial transport can be incorporated into equations governing these models. However, the fundamental basis of each model differs, and thus, under certain conditions, use of a particular model or another model altogether may be preferable (Maier et al., 1999).

Most models used to simulate aqueous-phase microbial transport are essentially based on the mass balance equation (often referred to as the advection-dispersion equation), which is modified by adding the reaction kinetics such as source/sink terms (Sun et al. 1999). This procedure assumes that microbes can be regarded in a manner similar to dissolved solutes, and hence, the concentration of the microorganisms can be expressed as their mass or number per unit volume of water (Sun et al. 1999).

Unmodified advection-dispersion models assume that the contaminant (microorganism) is in solution and thus has the same average velocity as the matrix solution (Maier et al., 1999). Values for average velocity and dispersion of a contaminant are generally obtained from conservative tracer tests. These values may not be appropriate for microbial transport because microbes are not dissolved but instead, suspended in the liquid medium.

Despite their widespread use, there remain several disadvantages to the strict use of advection-dispersion equations in subsurface microbial transport models. Available mathematical models of microbial transport using the advection-dispersion equation are too simple to describe the complex nature of field sites, or the natural environment. In 
most cases these models cannot reflect the non-homogeneous and anisotrophic nature of subsurface microbial systems ( $\mathrm{Li}$ et al. 1996). The current knowledge of microbial transport has not reached a stage where hydronamic parameters can be used to predict microbial transport in porous media (Germann et al., 1987). Additionally, advectiondispersion models assume the pathway of a microorganism is similar to that of a particle. This is simply not the case in nature (with the exception of viruses). The intricate mechanisms of microbial transport including behavioral characteristics and attachment methods to subsurface particulate differentiate themselves from simple particle transport.

\subsection{Model Validation}

Modeling microbial transport in the subsurface environment is relatively new to microbiological research. Since science has yet to reveal all the factors involved in the transport of microorganisms in the subsurface environment, we can only assume most microbial transport models are limited in predictive ability. According to Orekes et al. (1994), all scientific knowledge is provisional. At most, we can aspire to link a particular model to a current modeling practice elsewhere, or to justify the model by appealing to our best theories of natural processes, or to ground the model on a rich and highly constraining set of data. Although most transport models are deemed to be inconclusive, the demand for efficient and accurate models increases as the need to protect natural resources is amplified. According to Anderson and Bates (2001), the demand (for models) is increasing from policy makers and agencies where modelers are under increasing pressure to show th -ir long term predictions of microbial fate are "worthwhile" when the real context for such predictions may typically include unknown boundary conditions and lack historical data.

The greatest difficulty in producing accurate and readily accepted models lies in their validation and addressing their gaps (see figure 4.4). The inherent uncertainties of models have been widely recognized, and it is now commonly acknowledged that the term 'validation' is an unfortunate one because its root word - "valid" - implies a legitimacy that is not justified in transport models (Anderson \& Bates, 2001). Due to the complexity of the subsurface system along with the lack of experimental data (which 
account for all processes in microbial transport), the idea of validation is impractical.

Inherently, the demand for validation implies that the model will to a certain extent, be precise and ultimately strong in predictive capabilities.

Figure 4.4 - Stochastic Geometric and Reaction Kinetic Flow Models

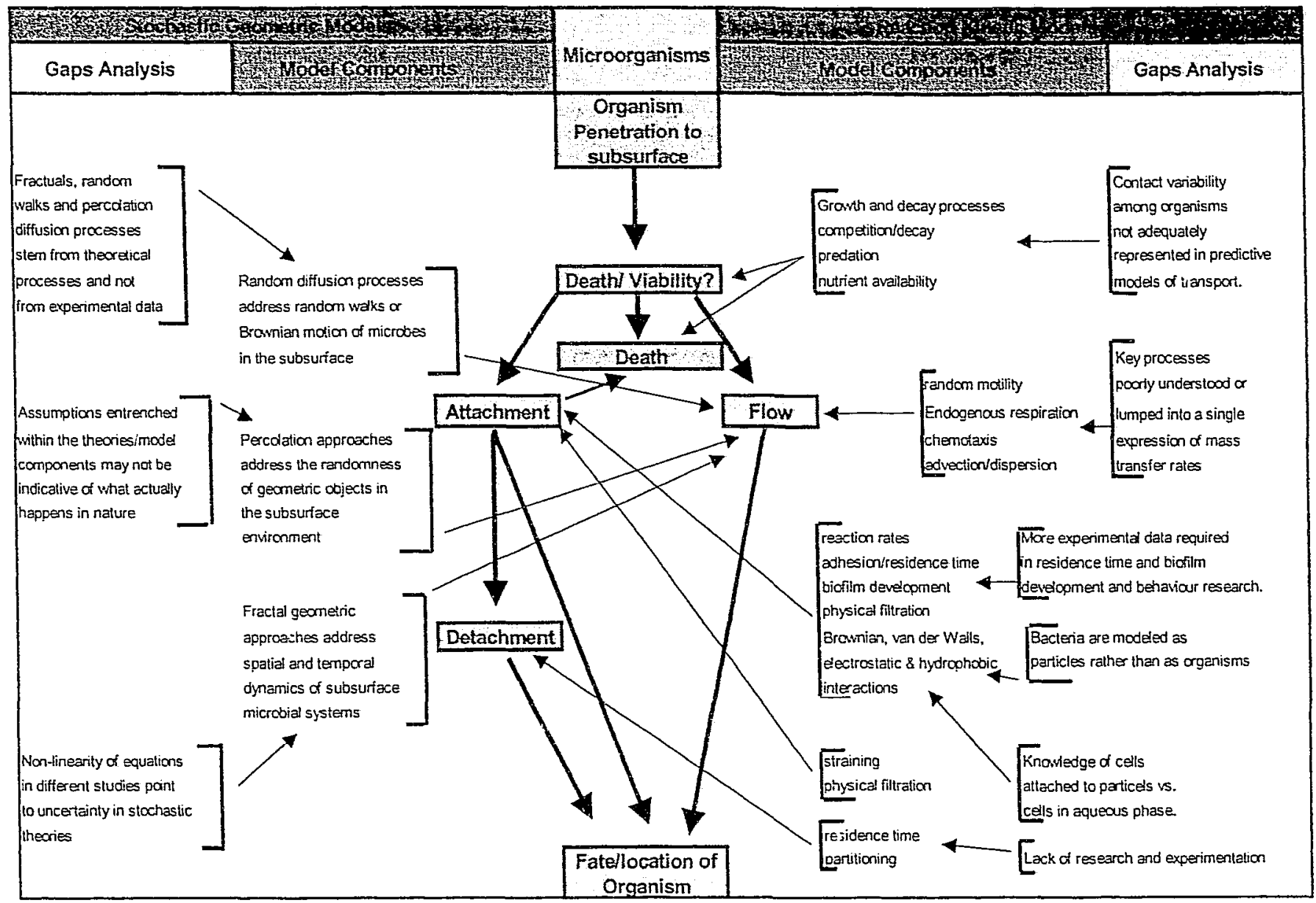

According to Sarewitz et al. (2000), much of the demand for model assessment derives from the desire to use models in a predictive manner. Furthermore, Sarawitz et al. (2000) note that a large number of models have been built in response to environmental problems - nuclear waste disposal, acid rain, water supply, groundwater contamination - which involve forecasting the behaviour of complex natural systems. However, Anderson and Bates (2001) note that predictions originating from the models are more often than not wrong. Moreover, while the number of studies that examine the predictive accuracy of model results is modest compared to the number of models that have been built, available studies are clear in their results, not enough is known about 
complex natural systems to be able to predict them accurately (Anderson \& Bates, 2001). Until more research is performed in microbiological transport science, predictive models will struggle to attain significant scientific validation.

\subsection{Discussion - The Nutrient Management Act, Subsurface Microbial Transport Modeling, and Risk Assessment and Analysis.}

The Ontario Nutrient Management Act (NMA) along with other legislation in the Province of Ontario (Ontario Water Resources Act, Safe Drinking Water Act) is a tool for the agricultural community to protect water sources from nutrient contamination whether from ground or surface water origin. The NMA does not address pathogen reductions directly nor does it endorse any type of model or risk analysis or assessment tools or techniques which will predict the fate of an organism in the subsurface environment. Analysis of both microbial subsurface transport and modeling shows that despite gaps, science has advanced significantly over the past 30 years to explain many of the relationships between pathogens and the subsurface. However, the province of Ontario has seemingly ignored the pathogen threat, instead aiming to address nutrient concens directly, and microbiological concerns indirectly. Furthermore, it is unclear why the province of Ontario has not developed pathogen control legislation.

Key factors identified both in this study and in microbial subsurface transport models that affect pathogen survival and transport are not mentioned in the NMA. The NMA does not explicitly address any of the biological, physochemical or environmental issues that have been raised in this : $ה y$. Some parts of the NMA indirectly address a number of the issues related to pathogen management and transport. They include, Part VI (land application standards), Part VII (outdoor confinement areas), Part VIII (siting and construction standards), and Part IX (sampling analysis, quality standards and land application rates). Future standards and regulations under the NMA are unlikely to address modeling or risk analysis issues as the scope of the Act does not lend itself to incorporate such processes. Rather, many of the issues in the NMA and other related legislation in Ontario point to preventative measures (restricting winter application section 48) which decrease risks associated with land application. 


\subsubsection{Challenges in Future Microbial Transport Modeling in the Subsurface Environment.}

Where a microbial transport model is applied to a subsurface environment to determine the risk of selected pathogens reaching a given point in the soil (such as ground water source), extreme caution must be taken when assessing accuracy of prediction. According to Maier et al. (1999), transport models should account for changing conditions that the microbe encounters as it migrates through the terrestrial profile. Laboratory and field studies should be conducted to verify the accuracy of the conceptual models. According to Maier et al. (1999), Corapcioglu and Haridas (1986) introduced a highly comprehensive equation designed to predict microbial movement in soils. In the study, many factors that influence microbial movement, including survival, chemical perturbations, clogging and declogging of the soil, soil moisture, $\mathrm{pH}$, soil composition, and microbial growth potential were taken into consideration. However, the complexity and expenses associated with running the experiment prevented the study from obtaining optimum results. Furthermore, although transport models can be useful tools, they can also generate predictions that are off by orders of magnitude (Maier et al., 1999). Therefore, even if all factors and variables in microbial transport are accounted for, only moderate levels of certainty in risk prediction can be assumed.

A number of transport models describe the pathway of microorganisms through the subsurface environment. The purpose of this study was to determine if microbial subsurface transport models could be safely used for pathogen management policy. The answer at this time in research is clearly no and therefore, policies based on models are not likely to be seen in the near future in Ontario because of their lack of precision and accuracy. Until more experiments are conducted and until transport modelers can develop a comprehensive model capable of incorporating all the relevant factors and variables in the subsurface environment, the effectiveness of subsurface transport models will no doubt be in question. Models should imitate reality and therefore, the level of data required to develop an effective model is contingent upon the ability of it to be valid to what actually occurs in the subsurface. According to Maier et al. (1999), increasing 
complexity in variables equates to increases in research time and expense because several experiments must be conducted in order to generate input data for numerous parameters. In cases where various parameters are not known and/or cannot be experimentally determined, estimates must be made which therefore increase the potential for error. Accordingly, it makes sense to decide on the transport model that will be applied to an environmental system before collecting data so that appropriate parameters can be measured whenever possible (Maier et al., 1999). Continuing research is required to strengthen the applicability of microbial transport models to realistic environments and to aid in risk assessment and predictive strategies.

Field and laboratory experiments demonstrate that the metabolic activity of subsurface microorganisms can create a dynamic distribution of a microbial population between aqueous and solid phases in groundwater systems (Murphy \& Ginn, 2000). Modeling studies often simplify the explicit presence of bacteria in both aqueous and attached phases, instead treating the biomass as a fixed, often uniform phase. In reality, bacteria are distributed both in the aqueous and solid phases and this distribution is dynamic in a contaminant plume (Murphy \& Ginn, 2000).

The interaction between microorganisms and their environment is unique in that they can form distinctive communities, called biofilms. An important aspect of microbial processes is the propensity of cells to adhere to and bind to a surface. The adsorbed cells produce a matrix of polysaccharide fibers binding the cells to the surface and to other cells. The structure associated with biofilms may be very different in porous media (Paulsen et al., 1997). Biofilms form an essential part of the porous media altering its microscale geometry and chemical environment. At the same time, substrates are transported from the bulk fluid to the biofilm by diffusion and advection proce:- ss and are consumed by the cells. Substrates may also be embedded within the soil matrix itself and diffuse into the bulk fluid or into the biofilm (Dillon \& Fauci, 1999).Both bacteria and viruses may inhabit biofilms, causing variable community structures and interaction. 
Despite their significance both in subsurface transport and in public health research, viral transport modeling has been ignored. Viruses are capable of surviving and traveling long distances in the subsurface environment (section 3.3.3). Recent studies carried out to support the United States Environmental Protection Agency's Ground Water Rule (EPA, 1997) have provided further quantitative evidence that confirms largescale subsurface virus transport can occur (Maxwell et al. 2003). The processes and mechanisms of viral transport, although well researched, have led to the creation (if few viral transport models. Typically, as viruses are smaller than bacterial or protozoan organisms, they are sometimes grouped together with larger organisms despite differences in surface properties and genetic make-up. According to Maxwell et al. (2003), mathematical models of virus transport in saturated porous media typically assume that viruses represent a class of submicron $(<1 \mathrm{um})$ particles. The principle processes affecting viral migration include, advection with liquid phase flow, hydrodynamic dispersion, physical or chemical attachment onto the solid phase of the porous medium, detachment of the liquid phase, as well as inactivation or die-off in either the liquid or solid phase (Maxwell et al. 2003). Based on this research, it is likely that viral modeling would likely be modeled effectively via advection dispersion-models since advection-dispersion models replicate the flow of particles in the environment.

Virus transport is usually based on commonly utilized equations for colloid filtration and inactivation in porous media and is augmented by an additional set of parametric relationships used to correlate filtration effects to aquifer permeavility (Maxwell et al. 2003). Understanding and quantifying the influence of geologic heterogeneity on the process of virus transport is important because geologic heterogeneity control processes (velocity, filtration) by the natural existence of pores, cracks, and preferred channels as well as barriers to virus movement (Maxwell et al. 2003). Observations by Powell et al. (2003) clearly suggest the influence of geologic heterogeneity on microbial transport. Therefore, in order to move forward in microbial subsurface transport modeling, viral-based models should be produced as separate entities to account for their diversity and interactions in the subsurface environment. 


\subsubsection{Uncertainty and Nutrient Management}

As this study shows, the accuracy and applicability of microbial subsurface transport models for risk assessment purposes in nutrient management venues are at best, negligible. Unlike other environments (atmospheric), the subsurface environment contains numerous factors which change the dynamic of a model for analytical risk analysis purposes. For example, in atmospheric science, researchers can accurately predict the size and shape of a smokestack plume emitted from an industrial stack along with the chemical concentration of its emissions at a select point along its path. By inputting factors into plume transport models such as wind speed, atmospheric temperature, height of stack along with various other atmospheric values, one can accurately predict the concentration within a select distance from the point of emission. However, due to microbial interaction with the subsurface, it is extremely difficult to develop a simple model capable of producing such consistency in subsurface microbial science. It becomes almost inconceivable to create a single microbial transport model that can predict the location of a single microbe in the subsurface environment.

Enhancing the existing control of pathogens in the environment can be accomplished by addressing the following pathogen reduction strategies in agricultural settings: Increasing practices which encourage animal health to reduce pathogen shedding strategies and contamination of young herd.

(ii) Utilizing methods of nutrient pre-treatment.

(iii) Implementing 'worst-case' policies in setback distances to increase distances to maximum levels so that risk of microbial contamination is reduced to acceptable degrees.

So-called 'beginning of the pipe' solutions to reduce microbial contamination potential are required for source protection and nutrient management. Consequently, risk reduction is achieved and subsurface pathway models and risk analyses become less significant. Why 'beginning of the pipe' processes have yet to be implemented into provincial legislation is unclear. However, it is hypothesized that many of the processes 
such as composting and facility development have high infrastructure costs and therefore, such processes would be financially unattainable for many agricultural operations.

\subsubsection{HACCP, Risk Analysis, and Subsurface Microbial Transport Technology} The Hazard Analysis Critical Control Point (HACCP) system is a risk control model capable of managing risks through the monitoring of critical points along the process pathway. A HACCP-based approach has been quite effective in the food industry. Consequently, subsurface transport mechanisms and models may utilize some experimental and risk-based mechanisms contained in the HACCP system. According to Hoornstra et al. (2001), most HACCP systems utilize a qualitative-based approach when determining critical control points (CCPs) in the hazard analysis process. An important aspect of the HACCP system is the specification of criteria (setting of critical control limits) to ensure that the activities at a specified critical control point are under control (Notermans et al. 1994). There are seven steps which serve as the foundation for a HACCP system;

1. Conduct a hazard analysis

2. Determine the CCPS

3. Establish critical control limits

4. Establish CCP monitoring procedures

5. Establish corrective actions

6. Establish effective record keeping procedures

7. Establish verification procedures

(Sparling et al. 2001).

Test results for the food industry are determined in controlled laboratory settings in order to mimic food preparation settings. This results in a poor underpinning for control measures. If controlled laboratory experiments are used to test activity in an unstable environment where activity is inconsistent (the vadose layer of the soil), testing may be found to be impractical to produce realistic settings. Laboratory-based studies are in principle more accurate and exact experiments. According to Hoomstra et al. (2001), the result of the 'hazard analysis' aspect of the HACCP system is the 
identification of control measures that are essential to (i) prevent contamination, (ii) prevent unacceptable increase of contaminants and (iii) reduce contaminants to acceptable levels. Such control measur as, while applicable in controlled settings, more often than not are not applicable in environments where many factors affecting microbial transport and viability can change. Although several studies of subsurface transport mechanisms have been performed, it is the in-situ based results which more often than not lead to inconsistent findings, as even the slightest changes in experimental method can skew results significantly.

A critical control based system (HACCP) does not provide a quantitative estimation of risk. The HACCP model was not designed to be a predictive model for microbial fate nor was it designed to determine the extent of contamination in a select environment. Rather, it is a hazard-based system which attempts to mitigate risks by controlling the factors which contribute to overall risk within the entire system. HACCP is a control point model capable of recognizing critical control points and achieving critical values at those points. While it is clear that there are several unknowns in the subsurface environment and in modeling the transport of microorganisms in it, the risks that contribute to pathogen loading and contamination are known to the agricultural industry. Therefore, in order to implement a successful critical control point system in the agricultural sector (specifically those sectors dealing with animal wastes), the industry must be seen more like a system of processes (as in the food industry) which are consistent throughout the entire nutrient management and agricultural industry.

Unlike the food industry, agricultural operations do not take place in a closed environment. Food production facilities are controlled environments where pathogen loads will likely fall within predictive ranges as testing (for pathogen loads) of one product to the next will likely yield similar results. 'Outside' factors such as environmental variables rarely, if ever, affect the production and HACCP process. If unforeseen occurrences take place, critical controls may be reassessed or reconfigured to conform to standards set at the select point in the production process. However, in the 
real environment, conditions consistently change and are unpredictable depending on global weather patterns, flooding events, and the like.

In order to develop a critical control strategy for agricultural operations (see Figure 4.5), it is essential that nutrient management operations are divided into manageable segments or points of control. The goal of a nutrient management critical control point system would be to produce a logical pathogen reduction strategy capable of reducing risks to a predetermined level where risks become so small that the likelihood of source water contamination becomes negligible. In order for hazards to be controlled, they must first be understood. Processes responsible for removal of microorganisms from nutrients are both complex and diverse. Pathogen loads range in value depending on several factors including animal species, animal health and diet, animal behaviour and nutrient storage and handling procedures. However, levels can be controlled simply by implementing primary control points ('beginning of pipe' controls) that aim to reduce pathogen load prior to land application.

Figure 4.5 - Critical controls in a nutrient management perspective

\begin{tabular}{|c|c|c|c|c|c|c|}
\hline \multirow[t]{5}{*}{ Processes } & $\begin{array}{l}\text { (1) Nutrient } \\
\text { Collection }\end{array}$ & & $\begin{array}{l}\text { (2) Storage I } \\
\text { Treatment }\end{array}$ & & (3) Application & \\
\hline & $\begin{array}{l}\text { Critical } \\
\text { control }\end{array}$ & Description & $\begin{array}{c}\text { Critical } \\
\text { control }\end{array}$ & Description & 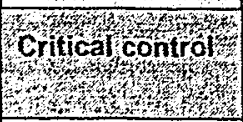 & Description \\
\hline & Biosecurity & & $\begin{array}{l}\text { Treatment } \\
\text { Methods }\end{array}$ & & Time of Application & \\
\hline & & \begin{tabular}{|l|} 
- decontaminate feed \\
- separate animals \\
during feeding
\end{tabular} & & \multirow[t]{2}{*}{\begin{tabular}{|l} 
- composting \\
- anaerobic digestion \\
-nutrient analysis \\
\end{tabular}} & & \multirow[t]{2}{*}{$\begin{array}{l}\text { - avoid winter application } \\
\text { - do not apply before } \\
\text { heavy rain fall } \\
\end{array}$} \\
\hline & & $\begin{array}{l}\text { - restrict immature } \\
\text { animals from grazing } \\
\text { nutrient applied land } \\
\text { - quarentine ill from } \\
\text { well }\end{array}$ & & & & \\
\hline
\end{tabular}

Important processes in the nutrient management pathway include (among others) (i) nutrient collection, (ii) storage and treatment processes and (iii) application methods (see Figure 4.5). In order to observe an overall reduction in pathogen loading at each step in the process, critical control points must be monitored and controlled where relevant. A number of critical controls are required for each process/method. For example, nutrient collection would include animal health and location of storage collection. Figure 4.5 
indicates three critical controls for each main process along the nutrient management pathway.

More science is required to help quantify critical control point processes so that processes and methods, regardless of location and operation are consistent. For example, certain animal wastes are higher in microbiological loads. However, if treatments such as composting were implemented, microbiological loading rates would be insignificant because composting, if performed correctly, will achieve a temperature that essentially kills a majority of organisms.

\subsection{Conclusion}

Biological, physochemical, and environmental factors govern the microbial movement of microorganisms through the subsurface environment. While scientific research has shown a number of relationships between microbes and elements in the subsurface environment, microbial transport models have yet to be established as reliable predictions of pathogen movement. As microbial transport models indicate, taking a conservative approach in modeling relevant parameters to subsurface microbial transport is key. Both reaction and stochastic geometric transport models address several of the issues that are relevant to microbial transport including biological and physochemical processes. It is the heterogeneity and unpredictability of variables in the subsurface environment that leads to the volatility of many transport models.

In the nutrient management forum, one must develop a model which best encompasses the main factors involved in transport and abatement. Until research demonstrates consistency and until sound scientific modeling principles are employed, source water protection initiatives must rely on alternative methods of reducing pathogenic and contamination risk. 'Beginning of the pipe' solutions to reduce microbial contamination should be entertained as alternative methods of reducing risk and protecting human health. 


\section{Chapter Five: Alternative Pathogen Management Strategy}

Approaches to source water protection are deeply rooted in risk analysis and risk assessment initiatives. Chemicals and microorganisms that originate from animal wastes are better controlled where active participation by key stakeholders takes place and where public policy is rooted in sound scientific knowledge, engineering principles, and management strategies.

Effective nutrient management should be governed by scientific principles founded in microbiological science and subsurface microbial transport mechanisms. Although scientific research has shed considerable light on nutrient management and subsurface transport, the literature has yielded inconsistent results. Significant gaps in nutrient research point to unreliable results and a lack of predictive capacity by proposed microbial subsurface transport models. Therefore, until valid and consistent results are observed, models can at best serve as standards for further research in the field of microbial transport in the subsurface environment.

Perhaps the only way to develop a management plan for nutrient management systems is to account for and manage the processes that precede the introduction of pathogenic microorganisms into the subsurface environment. By decreasing the microbiological load in the nutrient mass, one significantly reduces the chance that organisms will contaminate a potable water source. Ultimately, the goal of maintaining public health must be a priority for any environmental management strategy.

Generalized systems in environmental management include Hazard Analysis Critical Control Point (HACCP) and ISO 14001. These strategies, albeit efficient in several industries and organizations, are only as effective as the parameters and critical controls which govern them. It is the identification of critical controls in the management process which present the most difficulty to those responsible for their development and main ${ }^{`}$ nance. Setting quantitative parameters for environmental control is a complex task considering the variability in the subsurface environment and the biological matter 
contained within it. Furthermore, a lack

Earch focusing on the processes that

govern microbial abatement in the subsurface environment prevent specific parameters to be set for critical controls. Rather, general objectives, including operational, procedural, and public health strategies should be used in an effective nutrient management strategy to reduce risk of microbial contamination in the subsurface environment.

\subsection{Critical Factors in a Pathogen Management Strategy}

Like many management strategies in several industries and operations in Canada, a nutrient management policy requires a multidisciplinary approach in several areas of scientific research and management methods. The difficulty in developing a nutrient management approach lies in determining which scientific and management research is relevant and can be effectively applied to agricultural policy. According to Sims et al. (1999), agencies responsible for water quality protection have sought to integrate (nutrient management) rwsearch into environmental policy. However, they have often been frustrated by the fragmented and sometimes-contradictory nature of the information provided to them.

Due to the variability of the subsurface environment and the diversity of microorganisms which inhabit it, an all-encompassing nutrient management strategy should ensure that risks from all potential threats to source waters are accounted for and controlled. The strategy should satisfy either one or both of the following objectives;

(i) The strategy should have some microbial subsurface predictive capacity

(ii) The strategy should significantly reduce the risk of pathogens from reaching source waters by drastically eradicating organisms from nutrient stockpiles.

Since a microbial risk prediction strategy is unlikely, the focus of future management initiatives should center on pre-application processes to eliminate microorganisms before they are given the chance to be transported. Therefore, all risks and hazards that supports the shedding, growth, and stability of organisms in nutrient sources should be accounted 
for and controlled. Hazards and risks are identified by observing and studying the processes which contribute to potentially hazardous conditions.

\subsubsection{Operational and Procedural Objectives}

Each agricultural operation is essentially similar in several components of daily and seasonal operation. Agricultural operations are cyclical. That is, significant processes are repeated if crop yield or animal growth is sustained. The significant mechanisms of procedure in livestock operations, animal storage, animal grazing, nutrient collection, nutrient storage and nutrient distribution, more than likely occur in most agricultural operations which house livestock and/or utilize animal wastes on their lands. As seasonal temperature and atmospheric conditions vary, so do significant procedures and processes. These conditions and processes must be accounted for in any management process, especially in Ontario where atmospheric conditions play a crucial role in all agricultural operations.

The concept of constructing a flow diagram to document key procedures is nothing new to management systems. Flow diagrams would encourage consistency and habitual tendencies and behaviours amongst members of agricultural operations. For example, the food industry has utilized the HACCP approach (see section 5.3) along with a critical control point methodology in order to standardize its systems. HACCP ases a flow diagram structure so that critical control points are identified visually and objectives are met. Like the agricultural industry, operations in the food industry are both complex and diverse. However, the HACCP system has succeeded in the food industry and become standard for food safety programming and accreditation amongst most large food production facilities. As processes in the food industry are consistently repeated to produce a consistent product, the HACCP system works well to identify hazards in each step in the operation. The effectiveness of the HACCP system is further enhanced in most food settings considering the majority of food operations are performed under controlled conditions. Such conditions allow operators of HACCP systems to dictate local conditions of temperature and water availability which are key to the reproduction of all microorganisms and multi-cellular biota. 
The difficulty in implementing structural management systems (such as HACCP) in exterior environments (such as in farming operations) is that conditions of the environment are contingent upon variable atmospheric events. However, as long as preconditions for important processes are accounted for (the process of treating soils with nutrients), it becomes the responsibility of the operator of the management system to determine if conditions are appropriate for action.

\subsubsection{Public Health Objectives}

The history of nutrient management in Ontario is rooted deeply in maintaining public health initiatives and providing potable water sources to municipalities and their residents. The link between effective nutrient management practices and potable water sources was discovered long before the inception of the Ontario Nutrient Management Act. Provincial policies such as The Waste Management Act (1970) and the Agricultural Code of Practice (1973) included nutrient management and public health strategies known to reduce risk of microbial contamination to fields and water sources. However, despite efforts from both the agricultural community and policy makers in provincial and municipal governments, the incidences of ground and surface water contamination continued to occur. In order to develop an effective nutrient management strategy, local public health departments must play a prominent role in strategy development. The strategy should embrace the changing Ontario landscape of overlapping urban and rural environments.

Rather than focusing on reactive circumstances where a microorganism or groups of microorganisms have already entered the subsurface environment, researchers and policy developers should look to preventative mechanisms of microbial control. Hence, microbial risks to source waters may be significantly reduced if the nutrient applied to land is significantly reduced in pathogens or further, pathogen free. A 'multibarrier' approach is required which not only addresses the issues of microbial transport mechanisms, but also looks at how microorganisms can be eliminated from nutrient bearing materials. Pathogen viability must be considered in pathogen 
management strategies because essentially, non-viability of microbes eliminates their hazards along with the risks they pose to human and animal health.

\subsubsection{Risk Reduction Strategies}

In order to control risks at the nutrient level, it is essential that an analysis of all risks be conducted for all agricultural operations. In the Nutrient Management Act, risks are accounted for in nutrient management plans and nutrient management strategies. However, as reported by Stiefelmeyer (2003) not all aspects of risk are accounted for in plans and strategies such as pathogen load reduction, animal health and biosecurity. It is clear that the significance and degree of risk may range from one farm to the next, however, the basic farming processes, collection of animal nutrients, storage of animal nutrients, and treatment of animal nutrients and spreading of animal nutrients remain the same for most operations which harbour livestock. As discussed in Chapter 3, research which focuses on the abatement and transport of matter, specifically microorganisms, typically isolates single variables in experiments in order to measure the effect of the variable on overall microbial movement. However, it is ineffective to simply examine and focus on a single factor and analyze its effect on the entire system. Rather, we must look at the subsurface matrix as a myriad of factors that interact with one another, and act to impede, suspend or encourage movement of a particle in several possible directions. Similarly, as it is difficult to predict the pathway and fate of a microorganism in the subsurface environment, it is essential that other methods of risk reduction be implemented.

\subsection{Management Strategies}

Management systems work within a structure of repetitiveness where actions are measured, and then measured again to ensure that they are consistently working within the confines of what the system demands. An effective management strategy not only encourages consistency and habitual tendencies, but it also allows the organization to continually improve to both meet and exceed legislative requirements and progressively build the strategy to advance its efficiency and effectiveness. 
Developing a nutrient management strategy for agricultural operations is a strategic process involving several disciplines and aspects of scientific, economic, political and management components. One of the driving forces for management systems in today's economy is consumer demand. The demand is forcing organizations to implement management systems for several reasons including organizational due diligence and product safety. For example, an organization wishing to sell a certain crop to a food production plant may be required in future to become either HACCP or ISO 14001 certified as the certifications qualify that the organization has met and/or exceed what is required by local governing legislation, not to mention the demands of the purchaser.

To date, no environmental management strategy specifically pertaining to pathogen management has been developed. Several wide-ranging management systems ailow users to integrate and measure key processes of the system in order to adequately assess predetermined objectives. The following section discusses two key management systems used in environmental systems along with their applicability to nutrient management systems.

\subsection{HACCP}

As discussed in section 4.7, the HACCP system is a critical control model which is capable of managing risks through the monitoring of critical points along a process pathway. HACCP was crignally defined as "a systematic approach to the identification and assessment of the microbiological hazards and risks associated with the manufacturing, distribution and use of a particular foodstuff, and the definition of means for their control" (Noordhuizen \& Frankena, 1999). Implemented for the most part in the food industry, HACCP could potentially be used in the agricultural industry to control risks located both above and below the earth's surface. According to Noordhuizen and Frankena (1999), HACCP seems eminently suitable for identification and control of animal health risks. HACCP can be farm-specific, take a bottom-up approach, enable farmers to demonstrate herd-health status, is simple in its design, requires low labour 
input and little documentation, and proves a functional link with other government programs (Noordhuizen \& Frankena, 1999).

The HACCP system functions by identifying critical control points (CCPs). According to Noordhuizen and Frankena (1999), a CCP is a process step, condition or measuring point which is important in the elimination or reduction of a hazard to an acceptable level. A control point is deemed 'critical' if it is associated with the (hazard) under study, if measuring can be conducted, and if control measures can be taken which lead to the elimination or reduction of the risk (Noordhuizen \& Frankena, 1999). The effectiveness of CCPs lies in their ability to be found in a wide variety of processes, regardless of differences in procedures used from one agricultural operation to the next. CCPs will differ between farms to a certain extent because farm conditions and structures vary. For each $\mathrm{CCP}$, target levels and tolerances must be specified: for example, cleaning water temperatures have a set point of $80^{\circ}$ Celsius with a tolerance of $3^{\circ}$ Celsius, and cows newly introduced into the herd should be free from specified pathogens (tolerance zero level) (Noordhuizen \& Frankena, 1999). All the CCPS within the farm are interconnected through on-farm monitoring and surveillance system which ideally would be able to detect loss of process control and provide the farmer with information relevant to taking corrective actions. The number of CCPs should be limited in order to keep the monitoring and surveillance system manageable (Noordhuizen \& Frankena, 1999). The CCPs should be consistently monitored (via operational review) in order to determine if risks are accounted for and managed. According to Noordhuizen and Frankena (1999), a CCP has to meet certain requirements to be approved;

1. There should be a casual relationship between CCP and hazard

2. It must be measurable

3. There should be tolerance levels and targets defined for each $\mathrm{CCP}$

4. Measures should be available which, in the case of deviant CCP values, will lead to recovery of control, and

5. They should be minimal in number and interconnected in an on-farm monitoring network 
Companies employing HACCP in their organizations are said to be 'HACCP recognized' or 'HACCP approved'. In Canada, the Canadian Food and Inspection Agency (CFIA) is responsible for inspecting HACCP recognized companies to ensure compliance with the HACCP guidelines (Sparling et al. 2001). Companies implementing HACCP will benefit in several ways. According to Sparling et al. (2001), the following outlines the most significant benefits of HACCP recognition:

1. Meeting regulatory requirements for domestic and export markets

2. Meet customer demands for food safety specifications

3. Lower risk of product recall/potential liability

4. Lower operating costs

5. Provide management with better information for decision making

The HACCP system is essentially a method of process control. Those wishing to voluntarily implement the HACCP system in their agricultural operation are agreeing with the fact that the processes within their system will be strictly monitored and controlled. Ideally, if the HACCP system was implemented as a model for agricultural operations, a template would be used where the operation would be categorized based on identified risks within the operation. For example, if an agricultural operation was involved in high volume animal waste collection, had shallow subsurface water tables and was located on a water reservoir which served a large population, the operation would be deemed 'high risk'. A 'high risk' operation would require more control and increased inspection frequency from internal and external auditing sources. Similarly, the Nutrient Management Act bases its risk categorization on the number of animal units on the agricultural operation. Although this addresses the concern of potential nutrient loading, it does not address threats of soil composition, environmental events and subsurface make-up.

\subsubsection{HACCP and Nutrient Management Systems - Advantages}

The inherent advantage in utilizing the HACCP system in agricultural operations is that it limits the ability of the operation to become inconsistent in its processes and approach. Cyclical monitoring and testing coerces operators to be consistent so that risks 
or critical controls are managed. Otherwise, if the system is neglected, products or services are threatened and potentially hazardous occurrences may transpire.

According to Sparling et al. (2001), HACCP is most successful when applied to companies and process involved in the food supply chain from farm inputs to the consumer. This includes the entire process of 'farm-to-table' production. According to Sparling et al. (2001), on the farm, processes include monitoring inputs, maintaining sanitation procedures, and practicing good animal health management. At the processing level, the focus is on contamination prevention during processing, transportation, storage, and distribution. In retail, restaurant and food service organizations emphasis is on proper sanitation, refrigeration and storage, handling and preparation procedures. Although HACCP operates primarily at the processing level, there are numerous initiatives designed to prepare farmers for eventual HACCP implementation (Sparling et al. 2001). The HACCP concept is well suited for quality control at the farm level, involving risk identification and risk management. The on-farm monitoring and surveillance system of critical control points in the animal production process is the most important tool in this procedure (Noordhuizen \& Frankena, 1999).

\subsubsection{HACCP and Nutrient Management Systems - Disadvantages}

The HACCP system is most successful when applied to operations which are systematic and where critical controls can be identified. However, one of the largest difficulties in implementing a HACCP system in an agricultural operation would be the ability of an operator to identify and measure critical control points quantitatively. As discussed in Chapters Three and Four, research has yet to provide consistent and reliable results for all aspects and processes of microbial subsurface transport. For example, optimal ranges of temperature, $\mathrm{pH}$, soil composition, and moisture level for microbial transport have been studied, but have not necessarily been established. Furthermore, no common consensus has been agreed upon to identify what constitutes the optimal environmental conditions for microbial survival or transport. Due to the diversity of microorganisms and their transport mechanisms under variable conditions, it is difficult to establish appropriate 'ranges' to which critical controls could be measured by under different conditions. 
The complexity of critical controls in HACCP lies not in the process of measurement, but in establishing appropriate ranges for control in order to reduce the risk of an organism reaching a water reservoir, contaminating a potable water source, and threatening human health. Until further advances are made in understanding microbial subsurface transport, it would be difficult to create a comprehensive CCP system which incorporates all aspects of best management practices and protects public health.

Economic cost of applying the HACCP system is also a significant consideration for program implementation. According to Sparling et al. (2001), cost for HACCP implementation depends on the product and processes involved. For a single process in a small (agricultural) operation, the cost would be approximately $\$ 15,000$. To develop a HACCP plan and become HACCP-recognized typically takes from 6-9 months (Sparling et al. 2001). Essentially, it is the operation and the extent of program complexity that will invariably determine the overall cost of implementing HACCP, both economically and environmentally.

\subsection{ISO 14001 - Environmental Management}

The ISO standard is synonymous with successful management systems around the world in several industries and organizations. Following in the tradition of its predecessors, including ISO 9000, the ISO 14000 series of organizational systems is the complete program for environmental management. There are several different standards in the ISO 14000 family, but ISO 14001 is the cornerstone. ISO 14001 requires that organizations develop an environmental policy, and their Environmental Management System (EMS) (Sparling et al. 2001). The ISO 14001 system is responsible for the management of environmental hazards and critical controls located within the organization and apply to individual sites and organizations. According to Sparling et al. (2001), ISO 14000 sets no numerical limits for environmental management. Instead, it works within the existing environmental policy framework to ensure that a site or operation meets or exceeds all existing government regulations and practices 'continuous improvement'. It also identifies environmental issues and risks that are not regulated and 
develops policies and management procedures to deal with them (Sparling et al. 2001). Although it was not intended to be an environmental management system, the Nutrient Management Act (NMA) incorporates many of the components consistent in ISO 14001 within its legislation and protocols. Similarly, ISO 14001 requires similar participation from key stakeholders in order to promote effective environmental management through a systematic approach.

Key to all management systems in the ISO standard is the requirement for 'plando-check-act' activities which requires the organization consistently monitor components of their management system. The ISO 14001 system requires that the organization consider the following criteria for EMS implementation including;

1. Overview and Pclicy - requires a single policy be written for a specific environmental purpose

2. Planning - involves identifying critical controls, legal requirements and public participation

3. Implementation - where training and operational control of critical controls takes place

4. Measurement and Corrective Action - Includes monitoring and measurement activities and auditing procedures and;

5. Management Review - includes internal review of the system

According to Sparling et al. (2001), ISO 14000 is a global environmental management initiative of the ISO series and operates similarly to ISO 9000. Its objective is the creation of a voluntary agreement on EMS and practices on a worldwide basis. Certification is an instrument for increasing corporate accountability without government interference. Business must develop and meet environmental goals, as well as consider the impact the business has on the environment (Sparling et al. 2001). ISO 14001 is a self-governing system which requires that all hazards and controls (which could potentially affect the environment) be accounted for. ISO 14000 standards are meant to be a complement to existing laws and legislation, not a replacement. It is a voluntary standard, but, as noted by Sparling et al. (2001), many organizations will require 
certification in the future, if they wish to do business in the international market place. The ISO 14001 template is currently being implemented in the United States in Orange County, California. The system is being used to manage the land application of biosolids on municipal and agricultural lands.

\subsubsection{ISO 14001 and Nutrient Management Systems - Advantages}

Both voluntary systems, HACCP and ISO 14001 take a generalized environmental management system approach so that they can be applied specifically to several applications in industries where environmental hazards exist. The following points, according to Sparling et al. (2001) outline the most significant benefits that proponents claim can be obtained from the ISO 14000 certification. They include;

1. Better understanding of environmental costs

2. Motivate organizations to be aware of environmental legislation and problems

3. Not too costly, as many organizations can adjust current environmental practices to satisfy the ISO 14000 requirements

4. International acceptance and recognition trade marketing tool

5. Quicker response to environmental problems and occurrences

6. Process documentation and monitoring prevents problems

7. Fewer number of inspections by government

8. Self-regulation (proactive) to prevent government from interfering

9. Meeting customer demands and expectations for environmental stewardship

The effectiveness of the system is contingent upon its structure. Just because the system complies with the legislation does not mean that it will prevent hazardous events. Rather, the system engages current knowledge pertaining to the hazard and implements it. Then, the system should be monitored to ensure that critical controls are maintained.

\subsubsection{ISO 14001 and Nutrient Management Systems - Disadvantages}

Taking a proactive and globally consistent approach to environmental management would reduce the need for government intervention while at the same time reducing an organization's environmental risk exposure. The 14001 system is complex, potentially costly and requires participation from several key stakeholders in the 
community. Proponents of the management system claim that ISO 14001, similar to HACCP, would likely reduce hazards due to the plan-do-check-act requirement in the system as it forces operators of the systems to be accountable for their actions. However, the system is only as effective as the components which govern it (legislative requirements and scientific research). Therefore, without progressive legislation and research to support the reduction prohibition of environmental hazards, the management system cannot be expected to reduce hazards effectively

\subsection{The Alternative Nutrient Management Strategy}

Being increasingly viewed under the political and public microscope, agricultural operators require systematic approaches which stress habitual and consistent best management practices at the field level. The overall goal of such a strategy would be to mitigate or control the microbial contamination risk from manure applied to agricultural lands. A harmonization of management approaches and scientific data is required in order to bring together all aspects of microbial transport and risk assessment objectives into a single management system which supports due diligence practices.

The creation and implementation of the 'ideal' nutrient management strategy should include aspects of human, environmental, economical and scientific elements. If even one of the elements is ignored, the system may fail. According to Sims et al. (1999), the most common reason given for the failure to adopt practices aimed at reducing non-point source pollution is that they are not economically viable. Other reasons include:

(i) The cause of the environmental problem has not been conclusively identified by research or is not well understood by policy makers. Hence, there is reluctance to adopt practices that may not be effective in reducing the impacts of the nutrients

(ii) There is disagreement of the practicality of the solution

(iii) The infrastructure needed for the widespread adoption of a practice is not in place and therefore cannot be implemented for use.

(iv) The solution may have other environmental effects that are difficult to predict 
(Sims et al. (1999)).

The practice of reducing microbial risks is currently used to some degree both in the Nutrient Management Act and its protocols. However, there is a lack of any evidence of scientific data which informs requirements in the Act, regulations, or protocols which would indicate to what degree overall microbial risks are reduced. In the case of nutrient management, the concept of risk is calculated by the probability of a microorganism (bacteria, viruses, protozoa) reaching a select point in the subsurface environment (an aquifer) multiplied by the magnitude of a contamination event occurring (adverse health effects to humans and to animals who might consume contaminated water).

Enhancing the existing level of control of pathogens in the environment can be accomplished by addressing the following strategies in agricultural settings:

(i) Increase practices that discourage animal access to waterways and practicing effective animal health care so as to reduce pathogen shedding events and the microbial cross-contamination of young herd.

(ii) Utilize methods of nutrient pre-treatment so as to reduce microbial loads in animal nutrient sources.

(iii) Standardize manure application methods for variable environments.

'Beginning of the pipe' solutions to reduce microbial contamination potential should be implemented in source water protection and pathogen management legislation. Consequently, risk reduction is observed and therefore, the significance of relying upon the accuracy of subsurface pathway models and risk analyses projections becomes less significant. Cost and benefits should also play a role in any pathogen management strategy in order that all agricultural operations would be willing to participate in such a plan and reap rewards from using it. Overall, the ideal pathogen management system should satisfy the following criteria (in no particular order);

(i) The system should be cost effective for all agricultural operations

(ii) It should be consistent with reliable and consistent scientific literature

(iii) It should be consistent with public health initiatives and legislation 
(iv) It should reduce overall risk of source water contamination by both microbial and chemical elements

(v) The system should be practical, concise and be easily implemented

The HACCP satisfies the requirements given in the list above. The difficulty in implementing a HACCP system in nutrient management systems is that critical controls points (the main components of any HACCP system) cannot be determined for several controls at this time for many risk-based analyses and calculations. For example, what is the range of pathogen loadings permitted in nutrient piles prior to treating land with nutrients? Ranges of values are required for critical control points in order that critical values are met to control potential hazards.

Assuming that at some point, research provides accurate range values for optimal environments for microbial abatement and transport, it is assumed that one can better estimate the risk that a microorganism will reach source waters. For example, the food industry has been quite successful in using critical control points to reduce food borne illness. However, unlike the lack of research observed in nutrient manageinent studies, the food industry has precise and consistent values for control of food-borne pathogens. For example, it is well understood that the Escherichia coli bacterium is destroyed where it is exposed to a temperature of $76^{\circ}$ Celsius. Therefore, where Escherichia coli is a concern in a food product (in ground beef), a critical control of cooking the product to a temperature of $76^{\circ}$ Celsius is implemented within the system. Similarly, if implemented at the farm level, critical controls would be able to identify those conditions in the field which support transport (and abatement) of microorganisms and restrict the application of animal wastes (given pre-treatment took place) until optimal environmental conditions $(\mathrm{pH}$, temperature, water availability, etc.) permit placement to fields.

If legislation or a systematic approach to managing nutrients is found to be ineffective in future nutrient management efforts, drastic and likely costly economic solutions may have to be implemented. For example, nutrient treatment methods (such as composting) have been shown to be effective methods for reducing microbial populations 
in animal wastes. Microbial treatment methods such as composting are not necessarily difficult procedures to maintain, but require stable environmental conditions and facilities to host composting processes. The advantage of using microbial treatment methods is simple. If they are used correctly, they, for all intents and purposes reduce microbial loads and risk to subsurface aquifers as pathogenic microorganisms are either reduced significantly in magnitude or are eliminated.

Solutions are required which do not require in depth scientific knowledge but rather are consistent within a process and are habitual. Ultimately, proactive, rather than reactive methods of nutrient management strategies should be implemented in any future stratagem. Reactive measures are generally not considered to be effective political policy as they do little to protect the public. According to Sims et al. (1999), developing environmental policies that can sustain agricultural productivity in such a changing (agricultural) climate will require a collaborative approach between the scientific community and a consortium of farmers, agribusiness, provincial and federal advisory and regulatory agencies and public interest/environmental groups. Therefore, even if all critical controls are not identified, it still remains important that management systems be used to monitor and change the hazards which can be controlled.

\subsection{Conclusions}

Since all aspects of microbial abatement and transport through the soil have yet to be conclusively identified, it is impossible to make risk predictions based on microbial location in the subsurface environment. Therefore, alternative methods of nutrient management should be engaged which specifically look at 'beginning of the pipe' processes of microbial control. Hazard control systems, including Hazard Analysis Critical Control Point (HACCP) and ISO 14001 could potentially be effective at managing diverse and complex systems such as agricultural systems dealing with animal waste nutrients. The systems rely on strict parameters for identifying critical controls which require monitoring and testing. Until more specific parameters for optimal subsurface environmental conditions are acknowledged, adequate critical controls cannot 
be accurately identified. Therefore, alternative methods for protecting source waters require additional research.

Researchers have identified gaps in subsurface microbial research and transport models. Despite these gaps, research should continue so that studies continue to strive to identify the mechanisms of microbial subsurface transport. Objectives for an optimal nutrient management system include cost effectiveness of the system, the incorporation of consistent and reliable scientific data, ensuring consistency with public health initiatives and legislation along with reducing the overall risk of source water contamination both by microbial and chemical constituents. The management system should embrace several facets of community and environmental objectives including public health initiatives. Ultimately, it is the protection of public health interests which is key to all environmental programs in the public sector. 


\section{Chapter Six: Conclusions and Recommendations}

\subsection{Conclusion}

As the distance between urban and rural communities diminishes, practices and policies for nutrient and pathogen management control will become especially important where well-water and subsurface water sources are used for public consumption. Generally, it is assumed that nutrient management policies in Ontario use current scientific knowledge to protect against transport of nutrients along with pathogenic organisms to source waters. However, many of the nutrient management initiatives of past and present have focused less on the protection of public health, a smaller amount on microbial scientific research, and more on controlling nuisances stemming from agricultural operations. Research of both previous legislation and current subsurface transport studies requires one to question why the province of Ontario has not addressed pathogen management directly as opposed to indirect methods such as nutrient management? Furthermore, if the province of Ontario is indeed attempting to control pathogens by virtue of nutrient control, have they utilized scientific research to support their requirements?

While scientific studies have shown a number of relationships between microbes and the subsurface environment, risk analysis and predictive capacities of microbial subsurface transport models are at best unreliable. Despite this, a progression in knowledge of subsurface research is observed. Several relationships between microbial survival and transport have been correlated with environmental conditions. Through such studies, it is observed that microorganisms are in fact, quite resilient in several environments. Until sound scientific modeling principles are employed, source water protection initiatives must rely on other methods of reducing pathogenic contamination risks. So-called 'beginning of the pipe" or preventative 'critical control' solutions to reduce microbial contamination should be entertained as alternative methods of reducing risk from pathogens and protecting human health. 
In this study, it was hypothesized that based on current microbial subsurface transport research, nutrient management legislation in Ontario does not sufficiently protect ground water sources from pathogens. Although the hypothesis was not conclusively proven (nor was it discredited), findings point to the continuing need for further research in pathogen abatement and nutrient management research which specifically identifies the optimal conditions for abatement and transport of microorganisms through the subsurface environment. Such studies would support the implementation of a critical control based system which recognizes and controls for hazards prior to the treatment to land with nutrients. Therefore, there should be an ongoing effort to continue to identify the mechanisms of subsurface microbial abatement and transport so that critical factors to transport can be identified and later controlled.

\subsection{Recommendations}

1. Enhance the use of pre-treatment options in agricultural operations. Pre-treatment options, or 'beginning of the pipe' solutions can significantly reduce or eliminate pathogenic organisms from being land applied. The only way to develop an effective management plan for nutrient management systems is to account for and manage the processes that precede the dissemination of pathogenic microorganisms into the subsurface environment. By decreasing the microbiological load in nutrient mass, one significantly reduces the risk that a group or single organism will contaminate a potable water source.

2. The implementation of an effective management system is required in order to streamline the processes in agricultural operations throughout Ontario. Essentially, a critical control system model (HACCP, ISO 14001) would likely serve as an effective template for assessing and treating risks. In order for the system to be effective, critical control points must be established for quantitative parameters to be measured within the system. Therefore, research focused specifically on establishing value ranges for optimum conditions for microbial transport and abatement should move forward. 


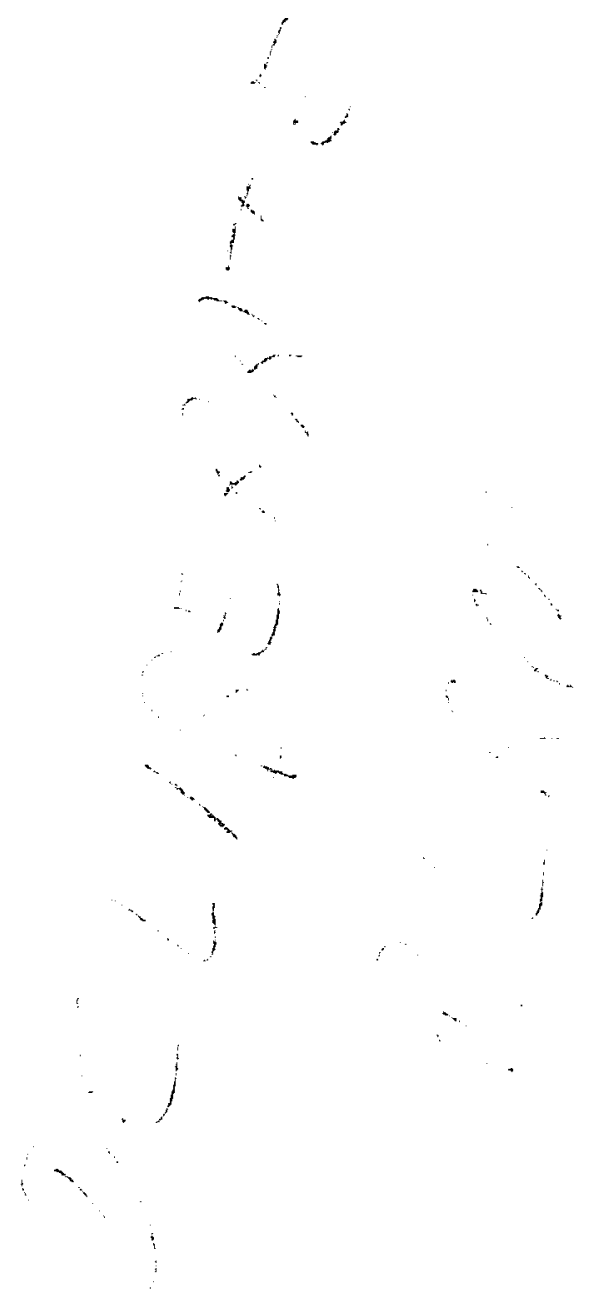




\section{References and Bibliography}

Abu-Ashour, J. \& Lee, H. (2000). Transport of Bacteria on Sloping Soil Surfaces by Runoff. Environmental Toxicology, 149-153.

Abu-Ashour, J., Joy, D.M., Lee, H., Whiteley, H.R., Zelin, S. (1994). Transport of Microorganisms through Soil. Water, Air and Soil Pollution, 75, 141-158.

Aguirre, C.G. \& Haghighi, K. (2003). Stochastic Modeling of Transient Contaminant Transport. Journal of Hydrology, 276, 224-239.

Anderson, M. \& Bates, P. (2001). Model Validation: Perspectives in Hydrological Science. England: John Wiley \& Sons.

Angers, D.A. \& Caron, J. (1998). Plant-induced changes in soil structure: Processes and Feedbacks. Biogeochemistry, 42, 55-72.

Associate Committee on the National Building Code. (1970). Canadian Farm Building Code. Ottawa, ON, Queen's Printer for Ontario.

Atwill, E.R., Hou, L., Karle, B.M., Harter, T., Tate, K.W., Dahlgren, R.A. (2002). Cryptosporidium pavrum Oocysts through Vegetated Buffer Strips and Estimated Filtration Efficiency. Applied and Environmental Microbiology. 68(11): 55175527

Bai-Lian, L., Loehle, C., Malon, D. (1996). Microbial Transport Through Heterogeneous Porous Media: Random Walk, Fractal, and Percolation Approaches. Ecological Modeling, 85, 285-302.

Bamforth, S.S. (1988). Interactions between protozoa and other organisms. Agricultural Ecosystems in the Environment, 24, 229-234.

Barley, K.P. (1954). Effects of Root Growth and Decay on the Permeability of a Synthetic sandy loam. Soil Science, 78, 205-211.

Beven, K. \& Germann, P. (1982). Macropores and water flow in soils. Water Resource. Res, 18, 1311-1325.

Bitton, G. \& Harvey, R.W. (1992). Transport of Pathogens through soils and aquifers. In: R. Mitchell (Ed.), Environmental Microbiology. England: Wiley-Liss.

Bitton, G., Lahav, N., Henis, Y. (1974). Movement and Retention of Klebsiella Aerogenes in Soil Columns. Plant and Soil, 40, 373-380.

Blanc, R. \& Nasser, A. (1996). Effect of Effluent Quality and Temperature on the Persistence of Viruses in Soil. Water Science Technology, 33, 237-242. 
Braund, A., Cousin, J., Nicoulland, B., Duval, O., Begon, J.C. (1996). Backscatter Electron Scanning Images of Soil Porosity for Analyzing Soil Compaction around Roots. Soil Science Society of America Journal, 60, 895-901.

Burge, W.G. \& Enkin, N.K. (1978). Virus Adsorption by Soils. Journal of Environmental Quality, 7, 73-76.

Caldwell, W.J. (2003). Managing the Transition Between Municipal and Provincial Governance as Required by the Regulations Under the Nutrient Management Act. Ministry of Agriculture and Food. Retrieved November 16, 2003, from http://www.gov.on.ca/omafra/english/nm/municipal/caldwltc.html.

Cameron, K.C., Di, H.J., McLaren, R.G. (1997). Is Soil an Appropriate Dumping Ground for our Wastes. Australian Journal of Soil Research, 35, 995-1035

Canada Committee on Agricultural Engineering. (1972). Canada Animal Waste Management Guide. Ottawa, ON, Queen's Printer.

Carter, M.R.., Johnston, H.W., Kimpinski, J. (1988). Direct Drilling and Soil Loosening for Spring Cereals on a Fine Sandy Loam in Atlantic Canada. Soil Tillage Research, 12, 365-384.

Cattaneo, M.V., Masson, C., Greer, C.W. (1997). The Influence of Moisture on Microbial Transport, Survival and 2,4-D Biodegradation with a Genetically Marked Burkholderia cepacia in Unsaturated Soil Columns. Biodegradation, 8,87-96.

Coleman, M.E. (2003). Guest Editorial: Interactions of Predictive Microbiology and Risk Assessment. Risk Analysis, 23, 175-178.

Coyne, M.S., Gilfillen, R.A., Rhodes, R.W., Blevins, R.L. (1995). Soil and Fecal Coliform Trapping by Grass Filter Strips during Simulated Rain. Journal of Soil and Water Conservation. 50: 405-452.

Crane, S.R. \& Moore, J.A. (1986). Modeling Enteric Bacterial Die-Off: A Review. Water, Air and Soil Pollution, 27, 411-439.

Cushman, J.H. (1997). The Physics of Fluids in Hierarchical Porous Media: Angsstroms to Miles. Kluwer, Netherlands: Academic Press.

Dagan, G. (1989). Flow and transport in Porous Formations. New York: SpringerVerlag Press.

De Mot, R., Joos, H., van Gool, A., Vanderleyden, J. (1991). Colonization of Wheat Roots by Pseudomonas Flourescens: Scanning Electron Microscopy and 
Biochemical Analysis. In: D.L. Keister and P.B. Cregan (Ed.), The Rhizosphere and Plant growth. Kluwer, Netherlands: Academic Press.

Dexter, A.R. (1991). Amerlioration of Soil by Natural Processes. Soil Tillage Res, 20 , $87-100$.

Dighton, J., Jones, H.E., Robinson, C.H., Beckett, J. (1997). The Role of Abiotic Factors Cultivation Practices and Soil Fauna in the Dispersal of Genetically Modifies Organisms in Soils. Applied Soil Microbiology, 5, 109-131.

Dillon, R. \& Fauci, L. (2000). A Microscale Model of Bacteria and Biofilm Dynamics in Porous Media. Biotechnology and Bioengineering, 68, 536-547.

Dizer, H., Nasser, A., Lopez, J.M. (1984). Penetration of Different Human Pathogenic Viruses into Sand Columns Percolated with Distilled Water, Groundwater, or Wastewater. Applied Environmental Microbiology, 47, 409-415.

Doran, J.W. \& Linn, D.M. (1979). Bacteriological Quality of Runoff Water from Pastureland. Applied Environmental Microbiology, 37, 985.

Duboise, S.M., Moore, B.E., Sagik, B.P. (1976). Poliovirus Survival and Movement in Sandy Forest Soil. Applied Environmental Microbiology, 31, 536-543.

Edwards, W.M., Shipitalo, M.J., Owens, L.B., Norton, L.D. (1989). Water and Nitrate Movement in Earthworm Burrows within Long-term no-till Cornfields. Journal of Soil Water Conservation, 44, 240-243.

Egli, T., Koster, W., Meile, L. (2002). Pathogenic Microbes in Water and Food: Changes and Challenges. FEMS Microbiology Reviews, 26,111-112.

Elliot, L.F. \& Ellis, J.R. (1997). Bacterial and Viral Pathogens Associated with Land Application and Organic Wastes. Journal of Environmental quality, 6, 245-251.

Entry, J.A., Hubbard, R.K., Thies, J.E., Fuhrmann, J.J. (2000). The Influence of Vegetation in Riparian Filterstrips on Coliform Bacteria: I. Movement and Survival in Water. Journal of Environmental Quality. 29: 1206-1214

Fenlon, D.R., Ogden, I.D., Vinten, A., Svoboda, I. (2000). The Fate of Escherichia coli and E.coli 0157:H7 in Cattle Slurry after Application to Land. Journal of Apllied Microbiology. 88: 149S-156S.

Fleming, R., Hocking, D., Fraser, H., Alves, D. (1999). Extent and Magnitude of Agricultural Sources of Cryptosporidium in Surface Water. National Soil and Water Conservation Program. Retrieved February 21, 2004, from http://res2.agr.ca/initiatives/manurenet/env_prog/gp/download/fleming_efp.pdf 
Fletcher, M. \& Loeb, G.I. (1979). Influence of Substratum Characteristics on the Attachment of a Marine Pseudomonad to Solid Surfaces. Applied Environmental Microbiology, 37, 67-72.

Gannon, J.T., Manilal, V.B., Alexander, M. (1991). Relationship Between Cell Surface Properties and Transport of Bacteria through Soil. Applied Environmental Microbiology, 57, 190-193.

Gerba, C.P., Wallis, C., Melnick, J.L. (1991). Fate of wastewater bacteria and viruses in soil. Journal of lrrigation and drainage, 101,157-174.

Gerba, C.P., Yates, M.V., Yates, S.R. (1991). Quantitation of factors controlling viral and bacterial transport in the subsurface. In: C.J Hurst (Ed.), Modeling the Environmental Fate of Microorganisms. Washington, DC: American Society for Microbiology.

Ginn, T.R, \& Murphy, E.M. (2000). Modeling Microbial Processes in Porous Media. Hydrogeology Journal, 8, 142-158.

Ginn, T.R, Wood, B.D., Nelson, K.E., Scheibe, T.D., Murphy, E.M, Clement, P.T. (2002). Processes in Microbial Transport in the Natural Subsurface. Advances in Water Resources, 25, 1017-1042.

Goss, M.J. (1991). Consequences of the Activity of Roots on Soil. In: D. Atkinson (Ed.), Plant Root Growth: An ecological perspective. Oxford, England: Blackwell Scientific Publications.

Goss, M.J., Rollins, K.S., McEwan, K., Shaw, R.J., Lammers-Helps, H. (2001). The Management of Manure in Ontario with Respect to Water Quality. Guelph, ON: University of Guelph Publication.

Gove, L., Cooke, C.M., Nicholson, F.A., Beck, A.J. (2001). Movement of Water and Heavy Metals ( $\mathrm{Zn}, \mathrm{Cu}, \mathrm{Pb}$, and $\mathrm{Ni}$ ) through Sand and Sandy Loam Amended with Biosolids under Steady-state Hydrological Conditions. Bioresource Technology, $78,171-179$.

Goyal, S.M. \& Gerba, C.P. (1979). Comparative Adsorption of Human Enteroviruses, Simian Rotavirus and Selected Bacteriophages to Soils. Applied Environmental Microbiology, 38, 241-247.

Grevers, M.C.J. \& De Jong, E. (1990). The Characterization of Soil Macroporosity of a Clay Soil Under Ten Grasses using Image Analysis. Canadian Journal of Soil Science, 70, 93-103.

Griffen, D.M. (1981). Water Potential as a Selective Factor in the Microbial Ecology of 
Soils. In: J.F Parr, W.R. Garder, L.F. Elliot (Eds.) Water Potential Relations in soil Microbiology. Madison, WI: Soil Science Society of America.

Griffen, D.M. \& Quail, G. (1968). Movement of Bacteria in Moist Particulate Systems. Australian Journal of Biology Science, 21, 579-582.

Guidi, G., Poggio, G., Petruzelli, G. (1985). The Porosity of Soil Aggregates from Bulk Soil and Soil Adhering to Roots. Plant soil, 87, 311-314.

Haines, P.J. \& Uren, N.C. (1990). Effects of Conservation Tillage Farming on Soil Microbial Biomass, Organic Matter and Earthworm Populations, in Northeastern Victoria. Australian Journal of Agriculture, 30, 365-371.

Harvey, R.W. (1991). Parameters involved in Modeling Movement of Bacteria in Groundwater. In: C.J. Hurst (Ed.), Modeling the Environmental Fate of Microorganisms. Washington, DC: American Society for Microbiology.

Harvey, R.W., Kinner, N.E., MacDonald, D., Metge, D.W., Bunn, A. (1993). Role of Physical Heterogeneity in the Interruption of Small-Scale Laboratory and Field Observation of Bacteria, Microbial-Sized Microsphere and Bromide Transport through Aquifer Sediments. Water Resources Research, 29, 2713-2721.

Ho, B.S. \& Tam, T.Y. (1998). Giardia and Cryptosporidium in sewage contaminated river waters. Water Research, 32, 2860-2864.

Hornberger, G.M., Mills, A.L., Herman, J.S. (1992). Bacterial Transport in Porous Media: Evaluation of a Model Using Laboratory Observations. Water Resources Research, 28, 915-938.

Hurst, C.J., Benton, W.B., McClellan, K.A. (1989). Thermal and Water Source effects upon the Stability of Enteroviruses in Surface Freshwaters. Canadian Journal of Microbiology, 35, 474.

Hurst, C.J., Gerba, C.P., Cech, I. (1980). Effects of Environmental Variables and Soil Characteristics on Virus Survival in Soil. Applied Environmental Microbiology, 40, 1076-1079.

Hurst, C.J. \& Goyke, T. (1986). Survival of Indigenous Enteric Viruses During Storage of Wastewater Sludge Samples. Canadian Journal of Microbiology, 32, 645.

Huysman, F. \& Verstraete, W. (1993). Water Facilitated Transport of Bacteria in Unsaturated Soil Columns: Influence of Cell Surface Hydrophobicity and Soil Properties. Soil Biology Biochemistry, 25, 91-97.

Jewett, D.G., Logan, B.E., Arnold, R.G., Bales, C.B. (1999). Transport of Pseudomonasflourescens Strain P17 through Quartz Sand Columns as a Function 
of Water Content. Journal of Contaminant Hydrology, 36, 73-89.

Jones, P.W. (1980). Disease Hazard̉s Associated with Slurry Disposal. British Veterinarian Journal, 136, 529-541.

Kemp, J.S., Paterson, E., Gammock, S.M., Cresser, M.S., Killham, K. (1992) Leaching of Genetically Modified Pseudomonas flourescens through Organic Soils; Influence of Temperature, Soil pH and Roots. Biological Fertile Soils, 13, 218224.

Kibbey, H.J., Hagedorn, C., McCoy, E.L. (1978). Use of Faecal Streptococci as Indicators of Pollution in Soil. Applied Environmental Microbiology, 35, 711 717.

King, D., Watson, G.C., Wall, G.J., Grant, B.A. (2000). The Effects of Livestock Manure Application and Management on Surface Water Quality. Ottawa, ON. Agriculture and Agri Food Canada Publication.

Knox, R.C., Sabatini, D.A., Canter, L.W. (1993) Subsurface Transport and Fate Processes. Boca Raton, FL. Lewis Publishers.

Kutz, S.M. \& Gerba, C.P. (1988). Comparison of Virus Survival in Fresh Water Sources. Water Science Technology, 20, 467.

Lammerding, A.M. \& Fazil, A. (2000). Hazard Identification and Exposure Assessment for Food Safety Risk Assessment. International Journal of Food Technology, $58,147-157$.

Lewis, D.R., \& McGechan, M.B. (2002). Transport of Particulate and Colloid-sorbed Contaminants through Soil, Part 1: General Principles. Biosystems Engineering, 83, (3) 255-273.

Loehr, R.C. (1984). Pollution Control for Agriculture (2 ${ }^{\text {nd }}$ Edition). Florida: Academic Press.

Madsen, E.L. \& Alexander, M. (1982). Transport of Rhizobium and Pseudomonas through Soil. Journal of Environmental Quality, 46, 557-560.

Madigan, T.M., Martinko, J.M., Parker, J. (1997). Biology of Microorganisms. New Jersey: Prentice-Hall Publishing.

Macler, B.A. \& Merkle, J.C. (2000). Current Knowledge on Groundwater Microbial Pathogens and their Control. Hydrogeology Journal, 8, 29-40.

Maier, R.M., Pepper, I.L., Gerba, C.P. (1999). Models for Microbial Transport. In: Environmental Microbiology. New York: Academic Press. 
Marshall, K.C. (1971). Sorptive interactions between soil particles and microorganisms. In A.D. McLaren and J. Skujins (Eds), Soil Biochemistry. New York: Marcel Dekker.

Marshall, K.C. (1996). Adhesion as a Strategy for Access to Nutrients. In: M. Fletcher (Ed.), Bacterial Adhesion, Molecular and Ecological Diversity. New York: John Wiley.

Mawdsley, J.L., Bardgett, R.D., Merry, R.J., Pain, B.F., Theodorou, M.K (1995). Pathogens in Livestock Wastes, their Potential for Movement through Soil and Environmental Pollution. Applied Soil Ecology, 2, 1-15

Maxwell, R.M., Welty, C., Thompson, A. (2003). Streamline-Based Simulation of Virus Transport Resulting from Long Term Artificial Recharge in a Heterogeneous Aquifer. Advances in Water Research, 26, 1075-1096.

Mills, A.L., Herman, J.S., Horberger, G.M., de Jesus, T.H. (1994). Effect of Ionic Strength and Iron Coatings on Mineral Grains on Sorption of Bacterial Cells to Quartz Sand. Applied Environmental Biology, 60, 3300-3306

Ministry of Agriculture. (1885). Animal Contagious Disease Act, S.C. 1885, c. 70. Ottawa, ON, Publication of Canada.

Ministry of Fisheries and Oceans. (1985). Fisheries Act, R.S.C. 1985, c. F-14. Ottawa, ON, Publication of Canada.

Murphy, E.M., Ginn, T.R., Chilakapati, A., Resch, T., Phillips, J.L., Wietsma, T.W., Spadoni, C.M. (1997). The Influence of Physical Heterogeneity on Microbial Degradation and Distribution in Porous Media. Water Resources Research, 33, 1087-1103.

Nasser, A.M., Fattal, B., Adin, A. (1993). Adsorption of Poliovirus 1 and F Bacteriophages onto Sand. Water Science Technology, 27, 331-338.

Nasser, A.M., Glozman, R., Nitzan, Y. (2002). Contribution of Microbial Activity to Virus reduction in saturated soil. Water Research, 36, 2589-2595.

Nauta, M.J. (2000). Separation of Uncertainty and Variability in Quantitative Microbial Risk Assessment Models. International Journal of Food Microbiology. 57, 9-18.

Noordhuizen, J.P.T.M., Frankena, K. (1999). Epidemiology and Quality Assurance: Applications at Farm Level. Preventative Veterinary Medicine, 39, 93-110.

Noornstra, E., Northolt, M.D., Notermans, S., Barendsz, A.W. (2001). The Use of Quantitative Risk Assessment in HACCP. Food Control, 12, 229-234. 
Notermans, S., Galldoff, G., Zwietering, M.H., Mead, G.C. (1994). The HACCP Concept: Specification of Criteria using Quantitative Risk Assessment. Food Microbiology, 11, 397-408.

O'Connor, D. (2001). Report of the Walkerton Commission of Inquiry. Ottawa, ON. Publication of Ontario.

Olsen, M.E., Thorlakson, C.L., Deselliers, L., Morck, D.W., McAllister, T.A. (1996). Giardia and Cryptosporidium in Canadian Farm Animals. Calgary, AB: University of Calgary.

Ogden, I.D., Fenlon, D.R., Vinton, J.A.A., Lewis, D. (2001). The Fate of Escherichia coli 0157 in Soil and its Potential to Contaminate Drinking Water. Internationa? Journal of Food Microbiology, 66, 111-117.

Ontario Agriculture and Food Department. (1966). Information Leaflet: Handling Liquid Manure for Utilization in Crop Production, Agdex 538. Guelph, ON. Ontario Department of Agriculture and Food Publication.

Ontario Environmental Farm Plan. (1993). Ministry of Agriculture and Food. Retrieved July 16, 2003 from http://www.gov.on.ca/OMAFRA/english/environment/efp/efp.html.

Ontario Ministry of Agriculture and Food. (2002). Nutrient Management Act Backgrounder. Retrieved on July 9, 2003, from http:/www.gov.on.ca/OMAFRA/english/infores/releases/062802.html.

Ontario Ministry of Agriculture and Food. (1990). Dead Animal Disposal Act, R.S.O. 1990, c. D.3.

Ontario Ministry of Agriculture and Food. (1992). Draft Interim Guidelines for the Utilization of Waste (Other than Sewage Sludge) on Agricultural Lands. Ottawa, ON: Publication of Ontario.

Ontario Ministry of Agriculture and Food. (1990). Drainage Act, R.S.O. 1990, c. D.17.

Ontario Ministry of Agriculture and Food. (1992). Guidelines for Sewage Sludge Utilization on Agricultural Lands. Ottawa, ON: Publication of Ontario.

Ontario Ministry of Agriculture and Food. NMP Forms and Protocols. (1999). Retrieved September 16, 2004 from http:/www.omaf.gov.on.ca/scripts/english/engineering/NMAN/default.asp.

Ontario Ministry of Agriculture, Food and Rural Affairs. (1990). Agricultural Tile Drainage Installation Act, R.S.O. 1990, c. A.14. 
Ontario Ministry of Agriculture, Food and Rural Affairs. (1998). Farming Food Production Protection Act, S.O. 1998, c. 1.

Ontario Ministry of Agriculture, Food and Rural Affairs and the Ministry of the Environment. (1996). Guidelines for the Utilization of Biosolids and Other Wastes on Agricultural Land. Ontario: Ontario Ministry of the Environment and Ontario Ministry of Agriculture, Food and Rural Affairs Publication.

Ontario Ministry of Agriculture, Food and Rural Affairs and the Ministry of the Environment and Energy. (1995). Guide to Agricultural Land Use. Gnelph, ON: Ontario Ministry of Agriculture, Food and Rural Affairs Publication.

Ontario Ministry of Agriculture and Food and the Ministry of the Environment. (1973). Agricultural Code of Practice. Ottawa, ON: Government of Ontario Publication.

Ontario Ministry of Agriculture, Food and Rural Affairs and the Ministry of the Environment and Energy. (1995). Minimum Distance Separation I (MDS I). Guelph, ON: Ministry of Agriculture, Food and Rural Affairs Publication.

Ontario Ministry of Agriculture, Food and Rural Affairs and the Ministry of the Environment and Energy. (1995). Minimum Distance Separation II (MDS II). Guelph, ON: Ontario Ministry of Agriculture, Food and Rural Affairs Publication.

Ontario Ministry of Agriculture and Food, the Ministry of the Environment and the Ministry of Housing. (1976). Agricultural Code of Practice. Ontario: Government of Ontario Publication.

Ontario Ministry of Energy and Resources Management. (1970). Waste Management Act, S.O. 1970 , c. 44.

Ontario Ministry of the Environment (1992). Environmental Protection Act, R.S.O. 1992, c.E.19.

Ontario Ministry of the Environment. (1992). Ontario Water Resources Act, R.S.O. 1992, c. O.40. Retrieved December 8, 2002, from http://192.75.156.68/DBLaws/Statutes/English/90o40_e.htm.

Ontario Ministry of the Environment. (1990). Pesticides Act, R.S.O. 1990. c. P.11.

Ontario Ministry of the Environment. (2002). Safe Drinking Water Act, S.O. 2002.

Ontario Ministry of Health. (1990). Health Protection and Promotion Act, R.S.O. 1990,

Ontario Ministry of Health. (1997). Mandatory Health Programs and Services Guidelines. Ottawa, ON: Publication of Ontario. 
Ontario Ministry of Lands and Forests. (1927). Lakes and Rivers Improvement Act, S.O. 1927 , c. 40.

Ontario Ministry of Mines. (1924). Well Drillers Act, S.O. 1924, c. 75.

Ontario Ministry of Municipal Affairs and Housing. (1990). Planning Act, R.S.O. 1990, c. P.13.

Ontario Ministry of Natural Resources. (1990). Conservation Land Act. R.S.O. 1990 , c. C.28.

Ontario Water Resources Commission. An Act to Establish the Ontario Water Resources Commission, S.O. 1956, c. 62 .

Patni, N.K., Toxopeus, R., Tennant, A.D. Hore, F.R. (1984). Bacterial Quality of Tile Drainage Water from Manuered and Fertilized Cropland. Water Research, 18, 127-132.

Paulsen, J.E., Oppen, E., Bakke, R. (1997). Immersed Interface for Stokes flow with Elastic Boundaries or Surface Tension. Journal of Sci Comp, 18(3), 709735.

Peterson, H., Luxton, M. (1982). A comparative analysis of soil fauna populations and their role in decomposition processes. Oikos, 39, 288-388.

Postma, J., van Veen, J.A. Walter, S. (1989). Influence of Different Initial Soil Moisture Contents on the Distribution and Population Dynamics of Introduced Rhizobium leguminosarum biovar trifolii. Soil Biology Biochemistry, 21, 437-442.

Powel, K.L., Taylor, R.G., Cronin, A.A., Barrett, M.H., Pedly, S., Sellwood, J. (2003). Microbial Contamination of the Two Urban Sandstone Aquifers in the UK. Water Research, 37, 339-352.

Province of Ontario. Public Health Act, S.C. 1873, c. XLIIL.

Reddy, K.R., Khaleel, R., Overcash, M.R. (1981). Behaviour and Transport of Microbial Pathogens and Indicator Organisms in Soils Treated with Organic Wastes. Journal of Environmental Quality, 10, 255-266.

Reneau, R.B., Hagedorn, C., Degen, M.J. (1989). Fate and Transport of Biological and Inorganic Contaminants From on-site Disposal Wastewater. Joumal of Environmental Quality, 18, 135-144.

Ruddick, S.M., Williams, S.T. (1972). Studies on the Ecology of Actinomycetes in Soil. Some factors Influencing the Dispersal and Adsorption of Spores in Soil. Soil 
Biology Biochemistry, 4, 93-103.

Salas, B., Stack, R.W. (1991). Influence of Tillage on Soil Populations of Fusarium Species in a Spring Wheat Cropping System. Phytophathology, 81, 1215-1216.

Sarewitz, D., Pielke, R.A.Jr., Byerly, R. Jr. (2000). Prediction: Science, DecisionMaking and the Future of Nature. Washington, DC: Island Press.

Scholl, M.A., Mills, A.L., Herman, J.S., Horberger, G.M. (1990). The Influence of Mineralogy and Solution Chemistry on the Attachment of Bacteria to Representative Aquifer Minerals. Journal of Contamination Hydrology, 6, 321336.

Scott, S.M., Thomas, G.W., White, R.E. (1983). Movement of bacteria through macropores to ground water: Research Report No. 139. Lexington, KY: Water Resources Research Institute.

Sinton, L.W., Finlay, R.K., Pang, L., Scott, D.M. (1997). Transport of Bacteria and Bacteriophages in Irrigated Effluent into and through an Alluvial Gravel Aquifer. Water, Air and Soil Pollution, 98, 17-42.

Sims, J.T., Goggin, N., McDermott, J. (1999). Nutrient management for Water Quality Protection: Integrating Research into Environmental Policy. Water Science Technology, 39, 291-298

Smith, M.S., Thomas, G.W., White, R.E., Ritonga, D. (1985). Transport of Escherichia coli through Intact and Disturbed Soil Columns. Journal of Environmental Quality, 14, 87-91.

Sparling, D., Lee, J., Howard, W. (2001). Murgo Farms Inc: HACCP, ISO 9000, ISO 14000. International Food and Agribusiness Management Review, 4, 67-79.

Stenstrom, T.A. (1989). Bacterial Hydrophobicity, an Overall Parameter for the Measurement of Adhesion Potential to Soil Particles. Applied Environmental Microbiology, 55, 142-147.

Stiefelmeyer, K. (2003). Assessment of the Pathogen Abatement Effects of Nutrient Management Policy: The Nutrient Management Act, 2002. Ryerson University.

Strauch, D. (1991). Survival of Pathogenic Micro-organisms and Parasites in Excreta, Manure and Sewage Sludge. Rev. sci. tech. Off. Int. Epiz, 10 (3), 813-846.

Sun, Y., Peterson, J.N., Bear, J., Clement, T.P., Hooker, B.S. (1999). Modeling Microbial Transport Systems in a Dual Porosity System. Transport in Porous Media, 35, 49-65. 
Tan, Y., Bond, W.J., Rovira, A.D., Brisbaine, P.G., Griffen, D.M. (1991). Movement through Soil of a Biological Control Agent, Pseudomonas flourescens. Soil Biology Biochemical, 23, 821-825.

Tan, Y., Gannon, J.T., Baveye, P., Alexander, M. (1994). Transport of an Aquifer Sand: Experiments and Model Simulations. Water Resource Res, 30, 3243-3252

Taubb, F.B. (1992). Synthetic Microcosms as Test Systems for Survival and Effects of Genetically-engineered Microorganisms. In: M.A Levin, R.J. Scidler, P.J. Regal (Eds), Microbial Biology: Principles, Methods and Applications. Maidenhead: McGraw Hill.

Tebes-Stevens, C., Valocchi, A.J., VanBriesen, J.M., Rittmann, B.E. (1998). Multicomponent Transport with Coupled Geochemical and Microbiological Reactions: Model Description and Example Simulations. Journal of Hydrology, 209, 8-26.

Teunis, P., Havelaar, A.H. (2002). Risk Assessment for Protozoan Parasites. International Biodeterioration and Biodegradation, 50, 185-193.

Toombs, M. (1992). Legislation \& Farming Practices. Ministry of Agriculture and Food Publications.

Trevors, J.T., van Elsas, J.D., van Overbeek, L.S., Starodub, M. (1990). Transport of a genetically engineered Pseudomonas flourescens strain through a soil microcosm. Applied Environmental Microbiology, 56, 401-408

United States Environmental Protection Agency. (1997) State Source Water Assessment and Protection Programs: Final Guidance. EPA 816-R-97-009 .

Vandevivere, P., Baveye, P. (1992). Effect of bacterial extracellular polymers on the saturated hydraulic conductivity of sand columns. Applied Environmental Microbiology, 58, 1690-1698.

Walls, I.\& Scott, V.N. (1997). Use of Predictive Microbiology in Microbial Food Safety Risk Assessment. International Journal of Food Microbiology, 36, 97-102.

White, D.C., Flemming, C.A., Leung, T.K., Macnaughton, S.J. (1998). In Situ Microbial Ecology for Quantitative Appraisal, Monitoring, and Risk Assessment of Pollution Remediation in Soils, the Subsurface, the Rhizosphere and in Biofilms. Journal of Microbial Methods, 32, 93-105.

Wu, J., Hu, B.X., Zhang, D. (2003). Applications of Nonstationary Stochastic Theory to Solute Transport in Multi-Scale Geological Media. Journal of Hydrology, 275, $208-228$. 
Wan, J. \& Wilson, J. (1994). Visualization of the Role of the Gas-water Interface on the Fate and Transport of Colloids in Porous Media. Water Resource Res, 30, 11-23.

Wang, G.T., Zhao., Doyle, M.P. (1998). Survival of Enterohemorrhagic Escherichia coli 0157:H7 in Bovine Feces. Applied and Environmental Microbiology, 62(7), 2567-2570.

Wellington, M.H., Cresswell, N., Saunders, V.A. (1990). Growth and Survival of Streptomycete Inoculants and Extent of Plasmid Transfer in Sterile and Nonsterile soil. Applied Environmental Microbiology, 56, 1413-1419.

Williams, B.M. (1979). The Survival of Pathogens in Slurry and the Animal Health Risks from Disposal to Land. ADAS Quarterly Review, 32, 59-68.

Wong, P.T.W. \& Griffen, D.M. (1976). Bacterial Movement at high matrix potentials part II. Soil Biological Biochemistry, 8, 219-223.

Yao, K.M., Habibian, M.T., O'Melia, C.R. (1971). Modeling Microbial Transport in the Subsurface: A Mathematical Discussion. In: C.J. Hurst (Ed.), Modeling the Environmental Fate of Microorganisms, Washington DC: American Society for Microbiology.

Yates, M.V. \& Yates, S.R. (1991). Modeling Microbial Transport in the Subsurface: a Mathematical Discussion. In: C.J. Hurst (Ed.), Modeling the Environmental Fate of Microorganisms. Washington, DC: American Society for Microbiology.

Yates, M.V., Thompson, S.S., Jury, W.A. (1997). Sorption of Viruses During Flow through Sand Columns. Environmental Science Technology, 31, 548-555.

Yeager, J.G. \& O'Brian, R.T. (1979). Enterovirus Inactivation in Soil. Applied Environmental Microbiology, 38, 694-701

Zhang, D. (1997). Conditional Stochastic Analysis for Multiphase Transport in Random Heterogeneous Variable Saturated Media. Transport in Porous Media, 27, $265-$ 287.

Zibilske, L.M., Weaver, R.W. (1978). Effect of environmental factors on survival of Salmonella typhimurium in soil. Journal of Environmental Quality, 7, 593-597.

Zyman, J., Sorber, C.A. (1988). Influence of simulated rainfall on the transport and survival of selected indicator organisms in sludge-amended soils. Journal of Water Pollution Control, 60, 2105-2110.

Zwietering, M.H. (2000). Sensitivity Analysis in Quantitative Microbial Risk Assessment. International Journal of Food Microbiology, 58, 213-221. 
Zysset, A., Stauffer, F., Dracos, T. (1994). Modeling of Reactive Groundwater Transport Governed by Biodegradation. Water Resources Research, 30, 243-2434. 
Appendix

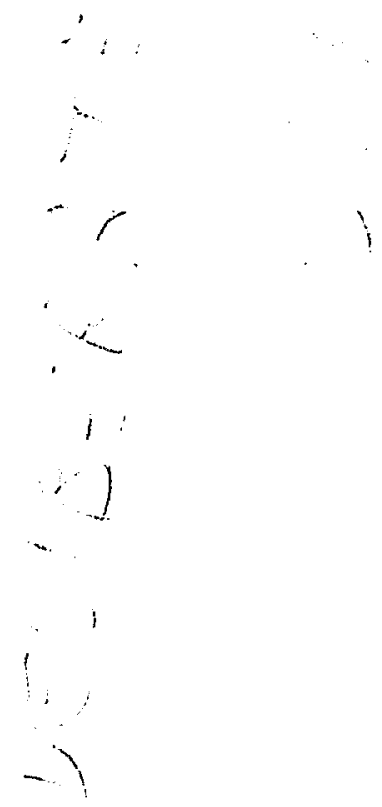




\section{Appendix 2.1: Pathogen Abatement and Nutrient Management in Ontario. Sequence of Events: 1873-2002}

\begin{tabular}{|c|c|}
\hline Decade & Legislation \\
\hline 1870 & 1. An Act Respecting the Public Health (1873) \\
\hline 1880 & 2. Act Respecting Infectious or Contagious Diseases Affecting Animals (1885) \\
\hline 1890 & None \\
\hline 1900 & None \\
\hline 1910 & None \\
\hline 1920 & $\begin{array}{l}\text { 3. The Well Drillers Act (1924) } \\
\text { 4. Lakes and Rivers Improvement Act (1927) }\end{array}$ \\
\hline 1930 & None \\
\hline 1940 & None \\
\hline 1950 & 5. An Act to Establish the Ontario Water Resources Commission (1956) \\
\hline 1960 & None \\
\hline 1970 & $\begin{array}{l}\text { 6.Canadian Code for Farm Buildings (1970) } \\
\text { 7. The Waste Management Act (1970) } \\
\text { 8. The Environmental Protection Act (1971) } \\
\text { 9. Canada Animal Waste Management Guide (1972) } \\
\text { 10. Agricultural Code of Practice (1973, 1976) }\end{array}$ \\
\hline 1980 & 11. The Fisheries Act (1985) \\
\hline 1990 & $\begin{array}{l}\text { 12. Agricultural Tile Drainage Act (1990) } \\
\text { 13. Conservation land Act (1990) } \\
\text { 14. Agricultural Drainage Tile Installation Act (1990) } \\
\text { 15. Health Protection and Promotion Act (1990) } \\
\text { 16. Drainage Act } \\
\text { 17. Planning Act (1990) } \\
\text { 18. Ontario Water Resources Act (1990) } \\
\text { 19. Ontario Building Code Act (1992) } \\
\text { 20. Guidelines for the Utilization of Waste (other than sewage sludge) on Agricultural land } \\
\text { (1992) } \\
\text { 21. Guidelines for Sewage Sludge Utilization on Agricultural Lands (1992) } \\
\text { 22. Ontario Environmental Farm Plan (1993) } \\
\text { 23. Guide to Agricultural Land Use (1995) } \\
\text { 24. Minimum Separation Distances (MDS I and II)- official Guideline (1995) } \\
\text { 25. Best Management Practices for Farmers (1995) } \\
\text { 26. Guidelines for the Utilization of Biosolids and other Wastes on Agricultural Land (1996) } \\
\text { 27. First Municipal by-law pertaining to nutrient management (Grey Township) (1997) } \\
\text { 28. Ontario Building Code (1997) } \\
\text { 29. Mandatory Health Programs and Services Guidelines (1997) } \\
\text { 30. Farming Food Production and Promotion Act (1998) }\end{array}$ \\
\hline 2000 & $\begin{array}{l}\text { 31. Municipal Act (2001) } \\
\text { 32. Safe Drinking Water Act (2002) } \\
\text { 33. Nutrient Management Act (2002) }\end{array}$ \\
\hline
\end{tabular}




\begin{abstract}
Appendix 2.2: Summary of Previous Legislation An Act Respecting the Contagious Diseases of Animals (1885)

The Department of Agriculture's first legislation, An Act Respecting the Contagious Diseases of Animals, was developed in 1869 for farmers who were trying to establish livestock herds and needed protection from diseases of the times such as rinderpest and other European pathogens coming from their respective homelands. Not surprisingly, the Act did not deal specifically with the management of nutrients, nor water quality or pollution abatement.
\end{abstract}

Indirectly, however, the Act managed to control for the movement of diseased animals and the products of waste they may have produced or may have come into contact with. For example, animals that might have come into contact with disease would have to be destroyed along with the food products they may have partially consumed. Furthermore, waste products from suspected diseased animals such as animal dung were not permitted for use and were required to be destroyed. Any storage facilities for animals along with transportation vehicles (boats and vessels) were required to be cleaned and disinfected prior to allowing any further transportation on the vessel.

\title{
The Well Drillers Act (1924)
}

Passed in 1924 as An Act to regulate the Boring and Protection of Wells, the Well Drillers Act was originally legislated under the authority of the Ministry of Mines. The Act primarily dealt with two issues of concern in well safety;

1. Wells containing natural gas deposits

2. Abandoned wells

Both circumstances could potentially lead to unsafe drinking water conditions where abandoned wells would have to be capped and water deemed officially undrinkable for public consumption. Protection clauses contained within the Well Drillers Act included the requirement to apply for a license prior to boring a well, along with plugging unused wells so as to "prevent any fresh or salt water or other injurious substances from entering..." (Well Drillers Act, 1924, s. 9(1)). The Well Drillers Act would be revised in 
updated versions until the early 1940s. Future acts including the Ontario Water Resources Act (1990) would focus on specific sections of well health and construction (see appendix 2.2) rather than focusing on specifications and other general details unrelated to well water health which was discussed in the Well Drillers Act.

\section{The Lakes and Rivers Improvement Act (1927)}

Originally released in 1927 and later adopted by the Ministry of Natural Resources, the general purpose of the Lakes and Rivers Improvement Act was to (among others) provide for the management, protection, preservation and use of the waters of the lakes and rivers of Ontario and the land under them. The 1990 version of the Act consisted of three components including;

(i) Construction, repair and use of dams

(ii) Public rights in lakes and rivers and

(iii) Water privileges.

One general clause in the 1990 revised edition of the Act pertained indirectly to nutrient management and the pollution of lakes and rivers. Section $36(1)$ of the Act required that;

"No person shall throw, deposit, discharge or permit the throwing, depositing or discharging of any refuse, substance or matter in a lake or river whether or not the lake or river is covered by ice, or on shores or banks of a lake or river under circumstances that conflict with the purposes of this act".

Farming practices or environments were not specifically mentioned within the text of the Act. However, it is unclear if the Lakes and Rivers Improvement Act was used as a tool by the Ministry of Natural Resources to restrict the disposal of pollutants to lakes and rivers which possibly could be disposed of by farmers. 


\section{An Act to Establish the Ontario Water Resources Commission (1956)}

Established in 1956, the Ontario Water Resources Commission had several functions and powers to provide water to the public and to supply them where required. It was the function of the commission to construct and operate water systems for the supply, purification and distribution of water and for the disposal of sewage and to enter into agreements with respect to the supply of water or the disposal of sewage (to land). The commission provided an annual report detailing the state of systems in Ontario to the Minister in power.

\section{Ontario Field Crop Recommendations (1961)}

Developed by the Ontario Ministry of Agriculture and Rural Affairs, the recommendations were released on an annual basis. Recommendations ranged from field application methods to storage basins and construction practices. The recommendations had no bearing on legislative matters, however, they were often concurrent with the legislation of the day.

\section{The Ontario Farm Management Program (1968)}

The program, developed by the Ontario Department of Agriculture and Food, was used by farmers in Ontario to provide help and guidance in areas of financial management, livestock management, soil and crop management, and machinery management.

\section{The Waste Management Act (1970)}

Commencing in September 1970, the Waste Management Act targeted waste management systems. More specifically, the Act targeted systems run in municipalities as either waste 'management systems' or 'waste disposal sites'. Under the Act, 'waste sites" required a certificate of approval from the Minister of Energy and Resource Management (as the EPA had yet to be passed into law). Additionally, the Act referred to municipal by-laws (see appendix 2.2) where no certificate of approval could be granted, unless the applicant had furnished a certificate from the municipality in which 
the waste disposal site was situated or where the waste disposal site could not contravene any of the by-laws of the encompassing municipality.

Subsequent acts (1992) focused on specific landfill sites (waste disposal sites) as a function of the time remaining for disposal in the area. The 1992 Act was placed under the Ministry of the Environment, which is responsible for Certificates of Approval under the Environmental Protection Act (1971) and environmental assessments (under the Environmental As:essment $A c t$ ) to determine where wastes may be applied.

\section{The Fisheries Act (1985)}

Developed by the Federal Department of Fisheries and Oceans, the Fisheries Act administered in Ontario by the Ontario Ministry of Natural Resources and the Federal Ministry of the Environment. The purpose of the Act is the conservation and preservation of fish and fish habitat (Toombs, 1992). The Act provides that no person shall carry on any work or undertaking that results in the harmful alteration, disruption or destruction of fish or fish habitat (Fisheries Act, 1985, s. 35(1)). Furthermore, the Act requires that no person shall deposit or permit the deposit of a deleterious substance of any type in water frequented by fish or in any place under any conditions where the deleterious substance or any other deleterious substance that results from the deposit of the deleterious substance may enter any such water (Fisheries Act, 1985, s. 36(3)). Similar to the Ontario Water Resources Act, the Fisheries Act does not specifically mention agricultural practices nor their pollution opportunities into specified waters. However, agricultural practices, specifically those practices that prohibit or restrict the flow of surface waters to locations such as streams, lakes and waterways should be wary of the consequences of such deposits, especially if the waters are inhabited by fish.

\section{Ontario Water Resources Act (1990) and the Safe Drinking Water Act (2002)}

The Province of Ontario's principal legislative instrument for the management of water resources, the Ontario Water Resources Act (1990) (OWRA) addresses most aspects of water quality in the province including water protection, extraction, treatment and control. Much like the Health Protection and Promotion Act, general clauses and 
definitions under the OWRA restrict and prohibit pathogens from entering potable sources, including ground water sources. For example, section 30(1), a general duty clause, prohibits the discharge of material that may contaminate waters.

Every person that discharges or causes or permits the discharge of any material of any kind into or in any waters or on any shore or bank thereof or into or in any place that may impair the quality of the water of any waters is guilty of an offense.

(Ontario Water Resources Act, 1990, s.30(1))

Although the OWRA generally applies to municipalities or utilities that wish to extract more than 50,000 litres of water per day from either surface or groundwater, the Act contains several provisions which operate to restrict the relevance of pathogens and other substances to water sources that may impair the general quality of that water. For example, sections 35 to 50 regulate well drilling and construction of wells, section 33 acts to protect public water sources from contamination, and section 32 of the OWRA provides the Ministry of the Environment with the power to order measures to prevent, reduce, or alleviate the impairment of water quality. Another important clause of the OWRA includes its regulation making powers so that regulations such as Regulation 459 (drinking water treatment, testing, and reporting) may be made. Other examples of legislation under the OWRA include the Ontario Drinking Water Standards which were developed as legally enforceable standards which set standards and limits for microbiological, chemical, physical, and radioactive characteristics of drinking water where microbiological quality is stressed as the most important element of water quality due to its potential to spread disease.

Developed under authority of the Ministry of Environment, the Safe Drinking Water Act (2002) (SDWA) was a product of Ontario's Safe Drinking Waier Strategy in response to Justice O'Connor's findings. Similar to the OWRA, the Safe Drinking Water Act provides general clauses for drinking water protection, especially as it relates to human health and well-being. The purpose of the SDWA is two-fold; 
1. To recognize that the people of Ontario are entitled to expect their drinking water to be safe.

2. To provide for the protection of human health and the prevention of drinking water health hazards through control and regulation of drinking water systems and drinking water testing.

The SDWA governs the operation of water supply systems but still relates to several rural outlets, especially those agricultural systems that share wells. Similar to the Health Protection and Promotion Act, the Act defines 'drinking water health hazard' as the following;

(a) a condition of the system or a condition associated with the systems waters, including anything found in the waters,

(iv) that adversely affects, or is likely to adversely affect, the health of the users of the system,

(v) that deters or hinders, or is likely to deter or hinder, the prevention and suppression of disease, or

(vi) that endangers or is likely to endanger public health,

(b) a prescribed condition of the drinking-water system, or

(c) a prescribed condition associated with the system's waters or the presence of a prescribed thing in the waters.

(Safe Drinking Water Act, 2002, s. 2(1))

The definition provides the ministry with broad powers capable of defining a drinking water health hazard whenever it is believed that a legitimate threat has been exposed. However, references made to the Nutrient Management Act, the Environmental Protection Act and the Ontario Water Resources Act allow for more specific inspection and/or charges to be laid.

\section{Agricultural Tile Drainage Act (1990) and The Drainage Act (1990)}

Mutually released in 1990, the Agricultural Tile Drainage Act and the Drainage Act were products of the then Ministry of Agricultural Food and Rural Affairs. Both Acts 
dealt with the construction and implementation of drainage systems including those involved in agricultural systems. In the Agricultural Tile Drainage Act, the definition of a 'drainage work' included 'a drainage system constructed of tile, pipe, or tubing of any material beneath the surface of agricultural land, including integral inlets and outlets for the purpose of improving the productivity of the land drained". In the Drainage Act, 'drainage works' included a drain constructed by any means, including the improving of a natural watercourse, and works necessary to regulate the water table or water level within or on any lands to regulate the level of the waters of a drain, reservoir, lake or pond, and includes a dam, embankment, wall, protective works or any combination thereof (section 1).

Licensed agreements in both pieces of legislation play vital roles in the approval of any system which is installed and/or being modified. Pathogen abatement and nutrient management principles are not found in the Acts as they are designed mainly for those parties interested in implementing or constructing such drains which would require licenses and approvals from engineering professionals.

\section{Conservation Land Act (1990)}

Passed under Authority of the Minister of Natural Resources, the Conservation Land Act was passed in 1990 and Jater amended in 1994 and 2000. The Act, "provides for the establishment of conservation authorities which are responsible for, conservation restoration, development and management of the natural resources other than gas, oil, coal and minerals within the jurisdiction of a Conservation authority.... and the prevention of floods, erosion and pollution and the adverse effects associated with these problems by controlling the flow of surface waters" (Toombs, 1992).

The Act provides for the establishment of programs and the allowance of grants to conserve lands along with work or alterations which may take place in designated areas of concern. Designated areas of concern include known flooding areas and protected lands such as the Niagara escarpment. 


\section{Planning Act (1990) and the Municipal Act (2001)}

Until the implementation of the Nutrient Management Act in 2002, many municipalities in Ontario had their own version of nutrient managemer:t by-laws along with other bylaws pertaining to the preservation and protection of water resources and land management. Most of these powers were levied when the province introduced the Planning Act under which the province gave municipalities jurisdiction over most local matters including the management of land and water resources and the control of all forms of pollution in the natural environment. Released by the Ministry of Municipal Affairs and Housing, the Planning Act allowed municipalities to gain control over local matters through the implementation of by-laws which were enforced mainly through local advisory committees. Similar to the Planning Act, the Municipal Act further highlighted and delegated the responsibilities of local matters to local governments. Local interests, including the management and preservation of public assets along with fostering the current and future economic, social, and environmental well being of the municipality were addressed (Planning Act, 1990, s. 2 (a), (b), (c), \& (d)).

Municipalities are created by the Province of Ontario to be responsible and accountable governments within their jurisdiction. Each municipality is given powers and duties under this Act and many other Acts for purposes including managing finances and fostering the current economic, social and environmental well-being of the municipality. An example of such powers is the enactment of local and municipal bylaws and zoning by-laws which (if implemented correctly) would reduce the likelihood of nuisances and environmental contamination of local waters and environments. For further information on local municipal by-laws, see appendix 2.2.

\section{Municipal By-Laws (1997).}

As a result of the Municipal Act and the Planning Act, municipalities were given the legislative option of creating by-laws within their jurisdiction over local matters, including nutrient management. The first municipality to create the first true nutrient management by-law was Grey Township in 1997. Several years after the first by-law, a total of 95 municipalities (lower and upper tier) adopted their own version of a nutrient 
management by-law. This included "a number of by-laws that apply to an entire county (either a single tier County such as Chatham Kent) or a by-law passed at the upper tier county level (such as Perth)" (Caldwell, 2003). As the issue of nutrient management grew in the province and as increasing numbers of municipalities contemplated requiring farmers to implement Nutrient Management Plans, "the Ontario Farm Environmental Coalition developed a Nutrient Management Strategy that included a draft by-law in March 1998" (Caldwell, 2003). The draft by-law, aptly named The Model By-Law to Incorporate the Nutrient Management Plan (NMP) Requirements into a Municipal ByLaw Pursuant to the Municipal Act was passed on July 23, 1999.

Although the framework for nutrient accountability had been made available to all municipalities across the province, inconsistencies in legislation still remained depending on where the region was located. Such inconsistency remained one of the main reasons for the implementation of the Nutrient Management Act in order that all farms and agricultural opcrations across the province would follow one, and only one law for managing their nutrients. The sample by-law incorporated many of the concepts contained in several Codes and Guidelines, including:

- Incorporation of livestock units.

- Use of Nutrient Management Plans.

- Acquiring sufficient land base requirements for spreading.

- Minimum separation distance formulac and

- Provisions for livestock barns

Despite differences among many nutrient management municipal by-law's, several key observations were identified in a report authored by Dr. W.J Caldwell named -Managing the Transition Between Municipal and Provincial Governance as Required by the Regulations Under the Nutrient Management Act ' (Caldwell. 2003). The report studied a total of 85 by-laws and observed several key findings listed below;

- Most municipalities require a Nutrient Management Plan for operations that establish or expand above 100 or 150 Livestock Units. 
- Most municipalities have not established a maximum distance between the source of manure and the land base to which it is to be applied

- The minimum storage requirement for manure was usually set by most municipalities at 240 days, although there was a range between 100 and 365 days

- Most municipalities apply M.D.S. II to help Guide the sighting of barns and manure storage facilities.

- Nearly 20 municipalities have established caps limiting the maximum size of a livestock operation

- Some municipalities have attempted to control development in wellhead protection areas.

Due to the variation in some of the municipal by-laws. it is the challenge of the 95 municipalities to streamline their practices to be consistent with the Nutrient Management Act. Fortunately, farms and agricultural practices have already implemented many of the requirements in the Nutrient Management Act. such as Nutrient Management Plans.

\section{The Pesticides Act (1990)}

Administered by the Ministry of the Envirmment. the Pesticides Act was developed to ensure for the safe management of pesticides in the Province of Ontario. The shift in thinking from a perspective of chemicals to the use of biological. or 'natural' pest control solutions validates the inclusion of the Pesticides Act and the management of pathogens in the environment. Larvicide application of cultures of Bacillus thuringiensis to storm water basins in several locations in the province to control mosquito populations to reduce the spread of West Nile virus is an example of such biological use of such applications.

\section{The Dead Animal Disposal Act (1990)}

Administered by the Ontario Ministry of Agriculture and Food, the Dead Animal Disposal Act was developed to provide for the safe management and disposal of dead 
animals. The disposal of animals includes horses, goats, sheep, swine and cattle (larger animals). Much like the Act Respecting Infectious or Contagious Diseases affecting Animals did in 1885, the Act requires farmers and agricultural operations to dispose of animals suspected of dying from natural causes or accidents (falling) in a safe and humane manner. Several clauses involved in the disposal include the requirement of burying the animal within a period of 48 hours of its death and covering it with at least 2 feet of earth. 


\section{Appendix 3.1 Other Microbial Subsurface Transport Models and Approaches}

\section{MACRO}

According to McGechan \& Lewis (2002), the most comprehensive field-scale model incorporating most of the important colloid-facilitated contaminant transport through soil is MACRO. This model simulates contaminant transport with a dualporosity structure allowing for different contaminant concentrations in the soil matrix and the macropores. MACRO was primarily developed for modeling pesticide transport, but it includes most of the features required for transport of phosphorus and biological microorganisms (bacteria and viruses). The model includes a three-phase representation of contaminant transport (contaminants in solution, sorbed onto static soil matrix and sorbed onto mobile colloidal particles) according to McGechan \& Lewis' (2002) model of particle sorption in the subsurface environment.

\section{Filtration MIodels}

Filtration models assume that the contaminant is particulate in nature and that its removal depends on physical straining and sorption processes. These processes are often combined into a filtration coefficient for the iystem (Maier et al. 1999). Such models take into account mechanisms by which colloids (in this case microbes) come into contact with particle surfaces and the relative size of the microbe compared with the pores in the medium (Maier et al., 1999). The premise of these models is that, as the microbial suspension passes through the terrestrial profile, microorganisms will be removed. Yao et al. (1971) demonstrated that filtration models might be applicable in terms of predicting bacterial immobilization during transport through the subsurface. As with the advection-dispersion equation, terms can be incorporated into the equation to account for net microbial decay (Maier et al., 1999). 


\section{Appendix 3.2 Advection Dispersion Model - General Formula}

According to Maier et al. (1999), advection-dispersion models assume that the contaminant (microorganisms) is in a solution and thus has the same average velocity as the matrix solution. Advection-dispersion equations can be expanded in order to take into account for subsurface heterogeneities in the environment. The following formula illustrates the influence of advection, dispersion, adsorption, and decay on the transport of a contaminant. According to Maier et al. (1999), a relatively simple advectiondispersion equation is:

\section{$\mathbf{R f} \partial \mathrm{C} / \partial \mathrm{t}=\mathrm{V} \partial \mathrm{C} / \partial \mathrm{x}+\mathrm{D} \partial^{2} \mathrm{C} / \partial \mathrm{x}^{2} \pm \mathbf{R x}$}

Where:

$\mathrm{C}$ is the concentration of the microbe (mass/volume)

$\mathbf{x}$ is the distance traveled through the porous medium (length)

$\mathrm{V}$ is the average linear velocity constant (length/time)

$\mathbf{R}_{\mathbf{x}}$ is the microbial net decay term (mass/time-volume)

$t$ is time and,

$\operatorname{Rr}$ is the retardation factor, accounting for reversible interaction with the porous medium. 